University of Louisville

ThinkIR: The University of Louisville's Institutional Repository

Electronic Theses and Dissertations

8-2014

\title{
Is that an opportunity? : a multilevel investigation of the individual- opportunity nexus and opportunity beliefs.
}

\author{
Eric Shaunn Mattingly \\ University of Louisville
}

Follow this and additional works at: https://ir.library.louisville.edu/etd

Part of the Entrepreneurial and Small Business Operations Commons

\section{Recommended Citation}

Mattingly, Eric Shaunn, "Is that an opportunity? : a multilevel investigation of the individual-opportunity nexus and opportunity beliefs." (2014). Electronic Theses and Dissertations. Paper 927.

https://doi.org/10.18297/etd/927

This Doctoral Dissertation is brought to you for free and open access by ThinkIR: The University of Louisville's Institutional Repository. It has been accepted for inclusion in Electronic Theses and Dissertations by an authorized administrator of ThinkIR: The University of Louisville's Institutional Repository. This title appears here courtesy of the author, who has retained all other copyrights. For more information, please contact thinkir@louisville.edu. 


\title{
IS THAT AN OPPORTUNITY? \\ A MULTILEVEL INVESTIGATION OF THE INDIVIDUAL-OPPORTUNITY NEXUS AND OPPORTUNITY BELIEFS
}

\author{
By \\ Eric Shaunn Mattingly \\ B.S., Brigham Young University, 2007
}

\author{
A Dissertation \\ Submitted to the Faculty of the \\ College of Business of the University of Louisville \\ in Partial Fulfillment of the Requirements \\ for the Degree of
}

Doctor of Philosophy
Department of Entrepreneurship
University of Louisville
Louisville, Kentucky

August 2014 
Copyright 2014 by Eric Shaunn Mattingly

All rights reserved 

IS THAT AN OPPORTUNITY?

A MULTILEVEL INVESTIGATION OF THE INDIVIDUAL-OPPORTUNITY

NEXUS AND OPPORTUNITY BELIEFS

By

Eric Shaunn Mattingly

B.S., Brigham Young University, 2007

A Dissertation Approved on

June 20, 2014

By the following Dissertation Committee:

Manju K. Ahuja

Michael J. Barone

Andrew S. Manikas

Dean A. Shepherd 


\title{
DEDICATION
}

\author{
To Michelle, Asher and Addison
}

for their tremendous sacrifice

for our better future. 


\section{ACKNOWLEDGEMENTS}

A well-known proverb says, "It takes a village to raise a child." I feel as though I am that child and the village is my dissertation committee, $\mathrm{Ph}$.D. program committee and advisors that have consistently provided illuminative-intellectual insights, support and encouragement. Their combined and individual intellectual talents guided and pushed me to pursue higher goals than I had for myself. I am extremely grateful for their invaluable support.

Manju Ahuja's service to me extends well beyond what is reasonable for a dissertation advisor. From day one in the Ph.D. program she has given so much of her time, energy and resources to help me navigate through the $\mathrm{Ph} . \mathrm{D}$. program and begin a career in academia. In addition to always opening her door to me, she refused to let me settle, constantly encouraging me to aim high.

Dean Shepherd, Michael Barone and Andrew Manikas provided invaluable support to me throughout the dissertation process. They consistently pushed me to pursue excellence. All remaining flaws in this dissertation are mine. I am extremely grateful for their intellects, encouragement and generosity.

I would also like to express gratitude for the support I received from all of the $\mathrm{Ph} . \mathrm{D}$. committee members who dedicate a great deal of energy to ensure this program helps students, such as myself, accomplish their goals. I am particularly grateful to James Fiet who served as my research advisor during my first two years in the Ph.D. program and continues to mentor me today.

To those mentioned above - and to the many others that I could not thank in this short space - thank you for helping me through what has been a difficult, but worthwhile adventure! 


\section{ABSTRACT \\ IS THAT AN OPPORTUNITY? \\ A MULTILEVEL INVESTIGATION OF THE INDIVIDUAL-OPPORTUNITY NEXUS AND OPPORTUNITY BELIEFS}

Eric Shaunn Mattingly

June 20, 2014

Early entrepreneurial action focuses on opportunities and involves two distinct evaluative phases: (1) recognizing that something is an opportunity for somebody and (2) deciding whether or not one wants to pursue exploitation of a particular opportunity. Scholars primarily explain the first of these phases using individual differences. However, entrepreneurial action involves the nexus of opportunities and individuals. In my dissertation, I examine the independent effects of opportunity differences on opportunity recognition as well as the degree to which they are contingent on individuallevel constructs.

Specifically, I examine this phenomenon in the context of technology commercialization. I use analogical problem solving to explain how individuals develop perceptions about their certainty that a technology can: (1) be feasibly implemented to a market, and (2) actually solve a market's problem. I predict that individuals will be more certain an idea is actually an opportunity when a technology and market share Superficial features (people, objects, materials), Structural relationships (technology capability resembles market's latent demand) and Procedural 
details (original user interaction with technology resembles a new market's user interaction with technology).

To capture the essence of entrepreneurship's opportunity-individual nexus, I theorize that the direct effects of Superficial, Structural and Procedural Similarities are contingent upon individual-level factors, such as Prior Knowledge and Global versus Local Precedence.

The results of this dissertation provide evidence that the newly introduced opportunity difference, Procedural Similarity, does positively influence Opportunity Beliefs consistent with Structural Alignment Theory. I also find support for the prediction that the relationship between Procedural Similarity and Opportunity Beliefs is contingent upon individuals' Global versus Local Precedence. A Global Precedence refers to a tendency to attend to configural aspects of information prior to individual pieces of information. A Local Precedence refers to a tendency to focus on details and individual pieces of information rather than focus on how many pieces of information combine to create a big picture. I find that the relationship between Procedural Similarity and Opportunity Beliefs is stronger for individuals who process information locally than it is for individuals who process information globally. 


\section{TABLE OF CONTENTS}

CHAPTER 1 - INTRODUCTION .....................................................................

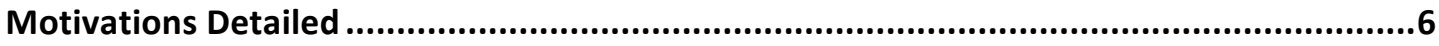

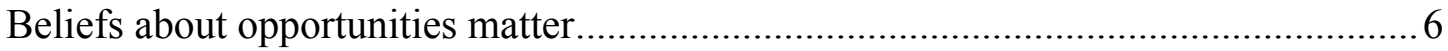

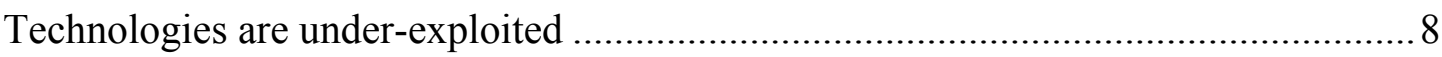

Opportunity-individual nexus: both aspects matter............................................... 9

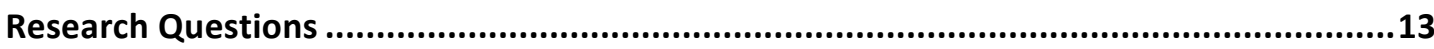

Boundary Conditions: Assumptions and Scope …........................................................15

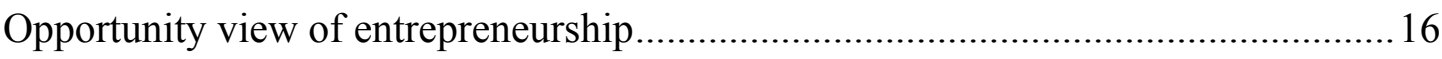

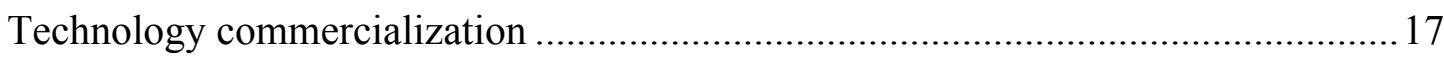

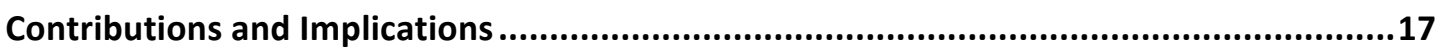

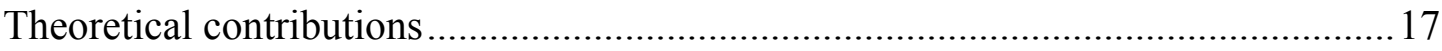

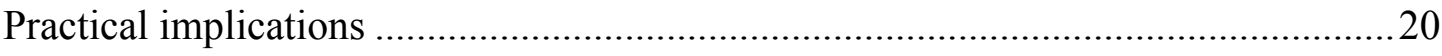

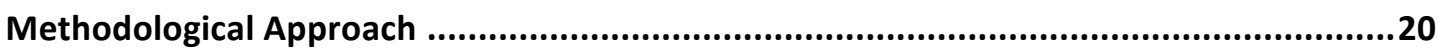

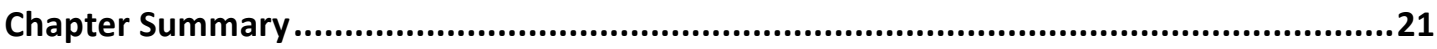

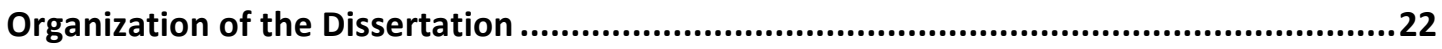

CHAPTER 2 - THEORY AND HYPOTHESES ........................................................24

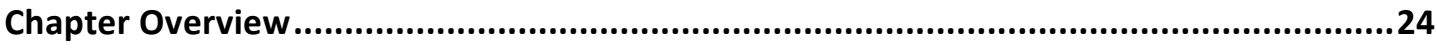

Opportunity-Individual Nexus and Opportunity Beliefs.................................................24

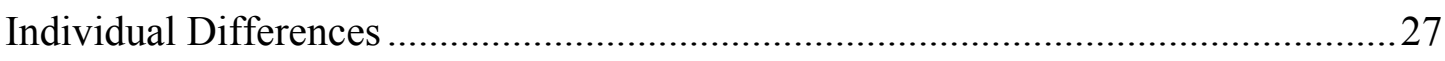

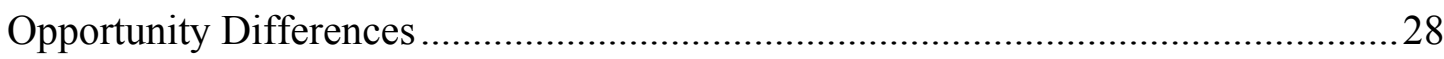

Structural Alignment Theory and Opportunity Recognition..............................................

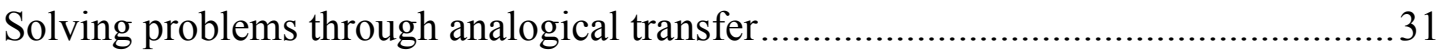

Table 1: The Process of Analogical Problem Solving............................................. 35

Opportunity Differences and Opportunity Beliefs .........................................................38 
Hypotheses Related to Research Question 1: Opportunity Differences and opportunity recognition

Hypotheses Related to Research Question 2: Procedural similarity's interaction with Superficial and Structural similarity

Interaction plots for the expected relationships outlined in hypotheses $4 \mathrm{a}$ and $4 \mathrm{~b}$ are shown in figure 1 below.

Figure 1: Interaction Plots for Hypotheses H4a, H4b, H6a, and H6b

The Opportunity-Individual Nexus

Hypotheses Related to Research Question 3: Moderating roles of Prior Knowledge and Global versus Local Precedence....

Figure 2: Model of Individual-Opportunity Nexus and Opportunity Beliefs.

Chapter Summary

CHAPTER 3 - RESEARCH DESIGN AND METHODS

Chapter Overview.

Sample

Table 2: Sample Description ... .77

Table 3: Industries Represented 78

Experiment Design .79

Beliefs about Opportunities (Level - 1 Dependent Variables) ..........................................81

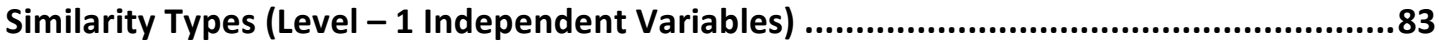

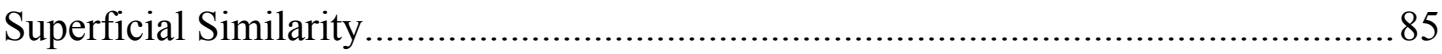

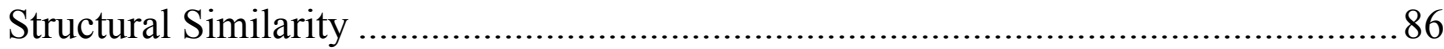

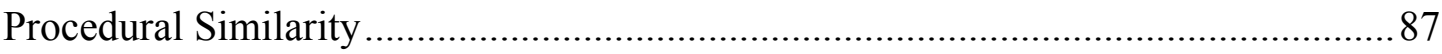

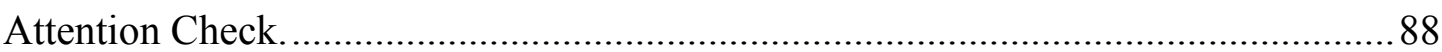

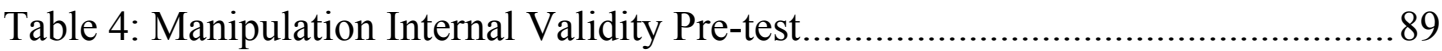

Prior Knowledge and Global versus Local Precedence (Level - 2 Moderator Variables) ....89

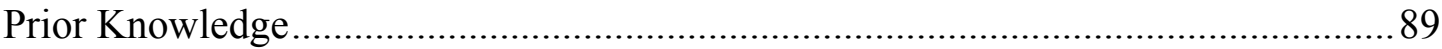

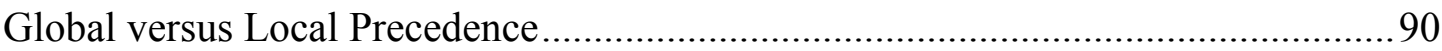

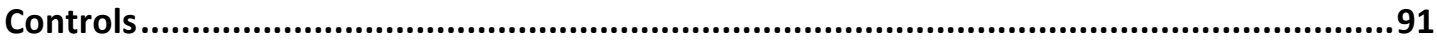

Individual Differences in education, background and experience ............................99

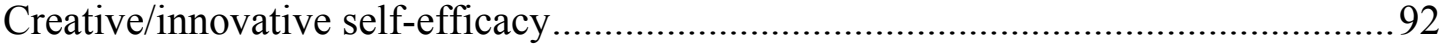

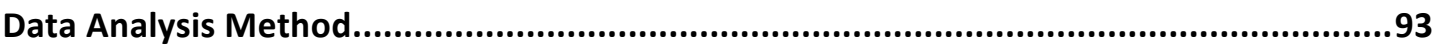




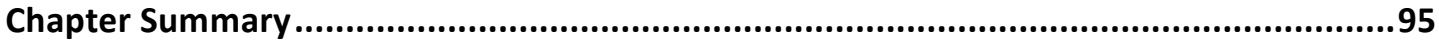

Table 5: Means, Standard Deviations and Correlations ...........................................96

CHAPTER 4 - ANALYSIS AND RESULTS ..................................................97

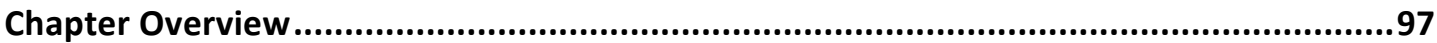

HLM and the Inter-class Correlation.........................................................................99

Table 6: Random Effects, Standard Deviations and Inter-correlation Coefficient.... 101

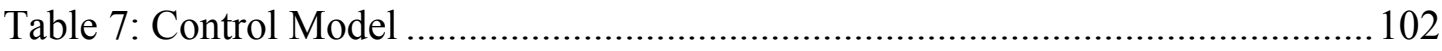

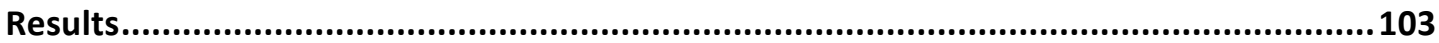

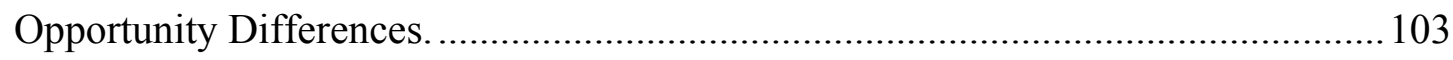

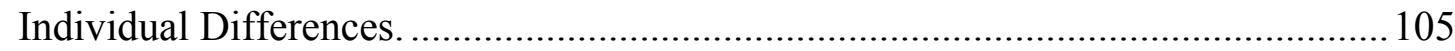

Table 8: Results - Opportunity Beliefs (fit \& feasibility Combined) ........................ 109

Table 9: Results - Opportunity Beliefs (fit Only) ................................................. 110

Table 10: Results - Opportunity Beliefs (feasibility Only)..................................... 111

Table 11: Summary of Hypotheses and Results .................................................... 112

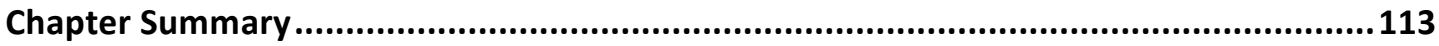

CHAPTER 5 - DISCUSSION AND CONCLUSION .......................................... 114

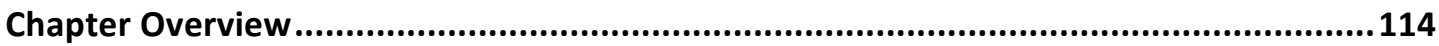

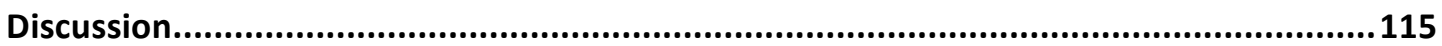

Opportunity Differences and Opportunity Beliefs. .............................................. 115

Individual Differences and Opportunity Beliefs. ............................................... 123

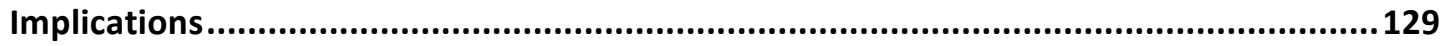

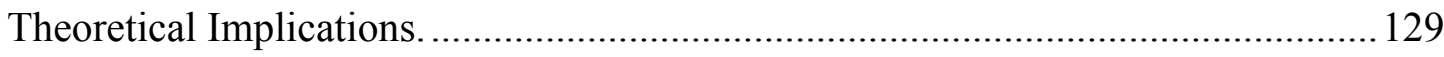

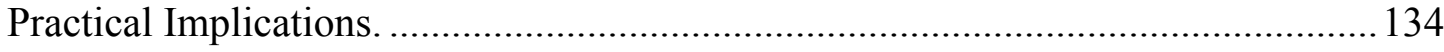

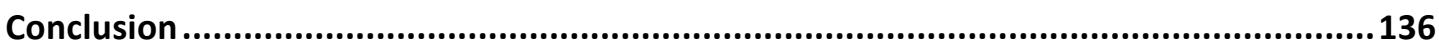

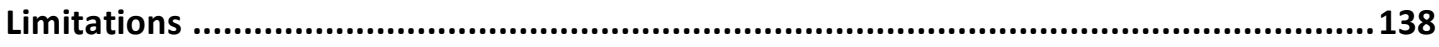

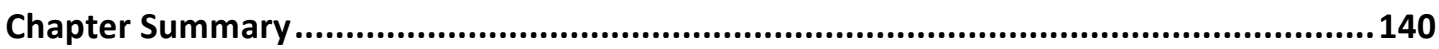

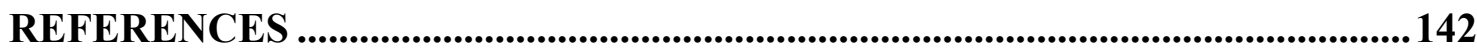

APPENDIX 1: DEPENDENT, INDEPENDENT, MODERATING AND PRIMARY

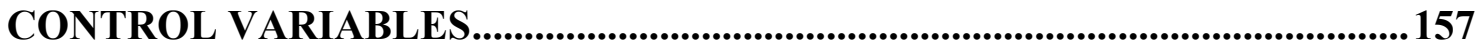


APPENDIX 2: SCENARIOS ......................................................................................... 160

APPENDIX 3 RESULTS FOR CASES LISTED IN FOOTNOTE 1 ....................168

CURRICULUM VITAE ................................................................................................ 169 


\section{LIST OF TABLES}

Table 1: The Process of Analogical Problem Solving. .59

Table 2: Sample Description .77

Table 3: Industries Represented .78

Table 4: Manipulation Internal Validity Pre-test. 89

Table 5: Means, Standard Deviations and Correlations .96

Table 6: Random Effects, Standard Deviations and Inter-correlation Coefficient... 101

Table 7: Control Model 102

Table 8: Results - Opportunity Beliefs (fit \& feasibility Combined) 109

Table 9: Results - Opportunity Beliefs (fit Only) 110

Table 10: Results - Opportunity Beliefs (feasibility Only)... 111

Table 11: Summary of Hypotheses and Results 112 


\section{CHAPTER 1 - INTRODUCTION}

Entrepreneurship is commonly conceptualized as the recognition, evaluation and exploitation of opportunities, where opportunities refer to the development of know-how into products and services to sell in markets (Shane \& Venkataraman, 2000). Scholars primarily account for the first of these processes, opportunity recognition, with factors such as prior knowledge, human capital and alertness due to their influence in whether individuals will find opportunity ideas (e.g., Fiet, 2007; Gruber, MacMillan, \& Thompson, 2012; Shane, 2000). This makes sense considering the first of two assumptions documented in the extant literature regarding the nature of entrepreneurial opportunities; namely, that (1) opportunities exist, waiting to be identified and (2) opportunities are uncertain ex ante (Casson, 1982; Knight, 1921; Shane \& Venkataraman, 2000).

However, as a field we know much less about factors related to the second assumption's role in opportunity recognition. Indeed, the actual success of new supplydemand pairings can only be assessed after incumbents or entrepreneurs try to exploit them (Grégoire \& Shepherd, 2012). Perceived uncertainty about entrepreneurial opportunities can delay or all together block action (cf., McMullen \& Shepherd, 2006). Uncertainty in entrepreneurship historically relies somewhat on Ajzen's Theory of Planned Behavior (Ajzen, 1985; Ajzen, 1991); entrepreneurial intentions derive from: (1) positive attitudes towards some behavior, (2) perceptions that the behavior is socially 
desirable and (3) perceptions that the individual can do the behavior and do it well (Grégoire, Shepherd, \& Lambert, 2010). Entrepreneurship scholars find that perceptions of feasibility and desirability actually relate to intentions to pursue entrepreneurship (Krueger, Reilly, \& Carsrud, 2000).

However, there is a fundamental difference between Ajzen's models of human behavior and the validated measure of opportunity-recognition beliefs utilized in this dissertation (Grégoire \& Shepherd, 2012). Ajzen's (1985) theory focuses on modeling particular individuals' intentions toward particular actions. However, entrepreneurship scholars point out that entrepreneurship involves two distinct evaluative phases: recognizing that something is an opportunity for somebody (anybody, not necessarily oneself), and the decision of whether one wants to pursue exploitation of that particular opportunity (McMullen \& Shepherd, 2006). Based on the first of these evaluation phases, entrepreneurship scholars proposed a general opportunity-recognition beliefs construct with three perceptual dimensions: (a) alignment or fit between an opportunities supply and demand, (b) general feasibility of implementing a new supply-demand pairing and (c) general desirability of implementing a new supply-demand pairing (Grégoire et al., 2010). However, general desirability was removed from the construct in the study that validated this construct because it was not significant and had low loadings in confirmatory factor analysis, resulting in opportunity-recognition beliefs referring to general perceptions of fit and feasibility (Grégoire et al., 2010; Grégoire \& Shepherd, 2012). Entrepreneurial action is influenced not only by the positive or negative valence of beliefs about opportunities, but also by individuals' perceived uncertainty (certainty) of these beliefs (cf., Grégoire et al., 2010). This dissertation models individuals' beliefs in 
regards to their certainty that a supply source fits with and can be feasibly implemented to a source of demand.

This dissertation focuses on opportunity recognition beliefs in the context of recognizing markets to license technologies in. Although, the theoretical model is likely to hold across numerous contexts, technology commercialization is a good choice given its importance at this time. Specifically, technology commercialization rates pale in comparison to technology advancement and appropriation rates (Markman, Siegel, \& Wright, 2008). This context is also a good example of the conceptualization of entrepreneurial action often referred to in the extant literature as the introduction of new applications of technologies through the introduction of new products, services or business models (Grégoire \& Shepherd, 2012; Gruber, et al., 2012). Before technologies can be exploited, opportunities to commercialize technologies need to be recognized; this research offers some insights into factors that influence the recognition of markets to commercialize technologies in. Here, the focus is on the recognition of second market applications for technologies because one way to increase technology commercialization overall is recognizing more applications for each technology.

The few studies the author is aware of that examine recognition questions that look beyond only on the ability of individuals to 'see', 'find', 'notice' or 'encounter' opportunities, have done so using Gentner's (1983) analogical reasoning as a theoretical lens to predict the general construct, opportunity-recognition beliefs (Grégoire et al., 2010; Grégoire et al., 2010, Grégoire \& Shepherd, 2012). Analogical problem solving involves individuals solving problems by drawing analogies between something known (a solution principle) and something novel or uncertain (e.g., a problem that needs a 
solution or perhaps a better solution) (Chen, 2002; Gentner, 1983). Grégoire and Shepherd (2012) find that opportunity differences, indicated by varying degrees of Superficial and Structural similarity in technology-market combinations, play a role in opportunity recognition because they influence the beliefs that individuals form about whether something is an opportunity for some person or some firm. Superficial similarity refers to when a source shares "Superficial similarities with the target problem, such as objects and characters" (Chen, 2002, p. 82). In the context of entrepreneurship and technology transfer,

"Superficial similarities arise when the basic elements of a technology (e.g., who develops the technology, the context where it is developed, its parts or components, the inputs it uses, the materials/people it works with in the lab, and the output it produces) resemble the basic elements of a market (e.g., the people in the market, the materials, and tools they use, etc.)" (Grégoire \& Shepherd, 2012, p. 754).

Structural similarity refers to the degree of similarity between how the components are causally linked to achieve the underlying goal or the aspect of analogical problem solving known as the solution principle (Chen, 2002). In the context of entrepreneurship and technology transfer,

"Structural similarities arise when the intrinsic capabilities of a ... technology (what it can do and the logical/scientific/functional mechanisms underlying how it can do this, such as how the various parts and input of a technology "work" together") resemble the "causes" and "mechanisms" underlying latent demand in a market (i.e., the reasons why people in the market are not completely satisfied with current means of meeting their needs)" (Grégoire \& Shepherd, 2012, p. 754).

Other scholars have also argued that we need to increase scholarly understanding of how beliefs are formed and suggest that similarity probably plays a key role (Hastie, 2001).

Undoubtedly, recent research on entrepreneurs cognitive processing of opportunity differences to make mental connections between a technology's capabilities 
and potential market applications of the technology through analogical transfer has increased our understanding of the role that differences in opportunities play in opportunity recognition (Grégoire \& Shepherd, 2012). However, knowing that Superficial and Structural Similarities play a role in the influence of opportunity differences on how certain entrepreneurs are that a source of supply fits with and can be feasibly implemented to a market begs the question if other types of similarities impact this relationship as well. Indeed, psychologists note that Superficial and Structural similarities, alone, do not adequately capture the complex relationships between source and target, especially when the context of analogical transfer is one of problem solving, such as the context here: solving market problems with technologies' solution principles (Chen, 2002). Instead, Chen (2002) suggests that among other types of similarity, Procedural Similarity is particularly likely to also influence the mental connections that individuals make from a source to target

This examination of opportunity recognition involves developing and testing a theoretical model that predicts potential entrepreneurs' beliefs about potential technology applications they encounter based on the degree of Superficial, Structural and Procedural Similarities between supply-sources and demand-sources. Specifically, the model predicts beliefs about whether a technology: can be used to solve a focal market's problems, answers the needs of a focal market, does what a focal market demands, is sufficiently developed to be applied profitably within a focal market and can be feasibly applied to a focal market. The central focus of this dissertation is on how the nexus of individual differences and opportunity differences influence fit and feasibility beliefs. Therefore, the theoretical model also considers the role of individual factors as 
moderators for the relationships between opportunity differences and fit and feasibility beliefs. Given that analogical transfer is a cognitive process, individual level differences that influence cognitive processing of information, such as Prior Knowledge and Global versus Local Precedence should impact the influence that analogies have (Basso \& Lowery, 2004; Grégoire \& Shepherd, 2012). Specifically, this dissertation considers moderating effects of Prior Knowledge related to a focal technology, Prior Knowledge related to a focal market and individual differences in Global versus Local Precedence. The balance of chapter 1 includes sections which: further detail the motivations for examining the focal topic; state the research questions and the corresponding research objectives; explain the research agenda, introduce the contributions and implications of the dissertation and summarize the chapter.

\section{Motivations Detailed}

Beliefs about opportunities matter. Generally speaking, the term 'beliefs' refers to individuals' subjective probability judgments that concern some discriminable aspect of the world (Fishbein \& Ajzen, 1975); beliefs can be in regards to a broad range of domains, such as: people, objects, value, concepts, attributes and the environment.

Fishbein and Ajzen (1975) explain that the dominant predictor of particular behaviors is intentions that particular people have; however, discovering that people usually do what they intend to do is not very illuminating. Instead, if we seek to understand behavior, we must specify factors that play a role in intentions, such as general beliefs that ultimately inform person specific, particular beliefs. Recognizing the influence that beliefs play in ultimately determining whether or not humans act in the face of uncertainty, scholars from a diverse set of fields note that recognizing the 
mechanisms underlying belief formation is an important scholarly understanding (Fishbein \& Ajzen, 1975; Foss, 2007; North, 2006; Oliver \& Winer, 1987; Shepherd, McMullen, \& Jennings, 2007). For example, there is evidence that: top managers' beliefs affect their organizations (Hambrick \& Mason, 1984; Walsh \& Fahey, 1986); beliefs that successful entrepreneurs are skilled can induce suppliers or customers to be more willing to commit resources to, or make deals with, repeat entrepreneurs (Gompers, Kovner, Lerner, \& Scharfstein, 2010); and information can change individuals' perception of future wealth creation prospects, such as entrepreneurial opportunities (Fiet J. O., 2007). These findings regarding the role of beliefs, and many others like them, aggregately demonstrate that beliefs matter. Indeed, psychologists note that individuals' beliefs (expectations, knowledge, means, etc.) help them choose a course of action (Hastie, 2001). Hastie (2001) argues that scholars need to develop models that outlay mechanisms that play a role in the formation of beliefs.

Entrepreneurship scholars recognize that we have little scientific understanding of where opportunity-recognition beliefs actually come from and what factors influence how they are formed (Shepherd et al., 2007). Many scholarly fields assume some degree (usually a great degree) of uncertainty in the world, thereby recognizing the idea that people must ultimately choose one out of many possible courses of action (Shepherd et al., 2007). Consider a world without uncertainty, in which the extent to which a supplydemand pairing was known to be feasible, and the degree to which it actually met market needs/wants were known; it is conceivable that there would not be a market for entrepreneurs because existing firms—with their readily available resources—-would exploit all encountered opportunities. However, we do live in an uncertain world where 
the value and likelihood of success of opportunities is uncertain and existing firms do not exploit all opportunities (Shane \& Venkataraman, 2000). The uncertainty of opportunity ideas feasibility and ability to actually solve market needs/wants efficiently, coupled with the phenomena of a market for numerous startups despite a large number of existingand potentially, more capable-incumbents, suggests that it is likely that: (1) there is variance in beliefs that people form about opportunities, and (2) the variability in Opportunity Beliefs influences some players (among entrepreneurs and incumbents) to act and not others. In short, effects of uncertainty that are not overcome can delay or even prevent action by incumbents, for example, thereby creating a market for entrepreneurs (McMullen \& Shepherd, 2006). Still, entrepreneurs must overcome their ignorance about the value of encountered opportunity ideas before acting. Therefore, understanding the mechanisms that influence how beliefs about opportunity ideas are formed is fundamental to entrepreneurship research.

Technologies are under-exploited. The context of this dissertation is technology licensing, or opportunities in the form of new markets to license technologies in. Given that the pace of technology advancement and appropriation are outpacing the rate of technology commercialization, management scholars note the importance of technology transfer through entrepreneurial action because internal R\&D capacity is generally no longer sufficient for organizations to maintain their competitive advantage (Grégoire \& Shepeherd, 2012; Markman, Siegel, \& Wright, 2008).

Technology transfer through entrepreneurial action refers to the introduction of new applications of technologies through the introduction of new products, services or business models (Grégoire \& Shepeherd, 2012; Gruber, MacMillan, \& Thompson, 2012). 
The introduction of new products, services or business models through entrepreneurial action is conceptualized as the nexus of individuals and opportunities (Shane \& Venkataraman, 2000).

Opportunity-individual nexus: both aspects matter. Recent research suggests that differences in opportunities - not just individual differences that have dominated the focus in opportunity recognition research—play a role in shaping individual's beliefs about opportunities thereby playing a role in opportunity recognition (Grégoire \& Shepeherd, 2012). We know that Superficial and Structural Similarities play a role in opportunity-recognition beliefs, but we do know if Procedural Similarity does as well. Procedural similarity refers "to the extent to which source Procedural details match or differ from a target" (Chen, 2002, p. 82). Procedural similarity concerns the degree to which implementational details of how individuals actually use or execute a solution principle within a target domain resemble the implementational details of how individuals execute a solution principle in a source domain. In the context of entrepreneurship and technology transfer, Procedural Similarities arise when the Procedural details of how a technology's intrinsic capabilities (solution principle) were originally implemented or used by the intended users match the Procedural details proposed for how a technology's capabilities will be delivered to a new market (i.e., the steps proposed for how the new class of users will interact with and execute the solution principle). Furthermore, although we know that individual differences in Prior Knowledge moderate the relationship between some opportunity differences and Opportunity Beliefs, we still do not know if other individual differences moderate the effect of opportunity differences on Opportunity Beliefs. 
In order to address these issues, that the theoretical model focuses on how differences between opportunities and differences between individuals influence Opportunity Beliefs about fit and feasibility. Understanding this issue will increase our understanding of how entrepreneurs make sense of the signals they receive about ideas to decide which ones they believe involve a technology that can be feasibly implemented to successfully solve a market's needs. Specifically, the model is based on the integration of psychology research and recent management research on the role of analogies in making novel mental leaps towards recognizing new applications of technologies.

The theoretical lens utilized to explain Opportunity Beliefs is analogical problem solving, which is one aspect of Structural alignment theory (Gentner, 1983). Gentner's (1983) theory is referred to by many names in the literature, such as Structural Alignment Theory, Structure Mapping Theory or sometimes Structural Analogy Theory because of its focus on analogy. Gentner (1983) explains that analogy is primarily a mechanism for conveying that domains share relational structure despite the arbitrary differences in the objects or components that make up the domains. Structural Alignment Theory is relevant to a broad variety of cognitive comparative processes, such as: creativity, categorization, decision-making, visual-spatial transfer and problem solving (Markman \& Gentner, 1993).

Procedural Similarity's direct influence on entrepreneurs' certainty regarding the fit and feasibility of supply-demand pairings, and its contingency impact on the other types of similarity is of central interest in this dissertation. In short, this dissertation examines potential interaction effects of Procedural and Superficial Similarities as well as 
Procedural and Structural Similarities. Furthermore, the theoretical model considers individual level contingency factors.

The individual factors of interest here are Prior Knowledge of Technologies, Prior Knowledge of Markets and individuals' Global versus Local Precedence. We already know that Prior Knowledge offers benefits such as narrowing search (Fiet, 2007), causing assimilative thinking (Cropley, 1999) and cognitive economy (Busenitz \& Barney, 1997). We also know that Prior Knowledge of Technologies and markets, specifically, moderates the impact of some types of opportunity differences in Opportunity Beliefs (Grégoire \& Shepherd, 2012); however, the prediction there is that Prior Knowledge of Technologies and Markets also offers the benefit of helping individuals assess, and deal with, complexity associated with implementing solutions to new market problems.

Another individual level construct that may play a role in the process of recognizing new markets to license technologies in is Global versus Local Precedence. Global Precedence occurs in the right hemisphere of the brain influences perceptual and attentional processes (Basso \& Lowery, 2004). A Global Precedence refers to a tendency to more readily perceive and attend to Global, configural, aspects of information rather than the features that comprise the configuration when presented with information containing both Global and Local features (Basso \& Lowery, 2004). Local Precedence occurs in the left hemisphere of the brain and also influences perceptual and attentional processes (Basso \& Lowery, 2004); however, a Local Precedence refers to a tendency to more readily attend to Local component parts and individuals who display a Local Precedence tend to manifest poor visual processing of Global configural information when presented with information containing both Global and Local features (Basso \& 
Lowery, 2004). The extant literature in cognitive psychology suggests that Global versus Local Precedence is likely to influence the degree to which various types of similarity influence mental connections that individuals are able to make between a source and target (Förster, 2009). However, Global versus Local Precedence has not yet been examined as a potential moderator of these opportunity differences influence in entrepreneurial opportunity recognition. Furthermore, research on Global versus Local Precedence has primarily only focused on explaining individuals' perceptions of visualspatial tasks, not action-oriented tasks as is the case here (Förster, 2009). I extend Förster's (2009) work by considering whether individuals' tendency to process information globally or locally has any influence on their perceptions about non visualspatial tasks.

Navon (1977) contends that Global Precedence is advantageous in that it is economic in its use of Precedence resources, utilizes low-resolution (or higher-order) information and clarifies ambiguous details. Given that Global Precedence is more efficient and individuals who exhibit a Global Precedence are more likely to attend to how features and parts are configured in visual-spatial tasks as opposed to focusing only on individual components, it makes theoretical sense to examine the role, if any, of Global Precedence in influencing the impact of Structural similarity on Opportunity Beliefs. Although known moderating influences of Global Precedence are within visualspatial contexts, Global Precedence may also serve as a moderator in non-visual analogies as well, such as action oriented analogies-namely, solving market problems with technological solutions (Solomon et al, 2004). Indeed, psychologists suggest that Global Precedence involves finding global relations between stimuli (Förster, 2009); this 
dissertation extends this insight by considering new sources of supply and demand as such stimuli. This dissertation is the first known study that considers Global versus Local Precedence as a potential moderator within Structural Alignment Theory's framework. Global Precedence is associated with attending to what is similar in visual-spatial tasks whereas Local Precedence is associated with a focus on dissimilarity (Förster, 2009); given that, along with the above explanation that the degree of similarity in regards to implementation details, I develop hypotheses in chapter 2 regarding the impact of Global Precedence on the effects of the relevant similarity types.

\section{Research Questions}

The high-level research question that this dissertation addresses is: how do opportunity differences and individual differences influence Opportunity Beliefs? Based on the theoretical lens that I address this question through, analogical problem solving, I separate the high-level research question into the following specific research questions: (1) How do opportunity differences in Superficial, Structural and Procedural Similarities influence Opportunity Beliefs? (2) How does Procedural Similarity moderate the effects that Superficial and Structural Similarities have on Opportunity Beliefs? and (3) How do individuals Prior Knowledge and Global versus Local Precedence moderate the relationship between opportunity differences and Opportunity Beliefs?

The increasing rates of technological advancement offer a practical reason to examine these questions. Specifically, the rate of technological advancement is "accelerating because widely distributed knowledge reduces costs related to organizing" information (Markman, Siegel, \& Wright, 2008, p. 1401). However, exploitation of new technologies is not keeping pace with technological advancement. As a result, companies 
try to mobilize their idle, unexploited and underutilized innovations, inventions and technological discoveries into the open market via mechanisms such as licensing (Markman et al., 2008). The gap between technology advancement and technology commercialization points to a need to increase our understanding of how individuals form beliefs about potential applications of technologies to commercialize.

To address these research questions, I develop a multi-level model that explains why decision-level attributes, which capture dimensions along which individuals compare potential technology applications to (opportunity differences), influence their evaluations as well as the role individual-level Prior Knowledge and Global versus Local Precedence (individual differences) plays in this cognitive process. I propose that the process of developing beliefs about potential technology applications rests, in part, on the cognitive processes of making similarity comparisons through Structural alignment. Furthermore, I suggest, and test, the notion that one particular Opportunity Difference, Procedural Similarity, can influence the impact of the other opportunity differences on Opportunity Beliefs.

Scholars posit that Prior Knowledge is related to opportunity recognition because it helps entrepreneurs uncover previously unnoticed opportunities as technological changes occur (Shane, 2000), and because individuals are able to discover more valuable opportunities when they focus opportunity search efforts within consideration sets comprised of information channels of tacit knowledge (Fiet J. O., 2007). Together, these theories point towards the normative implication that in order to notice an opportunity, individuals should rely on their Prior Knowledge (Fiet, 2007; Shane, 2000). 
However, many studies do not consider both aspects of the nexus; they focus on individual differences, such as Prior Knowledge, without also examining the role opportunity differences play. Cognitive psychology research suggests that Prior Knowledge influences the degree to which differences between two things or situations matter when forming beliefs about something new or uncertain (Gentner, Rattermann, \& Forbus, 1993; Gentner \& Markman, 1997). For example, consumers make sense of novel-target products that they are considering purchasing on the basis of how similar the target product is to some base product that they are already familiar with, with their degree of familiarity mattering (Markman \& Loewenstein, 2010). Furthermore, recent evidence suggests that entrepreneurs make sense of new potential opportunities in a similar way. That is, recent literature provides evidence that would be entrepreneurs form subjective perceptions about potential technology-licensing opportunities based on the degree of similarity between a technology's original application and its proposed application (Grégoire \& Shepherd, 2012). It follows that future recognition studies should consider both opportunity differences and individual differences.

\section{Boundary Conditions: Assumptions and Scope}

The results and discussion found in chapters 4 and 5 of this dissertation rely on important assumptions and are limited in scope by a boundary condition that I place on the study; namely that opportunities exist, their values are uncertain and opportunities herein refer to new supply-demand combinations in the form of technology licenses. The assumptions concern the nature of opportunities because opportunities and opportunity differences are of central focus herein. The boundary condition is related to the types of opportunities examined. Each of these is discussed individually in the next two 
subsections.

Opportunity view of entrepreneurship. Shane and Venkataraman (2000) explain two assumptions about the nature of opportunities, namely that they: (1) exist, waiting to be identified and (2) are uncertain. These assumptions about the nature of opportunities frame this study within the conceptualization of entrepreneurship explained by Shane and Venkataraman (2000), namely, that entrepreneurial action involves the nexus of enterprising individuals and the opportunity ideas that they believe are lucrative.

The first assumption is somewhat obvious for this study given the dissertation's focus on explaining opportunity recognition. Indeed, opportunities cannot be identified if they do not exist, waiting to be identified, as Shane and Venkataraman (2000) suggest they do. Some scholars may contend that some opportunities are not out 'there' waiting to be identified and are, instead, internally generated or created by enterprising individuals; this contention merely limits the bounds of the generalizability of the results of this dissertation. It is, therefore, important that I state this assumption explicitly, recognizing that this dissertation is not intended to explain beliefs about all opportunityindividual pairings that come into existence.

The second assumption brings to the forefront the phenomenon that individuals hold different beliefs about opportunities (Shane \& Venkataraman, 2000). This assumption becomes important to this study because the focus of this dissertation is explaining how the nexus of opportunity differences and individual differences influence the beliefs that individuals form about the fit and feasibility of opportunities. Given the assumptions that opportunities exist, waiting to be identified and that they are uncertain, an important question, then, is what factors influence whether or not particular 
individuals will recognize particular opportunities as valuable or attractive.

Technology commercialization. As discussed technologies are under-exploited and before commercialization opportunities can be exploited, they must be identified (Markman, Siegel, \& Wright, 2008). This dissertation focuses on explaining factors that influence the recognition of markets to commercialize technologies in. Although some may contend that this context bounds the generalizability of this dissertation's theoretical model, it is likely that the model can extend to other contexts. Specifically, technology licensing is merely one type of supply meeting demand combination and scholars conceptualize supply-demand combinations as opportunities even when they are not technology commercialization in nature (Shane \& Venkataraman, 2000). I chose technology commercialization as a context because the sources of supply and demand are very clear and the context is one of practical importance at this time.

\section{Contributions and Implications}

Theoretical contributions. I contribute to the ongoing stream in opportunity recognition that utilizes analogical problems solving as a theoretical lens by examining the extent to which Procedural Similarity directly impacts beliefs and changes the impact of other types of similarity. Specifically, Grégoire and Shepherd (2012) show that higher Superficial and Structural similarity are associated with more positive beliefs that an opportunity idea is, indeed, an opportunity for profit. I contribute to this stream by introducing Procedural Similarity as not only another predictor of Opportunity Beliefs, but also as capable of impacting the influence that Superficial and Structural Similarities have on Opportunity Beliefs. 
Specifically, research shows that despite humans' cognitive preference for Structural Similarity, processing Structural Similarities absent of Superficially similar elements is very cognitively demanding (Grégoire \& Shepherd, 2012). However, support for my predictions will provide new evidence to analogical reasoning theory supporting the theoretical argument that the presence of either Superficial or Procedural Similarities is sufficient to enable the processing of Structural Similarities. That is, we know that the presence of Superficial Similarities makes it much easier to process Structural Similarities; this dissertation contributes to this theory by considering whether Procedural Similarity (even in the absence of Superficial similarity) can play the role of making it easier to process Structural Similarities.

Furthermore, this dissertation contributes to opportunity recognition literature by examining the moderating effect of individual level differences on the relationship between opportunity differences and Opportunity Beliefs. This dissertation focuses on two types of individual differences, Prior Knowledge and Global versus Local Precedence.

Prior Knowledge of a Technology and Prior Knowledge of a Market are already established as moderators of the relationship between some types of similarity (Superficial and Structural) and Opportunity Beliefs. However, my examination of their moderating influence on the relationship between the implementation details of an analogy (Procedural Similarity) and Opportunity Beliefs is novel.

The second type of individual difference that is considered herein as a moderator is Global versus Local Precedence. Support for this moderator contributes to the literature on Global versus Local Precedence and analogical reasoning. First, support would 
demonstrate that individuals' Global versus Local Precedence influences the extent to which similarity types drives their beliefs about non-visual-spatial tasks. Second, support for Global Precedence as a moderator would demonstrate its influence on multiple types of similarity-belief relationships. Examining Global versus Local Precedence contributes back to the original psychology literature on analogical reasoning. Understanding the extent to which individuals exhibit a Global versus Local Precedence will increase our understanding of contingencies on the strength of the effects of Superficial, Structural and Procedural Similarities on general perceptions, such as Opportunity Beliefs. Indeed, without considering the degree to which individuals tend toward a Global or Local Precedence, we do now know if the effects of Superficial, Structural and Procedural Similarities hold across individuals; again, both aspects of the individual-opportunity nexus matter.

Evidence that Global versus Local Precedence does play a moderating role in Structural Alignment Theory would contribute to both literatures. First, it would contribute to Structural Alignment Theory by increasing scholarly understanding of some conditions that can influence the strength of some of the theory's predictions. Second, it would contribute to Global versus Local Precedence by providing evidence that its influence reaches beyond simple visual-spatial tasks to also direct individuals focus on similarity/dissimilarity for more abstract tasks.

Finally, this dissertation's theoretical model contributes to the stream of literature on the role of Procedural Similarity in analogical problem solving by studying the effects of Procedural Similarity on an individual's perceptions how is not actually the user. Specifically, extant literature on Procedural Similarity examines how the degree of 
Procedural Similarity impacts actual users of solution principles abilities' to: explain how to weigh elephants (Chen, 1995) or retrieve beads from glasses of water (Chen, 1996), for example. However, I am examining how the degree of Procedural Similarity impacts the perception of individuals who are not the actual users (market participants) of the solution principle. This will shed new light on the impact that Procedural Similarity has.

Practical implications. As mentioned, technology advancement and appropriation are rapidly outpacing the rate at which new technological advancements are commercialized (Markman et al., 2008). It follows that there is an opportunity within entrepreneurial action research to examine the factors that play a role determining when technologies will (or will not) be commercialized. As Haynie and Shepherd (2009) point out, the processes involved in opportunity recognition ultimately inform evaluation. In other words, before an individual decides if a potential technology application is a good application to pursue directly herself/himself, she/he must decide if they believe that it, indeed, is a technology application with any real potential for anyone (Shepherd et al., 2007). This dissertation will shed important light on the processes that underlie Opportunity Beliefs both within and across individuals.

\section{Methodological Approach}

There are some important considerations when deciding how to empirically examine the theoretical model that this dissertation offers. First, the model contains constructs at two levels, the opportunity level and the individual level. Second, the model aims to shed light on factors that influence Opportunity Beliefs both within and across individuals. Given these considerations, it is clear that a multi-level analysis is required (Shepherd, 2011). Therefore, the empirical examination of the theoretical model utilizes a 
multi-level, factorial experimental design in which subjects will determine the extent to which they believe that potential market applications of technologies (opportunity ideas) represent actual opportunities.

The experimental design captures opportunity differences; however the individual differences utilized in this dissertation are captured through questions that inquire about subjects' individual characteristics, experiences and levels of Prior Knowledge of a focal technology and potential market, for example. A full description of the methodological approach, sample, experimental design and analysis techniques is described in chapter 3.

\section{Chapter Summary}

This introductory chapter of this dissertation explains the following primary motivations for this study: (1) beliefs about opportunities matter, (2) technologies are under-exploited and (3) an insufficient scholarly understanding of how both aspects of the entrepreneurial nexus, opportunity differences and individual differences, work together. Furthermore, this chapter outlines the anticipated theoretical contributions of the dissertation. This chapter briefly introduces the methodological approach used to answer the related research questions of: (1) How do opportunity differences in Superficial, Structural and Procedural Similarities influence Opportunity Beliefs? (2) How does Procedural Similarity moderate the effects that Superficial and Structural Similarities have on Opportunity Beliefs? and (3) How do individuals' Prior Knowledge and Global versus Local Precedence moderate the relationship between opportunity differences and Opportunity Beliefs? In this dissertation, I focus on Structural Alignment Theory to explain the mechanisms underlying the cognitive processes involved in forming beliefs about opportunities. The introduction explains that the theoretical model 
will encompass both aspects of the nexus of entrepreneurial action, opportunity differences and individual differences. The introduction explains that the study utilizes a full-factorial experimental design to test the theoretical model and introduces the model's theoretical contributions and practical implications.

\section{Organization of the Dissertation}

The balance of this dissertation is organized according to the following outline. Chapter 2 reviews the literature on: the opportunity-individual nexus and belief formations, Structural alignment theory and its role in entrepreneurship literature, the role of Prior Knowledge in opportunity recognition and the influence Global versus Local Precedence plays in analogy. Chapter 2, then, uses the cognitive aspects of the literature review to develop testable hypotheses regarding entrepreneurs' beliefs about potential opportunities. Chapter 2 posits that opportunity recognition involves more than finding or encountering an opportunity idea; it also involves a cognitive process that individuals use to develop beliefs or opinions about fit and feasibility of potential supply-demand pairings. Furthermore Chapter 2 argues that such beliefs are influenced by opportunity differences in the form of Superficial, Structural and Procedural Similarities of a technology-market combination. In order to consider both aspects of the nexus, the theoretical model contends that individual differences in the form of differences in Prior Knowledge and the degree to which individuals exhibit a Global Precedence versus a Local Precedence will moderate the relationships between the various similarity types and Opportunity Beliefs. Chapter 3 explains the methodological approach for testing the predictions made in Chapter 2. Specifically, Chapter 3 provides details regarding the experimental design, instrument, sample, variables, controls and analysis techniques used 
to examine the data. Chapter 4 outlines the analysis and results of the experiment that is detailed in Chapter 3. Chapter 5 explains the theoretical meaning of the results listed in Chapter 4 as well as expands upon the theoretical conversation opened in Chapters 1 and 2. The sections following Chapter 5 provide a bibliography and complete list of appendices. 


\section{CHAPTER 2 - THEORY AND HYPOTHESES}

\section{Chapter Overview}

This chapter outlines the theoretical model of the dissertation. Specifically, this chapter is broken into subsections focused on: recognizing that both sides of the opportunity-individual nexus are likely to play a role belief formation, explaining Structural alignment theory and its role in entrepreneurship literature and developing hypotheses for each research question. The first few subsections are intended to introduce the dissertation model's constructs as well as convey the meaning of each construct. The latter subsections of chapter 2 develop hypotheses related to: the direct effects of opportunity differences on Opportunity Beliefs (research question 1), interaction effects between opportunity differences and their impact on Opportunity Beliefs (research question 2) and the moderating role of individual differences on the effect of opportunity differences and their interactions on Opportunity Beliefs (research question 3). After developing the hypotheses, the chapter is summarized.

\section{Opportunity-Individual Nexus and Opportunity Beliefs}

This section of Chapter 2 provides details about and further rational for the inclusion of the individual differences and opportunity differences that are theorized to influence Opportunity Beliefs within this dissertation. Because the focus of this subsection is only on explaining the meaning of constructs as well as the reason(s) for their inclusion; specific predictions regarding the dependent variable of interest, Opportunity Beliefs, are 
detailed later, in subsequent subsections.

Shane and Venkataraman (2000) explain that entrepreneurship involves acting individuals and the opportunities they act upon; that is, entrepreneurship involves the nexus of lucrative opportunities and enterprising individuals, or at least opportunities that individuals believe are lucrative. As discussed in the introductory chapter, this dissertation makes the following assumptions about the nature of entrepreneurial opportunities: (1) opportunities exist, waiting to be identified and (2) opportunities are uncertain. These assumptions place the focus of this dissertation at the heart of the opportunity recognition aspect of entrepreneurial action (Shane \& Venkataraman, 2000). Specifically, individuals must: (1) find-explained by different scholars using various terminology including: encounter (e.g., Kaish \& Gilad, 1991), discover (e.g., Fiet, 2007; Shane, 2000), recognize (e.g., Baron \& Ensley, 2006) and notice (e.g., Baron, 2004)— opportunities, and (2) form a sufficiently positive beliefs about the attractiveness of an opportunity idea, such that they believe what they have 'found' is, indeed, an entrepreneurial opportunity before they can proceed to evaluate if the opportunity is something they, themselves, want to pursue (Grégoire \& Shepherd, 2012; Haynie, Shepherd, \& McMullen, 2009).

Because individuals hold different beliefs about opportunities, not all individuals who encounter an opportunity idea will believe that an opportunity idea is feasible, nor will a particular individual believe every opportunity idea they encounter constitutes a more efficient solution to a market problem/want/need (Shane \& Venkataraman, 2000). What, then, influences whether or not individuals will believe that something they have encountered is an opportunity? Undoubtedly, individual differences will contribute to the 
variance in beliefs about the attractiveness of opportunities. The extant literature provides examples of numerous individual differences that influence whether or not individuals recognize particular opportunities, such as: Prior Knowledge (Shane, 2000), expert prototypes (Baron \& Ensley, 2006), previous personal accomplishments (Fiet, 2007), entrepreneurial passion (Cardon, Wincent, Singh, \& Drnovsek, 2005) and personality traits (Ardichvili, Cardozo, \& Ray, 2003). For example, some of the explanations that scholars offer for initial opportunity recognition include: the notion that a lack of Prior Knowledge prevents individuals from noticing potential solutions to customer problems (Shane, 2000, p. 452); the prescriptive finding that "searching is a bounded attempt to find signals related to a specific set of criteria" individuals should search considerations sets comprised of their Prior Knowledge to find ideas that fit with their Prior Knowledge (Fiet, 2007, p. 593); and the claim that Prior Knowledge is a prototype which serves as templates that assist the persons who possess them to notice links between patterns between diverse events or trends and to perceive recognizable, meaningful patterns in these connections" (Baron \& Ensley, 2006, p. 1333).

However, recent research suggests that differences among opportunity ideas also matter (Grégoire \& Shepherd, 2012). Despite the contributions to our understanding that individual difference studies have made, research has generated incomplete definitions because researchers focus primarily on the individual alone (Shane \& Venkataraman, 2000). In order to form a more complete model of entrepreneurial opportunity recognition, this dissertation considers both individual differences and opportunity differences. 
Recently, scholars have identified individual and opportunity level factors that impact the beliefs that individuals form about the attractiveness of opportunities, thereby influencing opportunity recognition (Grégoire \& Shepherd, 2012). In this subsection of this chapter, I first identify the individual differences that are theorized about in this dissertation, followed by an introduction of the opportunity differences theorized about in this dissertation.

Individual Differences. In their explanation of McMullen and Shepherd's (2006) findings, Grégoire and Shepherd (2012) explain that personal motivations (desires to do something about particular problems) and Prior Knowledge of problems, changes and know-how relevant to markets are the primary contributors at the individual level. Specifically, McMullen and Shepherd (2006, p. 133) explain that:

" $\ldots$ each of these elements produces a belief that is qualified by uncertainty. This uncertainty takes the form of doubt, which prevents action by undermining the prospective actor's beliefs regarding (1) whether an environmental stimulus presents an opportunity for someone in the marketplace, (2) whether this opportunity could feasibly be enacted by the actors, and (3) whether successful exploitation of the opportunity would adequately fulfill some personal desire."

In other words, entrepreneurial action is predicated on sequentially formed beliefs about: (1) whether something encountered is an opportunity for someone or not, and (2) whether an individual could feasibly execute an opportunity and, if so, whether it would fulfill some underlying desire of the individual (McMullen \& Shepherd, 2006). A belief that some environmental stimulus is, indeed, an opportunity for someone (third person) is a pre-requisite for and informs beliefs about whether a particular opportunity is an opportunity for a particular individual (first person) (McMullen \& Shepherd, 2006). Consistent with their findings about the formation of initial Opportunity Beliefs regarding whether environmental stimuli (potential opportunities) are actually opportunities for 
someone, this dissertation theorizes about the role of individual differences in Prior Knowledge about technologies and contexts they are applied to, as well as controls for personal motivations.

This dissertation will argue that personal motivations and Prior Knowledge are not the only individual differences that are likely to play a meaningful role in the formation of Opportunity Beliefs; Global versus Local Precedence will also have a meaningful impact on Opportunity Beliefs. Specifically, I argue that because analogical transfer is a cognitive process, individual level differences that influence cognitive processing will significantly influence analogical transfer in an entrepreneurial context. As mentioned in Chapter 1, the degree to which individuals exhibit a Global or Local Precedence influences their cognitive processing of information (Navon, 1977). This construct refers to the extent to which individuals have a tendency to either (1) more readily perceive the configural aspects of information (Global Precedence) or (2) more readily perceive the Local components or features of information rather than how that information is configured (Local Precedence) (Basso \& Lowery, 2004). Given that we know analogical transfer plays a role in the formation of Opportunity Beliefs in part based on how information is configured (Grégoire \& Shepherd, 2012); it logically follows, that Global versus Local Precedence is also likely to play a role in the formation of Opportunity Beliefs. Therefore, Global versus Local Precedence is examined as a potential moderator in the development of hypotheses in subsequent sections of this dissertation.

Opportunity Differences. Dahlqvist and Wiklund (2011) explain that a part of the nexus is actually missing because for the most part entrepreneurship scholars do not 
empirically study opportunities instead focusing only on differences between individuals or firms. In response to Dahlqvist and Wiklund's (2011) call for focus on both aspects of the nexus, recent research has shown that the often neglected aspect of the nexus, opportunity differences, also plays a role in belief formation (Grégoire \& Shepherd, 2012). However, this is an area that we still know very little about. Indeed, Grégoire and Shepherd (2012) note that their study is one of the first to systematically investigate potential independent effects of opportunity differences on Opportunity Beliefs and their potential contingent relationships with differences across individuals. So, what do we know about the effects of opportunity differences on Opportunity Beliefs? We know that entrepreneurs make mental connections between technologies and potential markets to commercialize technologies in through a process of analogical problem solving (Grégoire \& Shepherd, 2012). Specifically, we know from Grégoire and Shepherd's (2012) study that, on average, the higher the Superficial and Structural similarity in a technologymarket combination (opportunity idea) the more positive beliefs individuals will form about the attractiveness (fit and feasibility) of opportunities.

To further clarify the distinction between the two types of similarity, Gentner (1983) uses the example of comparing a battery to a reservoir. At a Superficial level, a battery and a reservoir are not very similar; the basic elements of each are very different. Indeed, a battery is made of electrolytes and electrodes; on the other hand, a reservoir is made of water. Despite the low level of Superficial Similarity between a battery and a reservoir, Gentner (1983) explains that the two are Structurally high in similarity; specifically, the two are similar in that they both store energy until something triggers them to release that energy into a system. That is, the solution principle between how 
each technology meets latent demands is Structurally similar: (1) store energy, (2) have a known trigger and (3) release stored energy into a system upon trigger.

Psychologists note, however, that Superficial and Structural Similarities, alone, are inadequate to fully capture the relationships that exist between a source (an existing technology application) and a target (a new or potential market application of a focal technology) when one attempts to solve a problem through analogy (Chen, 2002). Instead, some cognitive psychologists suggest that Procedural Similarity should also be considered when examining the mental connections that individuals make from a source to target (Chen, 2002).

Recall that McMullen and Shepherd (2006) identify feasibility to enact an opportunity as one of the types of Opportunity Beliefs that plays a role in whether individuals' perceptions of uncertainty will be overcome sufficiently to result in subsequent action. In their conceptualization, feasibility is related to beliefs formed in the evaluation stage about whether a particular opportunity is one that a particular individual wants to pursue directly (McMullen \& Shepherd, 2006). However, subsequent sections explain that expectations about how a technology can be implemented to meet market needs - based on the degree of Procedural Similarity between a source and target—will also influence early beliefs about whether the opportunity idea is an opportunity at all.

Therefore, this dissertation examines the roles of Superficial, Structural and Procedural Similarities in opportunity belief formation. The following sections of this chapter detail: the steps of the process of analogical transfer and how each type of similarity under consideration fits into the process of analogical transfer; how each of the focal types of similarity directly influences Opportunity Beliefs; how consideration for 
Procedural Similarity can influence the impact of Superficial and Structural similarity; and how individual level differences moderate some of these relationships.

\section{Structural Alignment Theory and Opportunity Recognition}

Solving problems through analogical transfer. The fields of cognitive psychology, consumer psychology and behavioral marketing emphasize the role of comparison in the process of individuals deciding whether they believe certain objects or situations are attractive (e.g., Markman \& Loewenstein, 2010; Kahneman \& Tversky, 1979; Zhang \& Fitzsimons, 1999). Analogical transfer is one kind of comparison that is particularly useful when trying to acquire an understanding of something new or novel (Gentner, 1983). People deal with new encounters by reapplying knowledge and solution strategies they already have (Cropley, 1999). For example, Roehm and Sternthal (2001) provide evidence that consumers evaluate target products (new products that they are not familiar with) through a process of analogical transfer in which they compare the new product with an existing product they are more familiar with. They explain that in order to acquire a deep understanding of a target product's benefits, consumers make use of existing product knowledge by comparing the target product with the closest known existing product (Roehm \& Sternthal, 2001). Furthermore, psychologists have evidence that suggest the use of analogical transfer to make decisions and form preferences regarding novel or uncertain objects or situations starts at a young age (Geake, 2009; Goswami \& Brown, 1990). Analogical transfer is apparently likely to play some role in the formation of beliefs, preferences and opinions about how desirable, attractive or valuable things or situations are across of wide variety of domains. This dissertation focuses on the role of analogy in solving market problems. Indeed, the extant literature 
demonstrates that both children and adults are successful at solving novel problems or making sense of novel situations in a variety of domains by applying solutions from analogous situations (e.g., Bassok, 1990; Catrambone \& Holyoak, 1989; Catrambone, 1996; Chen, 2002; Gick \& Holyoak, 1980; Hsieh, Nickerson, \& Zenger, 2007).

As Chen (2002) points out, an adequate theory of using analogies to solve problems needs to offer an explanation of both how an analogy is drawn and of how an analogue is implemented. In an entrepreneurial context, we already know that the human mind perceives Superficial and Structural Similarities to draw an analogue which then influences individuals' beliefs about entrepreneurial opportunity ideas (Gentner, 1983; Grégoire \& Shepeherd, 2012). However, research in cognitive psychology indicates that the completion of analogical transfer involves three cognitive components: (1) individuals must notice a potential for analogy, (2) individuals must mentally map the correspondences they noticed between a source and target to form higher order relations and (3) individuals must make a mental connection about how to execute or implement the source's solution principle in the target's domain (Chen, 1996; Chen, 2002; Gick \& Holyoak, 1983; Holyoak \& Koh, 1987). Most research on analogies focuses on the first two of these cognitive processes without regard to the third (Chen, 2002). However, when Procedural Similarity is low, the third cognitive component fails and analogical problem solving is not completed (Chen, 1996). Other scholars also note that although Structural similarity may be the chief contributor in analogical transfer, other kinds of similarities also enter into analogical problem solving and, therefore, ask about the influence of other types of similarity as an open question for future research (Gentner \& Markman, 2005). Before explaining how each type of similarity within a potential 
supply-demand pairing influences individuals' certainty in that pairing, I will detail the process of analogical problem solving and how each type of similarity fits into that process.

Each type of similarity is conceptualized as particularly relevant to one of the following three steps of analogical problem solving: (1) "the potentially analogous relationships between the problems must be noticed"; (2) "the correspondences between the key elements ... and the causal relations must be mapped to the target problem"; and (3) the Procedural (implementational) details of how to execute the solution principle within the target domain must be identified (Chen, 2002, p. 82). Although various scholars describe the process of analogical processing using different terminology, table 1 of the appendix provides a sample of various explanations of the process to demonstrate that the underlying concepts of noticing an analogous relationship, mapping correspondences and executing a solution principle are captured by each (Chen, 1996; Chen, 2002; Gentner \& Markman, 2005; Gick \& Holyoak, 1983; Holyoak \& Koh, 1987).

The various descriptions listed in table 1 describe step 1 of analogical problem solving using various phrases which all capture an initial step that involves noticing a potentially analogous relationship between a solution to a problem (source) and an unsolved problem (target). Similarly, the cited scholars describe step 2 of analogical problem solving using different phrases to describe the same cognitive action, mapping. Indeed, all of these citations describe step 2 with some version of the word 'map' except one; the one exception uses the phrase "sorting the matches" to arrive a conceptually equivalent step to mapping (Gentner \& Markman, 2005, p. 1-2). Finally, the extant literature is clear that the third step involves extending the solution principle from the 
source to the target problem. The previously mentioned scholars detail the third step using phrases such as: "generate a solution to the target" (Holyoak \& Koh, 1987, p. 332), "implementation of an acquired solution to solve the target problem" (Chen, 1996, p. 411); "executing a solution principle" (Chen, 2002, p. 83); and "pattern completion from base to target" (Gentner \& Markman, 2005, p. 5). Each of these various phrases is describing the cognitive action of applying (implementing) a solution principle that was noticed or acquired from a source problem to a target problem.

The first two steps primarily dominate research on solving problems through analogical transfer (Gentner et al., 1993; Grégoire \& Shepherd, 2012; Holyoak \& Koh, 1987; Markman \& Loewenstein, 2010); however, individuals will have more difficulty when executing a solution if the source solution does not provide enough details to explain how the solution principle can be executed with users (problem solvers) in the target domain (Chen, 2002). In other words, all three steps are necessary for successful analogical transfer; yet, the third step is usually ignored.

There are three types of opportunity differences considered in this dissertation: Superficial, Structural and Procedural Similarities - each of which contributes to the degree of success of analogical transfer and, therefore, the formation of beliefs about the target (in this case, opportunity ideas). These similarity types are established as those relevant within Structural Alignment Theory (cf. Chen, 2002). Furthermore, recent management literature has identified these similarity types as capturing differences across opportunities (cf. Grégoire \& Shepherd, 2012). 


\section{Table 1: The Process of Analogical Problem Solving}

\begin{tabular}{|c|c|c|c|c|c|c|}
\hline \multirow{2}{*}{$\begin{array}{l}\text { Citations } \\
\text { for } \\
\text { Examples }\end{array}$} & \multirow[b]{2}{*}{ Step 1} & \multirow[b]{2}{*}{ Step 2} & \multirow[b]{2}{*}{ Step 3} & \multicolumn{3}{|c|}{ Measured Similarity Types } \\
\hline & & & & $\begin{array}{l}\text { Superficial } \\
\text { Similarity }\end{array}$ & $\begin{array}{l}\text { Structural } \\
\text { Similarity }\end{array}$ & $\begin{array}{l}\text { Procedural } \\
\text { Similarity }\end{array}$ \\
\hline $\begin{array}{l}\text { Gick \& } \\
\text { Holyoak, } \\
1983\end{array}$ & $\begin{array}{l}\text { "... spontaneously } \\
\text { notice the analogy" (p. } \\
\text { 3) }\end{array}$ & $\begin{array}{l}\text { "... mapping - finding a } \\
\text { set of one to one } \\
\text { correspondences" (p. 2) }\end{array}$ & $\begin{array}{l}\text { "...generate an } \\
\text { analogous solution" (p. } \\
32)\end{array}$ & \multicolumn{3}{|c|}{$\begin{array}{c}\text { Pre-dates empirical distinction } \\
\text { between types }\end{array}$} \\
\hline $\begin{array}{l}\text { Holyoak } \\
\& \text { Koh, } \\
1987\end{array}$ & $\begin{array}{l}\text { "... constructing mental } \\
\text { representations of the } \\
\text { source and the target ... } \\
\text { [and] "... selecting the } \\
\text { source as a potentially } \\
\text { relevant analogue to the } \\
\text { target" (p. 332) }\end{array}$ & $\begin{array}{l}\text { "... mapping the } \\
\text { components of the } \\
\text { source and target" (p. } \\
332 \text { ) }\end{array}$ & $\begin{array}{l}\text { "... extending the } \\
\text { mapping to generate a } \\
\text { solution to the target" } \\
\text { (p. } 332 \text { ) }\end{array}$ & $\mathrm{X}$ & $\mathrm{X}$ & $\begin{array}{l}\text { Did not } \\
\text { assess }\end{array}$ \\
\hline $\begin{array}{l}\text { Chen, } \\
1996\end{array}$ & $\begin{array}{l}\text { "The initial step in } \\
\text { analogical transfer is to } \\
\text { construct a } \\
\text { representation or schema } \\
\text { of the source and target } \\
\text { problems." (p. } 411 \text { ) }\end{array}$ & $\begin{array}{l}\text { "The second step in } \\
\text { solving problems by } \\
\text { analogy is to perceive } \\
\text { the analogical } \\
\text { relationship and to map } \\
\text { the correspondences } \\
\text { between the key } \\
\text { elements of the source } \\
\text { and target problems" (p. } \\
411 \text { ) }\end{array}$ & $\begin{array}{l}\text { "The third step } \\
\text { involves the } \\
\text { implementation of an } \\
\text { acquired solution to } \\
\text { solve the target } \\
\text { problem ... [subjects] } \\
\text { encounter difficulty in } \\
\text { implementing an } \\
\text { analogous solution } \\
\text { when the source and } \\
\text { target problems } \\
\text { required different } \\
\text { procedures, even if } \\
\text { they shared a general } \\
\text { principle." (p. 411) }\end{array}$ & $\mathrm{X}$ & $\mathrm{X}$ & $\mathrm{X}$ \\
\hline $\begin{array}{l}\text { Chen, } \\
2002\end{array}$ & $\begin{array}{l}\text { "First, the potentially } \\
\text { analogous relationship } \\
\text { between the problems } \\
\text { must be noticed" (p. 83) }\end{array}$ & $\begin{array}{l}\text { "... the correspondences } \\
\text { between the key } \\
\text { elements of the source } \\
\text { and target must be } \\
\text { mapped" (p. 83) }\end{array}$ & $\begin{array}{l}\text { "Yet, noticing and } \\
\text { mapping the analogous } \\
\text { relations between } \\
\text { source and target } \\
\text { problems does not } \\
\text { ensure that a solution } \\
\text { principle can be } \\
\text { automatically } \\
\text { transformed into a } \\
\text { solution for a target } \\
\text { problem; another } \\
\text { important process } \\
\text { involves executing a } \\
\text { solution principle in } \\
\text { solving a concrete } \\
\text { problem" (p. } 83 \text { ) }\end{array}$ & $\mathrm{X}$ & $\mathrm{X}$ & $\mathrm{X}$ \\
\hline $\begin{array}{l}\text { Gentner } \\
\& \\
\text { Markman, } \\
2005\end{array}$ & $\begin{array}{l}\text { "...finding a } \\
\text { correspondence between } \\
\text { the conceptual structures } \\
\text { of the two domains } \\
\text { compared" (p. } 1-2)\end{array}$ & $\begin{array}{l}\text { "In the next stage, } \\
\text { Structural consistency is } \\
\text { imposed, with the effect } \\
\text { of sorting the matches } \\
\text { into Structurally } \\
\text { consistent kernels." (p. } \\
\text { 5) }\end{array}$ & $\begin{array}{l}\text { "Finally, inferences are } \\
\text { drawn by a kind of } \\
\text { pattern completion } \\
\text { from base to target." (p. } \\
\text { 5) }\end{array}$ & $\mathrm{X}$ & $\mathrm{X}$ & $\begin{array}{l}\text { Did not } \\
\text { assess }\end{array}$ \\
\hline
\end{tabular}

Emphasis added 
In the context of recognizing new markets to license technologies within (markets which differ from existing applications of technologies), recall that: Superficial similarity represents opportunity differences with respect to who developed a technology, the context where a technology was developed, its parts or components, any inputs it uses, the materials/people that work with in the lab and the output it produces (Grégoire \& Shepherd, 2012).

Structural Similarity represents opportunity differences with respect to how a technology meets market needs (the solution principle) and any reasons why people in the market might not be completely satisfied with their current solutions (Grégoire \& Shepherd, 2012). That is, Structural Similarity captures differences in how similar a technology's original purpose is to the problem that is supposed to solve in a new market.

Procedural similarity represents opportunity differences with respect to the Procedural details of how a technology delivers its intrinsic capabilities (details regarding the execution of a solution principle or how a solution is implemented to a target, in this case users in the market) between an existing application or a technology's original implementational details and a potential new market application (Chen, 1996).

Each of these three similarity types is relevant to one of the steps of analogical problem solving. Chen (2002) explains that Superficial and Structural similarity are most relevant to the first two steps of the process of analogical transfer, noticing a potentially analogous set of problems and then mapping the correspondences between them, thereby recognizing what the solution principle is and whether it maps well to the target's problem. Chen (2002) further explains that the heavy emphasis on these two types of 
similarity in extant research suggests that failing to notice analogous relationships (access a source analogue) is a major obstacle to analogical transfer. Indeed, the preceding discussion notes that the first of the two hurdles to overcome to achieve successful opportunity recognition is noticing an opportunity idea. The third type of similarity, Procedural Similarity may not play as large of a role in noticing opportunity ideas; however, Procedural Similarity is likely to play a role in opportunity recognition through its influence on the formation of beliefs about opportunities because of its relevance in determining whether or not a solution principle can actually be applied to solve a target problem. Indeed, I will argue that all three types of similarity play a role in the second hurdle to overcome to achieve successful opportunity recognition, forming positive beliefs about the attractiveness of opportunity ideas.

Individuals are likely to recognize ex ante if execution of mapped correspondences from a source to target is unlikely and, subsequently, decide that the target is not a good fit and/or not feasible. That is, when Procedural Similarity is low, individuals will perceive successful execution as unlikely and, therefore, determine that such a potential market application of a technology is not a good fit and/or not feasible. The central premise here is that even when the Structural similarity of a technologymarket combination is high, individuals may decide that they are not certain the combination represents an actual opportunity if the Procedural details of how to implement the solution principle in the target domain are very abstract or different from how the technology was originally implemented, thereby leaving the individual with the cognitively demanding task of detailing how to implement a new market application (Chen, 2002). 


\section{Opportunity Differences and Opportunity Beliefs}

In the context of recognition of new applications of technologies, Opportunity Beliefs refer to beliefs about fit between a focal technology and a focal market and feasibility of applying the technology profitably to a focal market (Grégoire \& Shepherd, 2012; Shepherd et al., 2007). Specifically, fit refers to beliefs about whether or not a focal technology fits with the problems of a focal market, is capable of meeting a focal market's needs and does what the focal market demands; feasibility refers to beliefs about whether or not it is feasible to apply a technology profitably within a focal market (Grégoire \& Shepherd, 2012).

As discussed in the rationale for focusing on technology commercialization, the rates of technology research and development (supply of technologies, or solution principles) are outpacing the commercialization of technologies (demand for technologies, or market problems) (Markman et al., 2008). One plausible way to more closely align the pace of technology commercialization with the pace of technology development is to recognize more commercialization opportunities for each technology. Indeed, evidence, such as that provided in Shane's (2000) explanation of 8 different markets that 3-dimensional printing (3DPTM) technology was exploited in, demonstrates that it is possible to commercialize one technology in many different markets. In other words, instead of recognizing new solution principles (technologies or know-how), the focus here is on recognizing more problems (market applications) to apply an existing solution principle to.

Analogical problem solving asks the straightforward question: why try to come up with a new solution to problem ' $\mathrm{B}$ ' when you already have a perfectly satisfactory 
solution available from a comparable problem-solution paring, 'A'? Consider Gentner and Markman's (1997) example of a child learning a solution principle, and then later trying to recognize a problem to apply it to. A two year-old boy, Lucas, plays with a new toy which has six doors, each a different color. Each door has a unique key-a red key for the red door, a blue key for the blue door and so on. Lucas uses the corresponding keys to open each colored door. Then he notices off to the side a seventh white key. He carefully looks at the toy from top to bottom, trying to make sense of it. Then he confidently turns to his parents and asks, "Where is the white door?" As humans develop the ability to notice potential for analogy overtime, they learn to make analogies between less obviously comparable sets of targets and sources than keys and keyholes. Although it may be the case that not all problems have a known comparable, many do. Furthermore, scholars note that a target and source do not need to be obviously comparable; indeed, analogy is a clever and sophisticated process that is often used in creative discovery (Gentner \& Markman, 1997). Gentner and Markman (1997) explain that humans box experiences within categories that are chosen based on how similar an experience is to category representations. Analogical transfer, then, can be initiated when individuals recognize a new problem as analogous with a category from which the individual selects a known solution principle to consider applying. In short, newly encountered problems are solved using solution procedures taken from prior similar problems that are accessed via the more abstract categories that individuals store experiences within (Gentner \& Markman, 1997). Scholars note examples of clever and creative uses of analogy such as between: motive force and light (Gentner \& Markman, 1997), a reservoir and a battery 
(Gentner, 1983) and flight training and ADHD treatment (Grégoire \& Shepherd, 2012), to name a few.

As discussed, the aspect of recognition that is key here is the formation of beliefs about opportunity ideas (positive beliefs about the fit between a technology and a focal market and the feasibility of applying the technology profitably to a focal market). Such positive beliefs are important aspects of opportunity recognition because they can help individuals overcome the action deterring influence of uncertainty. Although the dependent variable, Opportunity Beliefs, encompasses beliefs about fit and feasibility, I aggregate them for the sake of parsimony in listing the hypotheses because the sign of the hypotheses is consistent between the two types of beliefs. However, as detailed in chapter 3, each type of Opportunity Beliefs is assessed and tested independently with multiple items.

\section{Hypotheses Related to Research Question 1: Opportunity Differences and} opportunity recognition. The introductory chapter identified the first research question of this dissertation as: how do opportunity differences in Superficial, Structural and Procedural Similarities influence Opportunity Beliefs? The extant literature already provides evidence that Superficial similarity positively influences beliefs about: (1) the fit between technologies and markets, and (2) the feasibility of profitably applying technologies to markets (Grégoire \& Shepherd, 2012). This dissertation replicates the findings regarding Superficial and Structural similarity as well as considers the role that Procedural Similarity plays in the formation of Opportunity Beliefs. The replication is useful because later hypotheses consider moderating effects on these relationships as well as test whether or not Superficial and Structural Similarities' influence on Opportunity 
Beliefs are contingent on Procedural Similarity. I discuss each of these opportunity differences separately.

First, the author is only aware of two articles that theorize regarding the effects of Superficial Similarity on entrepreneurial opportunity recognition. The first of these articles focuses on entrepreneurial efforts to find new opportunity ideas for technologies (Grégoire, Barr, \& Shepherd, 2010). Grégoire et al.’s (2010) study provides evidence that the Superficial elements of a technology (its parts, components, people who developed it, etc.) directed mental attention or reasoning efforts towards markets that shared similar Superficial elements. For example, this finding would suggest that individuals looking for a new market to exploit a technology developed by NASA would naturally lead to individuals focusing on markets that had something to do with flight, space, physics or the like. Similarly, Grégoire and Shepherd (2012) theorized, and found evidence for a relationship between Superficial Similarity and beliefs. They note that high Superficial Similarity between a new technology and a new target market fosters a cognitive path to facilitate entrepreneurs' thinking about potential ideas and reinforces emerging beliefs that a technology will 'work well' in a target market, just as Superficial similarity between new stimulus and old knowledge helps individuals in thinking about new products.

The logic for the relationships between the degree of Superficial Similarity between a technology and market and opportunity recognition has to do with overcoming the action deterring effects of perceived uncertainty (Grégoire \& Shepherd, 2012). The similarities discussed herein impact individuals' Opportunity Beliefs in terms of their certainty that some 'venture idea' actually represents an opportunity. Opportunities 
represent the possibility to act, the possibility to do something different to better satisfy a market failure in hope bettering the individual, firm or society (Grégoire et al, 2010). Entrepreneurship is to a large degree about carrying out more efficient supply-demand transactions (Denrell, Fang, \& Winter, 2003; Shane \& Venkataraman, 2000). However, recognition of the possibility for more efficient supply-demand transactions rests on subjective perceptions (what one thinks a market demands, one's perception of what a source can achieve, etc.) of objective reality (what a market actually demands, what a source is actually capable of, etc.). The realization that an idea or new pairing of supply and demand is possible (feasible) coupled with a belief that a pairing represents a more efficient transaction because it meets the needs/wants of the market (fit) is what constitutes entrepreneurial opportunity recognition (Davidsson, 2003; Sarasvathy, 2008), Similarity between sources of supply helps drives such perceptions and beliefs because they influence individuals' perceived uncertainty (certainty).

In their paper explaining why entrepreneurship is a unique field of research, Shane and Venkataraman (2000) explain that equilibrium models-which suggest that entrepreneurs are people whom actually prefer uncertainty (Kihlstrom \& Laffont, 1979) - paint an incomplete picture of entrepreneurship. Instead, they suggest that both peoples' tendencies and the situational cues of opportunities play a role in determining which individuals will engage in entrepreneurial behavior (Shane \& Venkataraman, 2000). Further, they suggest that an entrepreneurial discovery is a "conjecture" or a "belief" about some combination of source and demand. At the point of opportunity recognition, we do not know if a conjecture is correct or not; indeed, the feasibility and fit between source and demand associated with an opportunity is still uncertain, it will 
always be uncertain until we can look back after it is exploited. However, the action negating effects of uncertainty are diminished when an individual forms a belief that an uncertain opportunity idea is feasible and fits with what a market wants, regardless of whether or not the conjecture is accurate. Grégoire \& Shepherd (2012) explain that the more Superficial features and elements that a technology and market share, the less uncertain entrepreneurs will be regarding the possibility of applying that technology in the target market.

Perceived uncertainty is reduced with increases in common features in a variety of domains. For example, people tend to have decreased perceived uncertainty for: business models that have components similar to or the same as elements used in other areas (Santos \& Eisenhardt, 2009), new products that share more common features with wellestablished products than not (Markman \& Loewenstein, 2010; Zhang \& Fitzsimons, 1999) and animal categorizations based on the degree of similarity between surface or obvious characteristics (Goldstone, 1994).

Research on cognition has identified Superficial Similarities as the default reasoning mode because Superficial Similarities drive retrieval of knowledge from memory (Holland, Holyoak, Nisbett, \& Thagard, 1986; Keane, Ledgeway, \& Duff, 1994). New stimuli naturally focus a human's mind to consider objects, things or ideas that have Superficially similar elements to the new stimuli (Grégoire \& Shepherd, 2012). Considering such objects, things or ideas, one primes mental models stored in memory so that the individual does not have to rely on passive recall (Namy \& Gentner, 2002). This process makes individuals feel as though it is easier to make sense of and understand new stimuli, thereby reducing how uncertain they perceive the new stimuli to be (Grégoire et 
al, 2010). Indeed, Grégoire et al. (2010) find that a new technology's Superficial elements actually guided reasoning toward markets that contained Superficial elements. Consistent with these observations, Grégoire and Shepherd (2012) found evidence that Superficial Similarity between a technology and market does have a small, positive effect on individuals' certainty that a technology-market pairing represents an actual opportunity for profit. I offer the following, consistent prediction:

Hypothesis 1. Beliefs that a new market application of a focal technology represents an opportunity will be more positive when Superficial Similarity between a technology and a potential market application is high than when Superficial Similarity between the two is low.

As discussed, replicating Grégoire and Shepherd's (2012) hypothesis regarding the effect of Superficial and Structural Similarities on Opportunity Beliefs accommodates building towards moderation hypotheses. Specifically, this dissertation offers moderation hypotheses for Global versus Local Precedence on Superficial and Structural Similarities, as well as tests whether or not their influence is contingent on Procedural Similarity.

As mentioned previously, the process of analogical problem solving involves three sequential steps: noticing, mapping and executing (Chen, 2002). Step one, noticing a potential analogy, is often stemmed from Superficial Similarities whereas step two is primarily influenced by higher order relationships as in the degree of Structural similarity within a potential match (Chen, 1996; Chen, 2002; Gentner \& Markman, 2005; Gick \& Holyoak, 1983; Holyoak \& Koh, 1987). Structural consistency is satisfied by compliance of two constraints, parallel connectivity and one-to-one correspondence. Parallel connectivity "requires that arguments of matching predicates must themselves be able to 
be placed in correspondence" (Gentner \& Gunn, 2001, p. 566). One-to-one correspondence can only exist if parallel connectivity is achieved and requires that each relevant element of a representation match or correspond with no more than one element of the other representation (Gentner \& Gunn, 2001). Structural Similarity is part of the mapping step that involves the individual one-to-one correspondences culminating into an overall depiction of a collective of high-order relationships. These higher order relationships form a network that reflects the overarching capabilities of the technology — its aims and/or its uses—on the technology side of the pairing. On the market side of the pairing, step two of analogical problem solving involves the development of mental models of why people use products/services - what motivates their purchases and spurs their collective behaviors (Grégoire \& Shepherd, 2012). In other words, mapping refers to developing mental models about configurations or how things work together toward some end. In the context of technology commercialization, Structural similarity is high between a technology and market when the capabilities of the technology match the needs, demands or wants of a market.

Consider the following examples of three applications of one technology, the first two represent high Structural similarity with the technology's original aims and/or its uses and the last represents lower Structural similarity. In 1927, W.D. McNalley invented a Breathalyzer technology that was capable of determining the amount of ethanol in a person's exhaled breath. Initially the technology was embedded into a somewhat large and bulky apparatus; the first known application of the technology involved housewives using the apparatus to test whether or not their husbands were intoxicated upon arriving home late in the evening. About a decade later, Professor Rolla H. Harger, embedded the 
technology in a much smaller, more mobile device coined the Drunkometer which was used to test motorists' breath to determine if they were driving while intoxicated.

Recently, the technology has been embedded into a device called HyGreen by University of Florida inventors. HyGreen does not test whether someone is intoxicatedthe original aim or use of Breathalyzer technology—rather, it tests whether someone has adequately washed their hands. The demand for such a device stems primarily from the healthcare industry's need to reduce the millions of infections that are acquired in hospitals each year. In the last example, the latent demand of wanting to reduce the spread of infection in hospitals by ensuring medical providers' hands are sanitary, is not similar to the cause, aim or use the technology was developed for, determining the degree to which an individual is intoxicated. Admittedly, other opportunity attributes and individual characteristic besides the degree of Structural Similarity will play a role in determining whether a particular individual believes HyGreen is a profitable opportunity or not; yet, cognitive researchers have documented that the degree of Structural Similarity is particularly influential when individuals are interpreting, making judgments and/or drawing inferences (Grégoire \& Shepherd, 2012).

Cognitive psychologists indicate that, all else equal, people tend to prefer Structurally similar matches (Gentner, 1983; Gentner \& Gunn, 2001). That is, as people make sense of something new or uncertain, they tend to give preference to things or situations that exhibit many one-to-one correspondences with something they are more familiar with; people tend to prefer deep matching systems over systems with only isolated or scatter matches (Gentner \& Gunn, 2001). Gentner \& Gunn (2001) further note that Structural similarity becomes more and more preferred as individuals' age and gain 
experience. This is consistent with Grégoire et al.'s (2010) finding that expert entrepreneurs tend to devote a great deal of attention to the Structural features of a potential technology-market combination; that is, expert entrepreneurs focus on the needs of the market and the reasons that underlie those needs as well as the capabilities of a technology when assessing their degree of certainty that the potential match will work well. In sum, cognitive research provides evidence that when trying to interpret new stimuli in the face of uncertainty, humans have a noticeable preference for reasoning through higher orders of Structural relationships (Gentner, 1989; Grégoire \& Shepeherd, 2012; Holland, Holyoak, Nisbett, \& Thagard, 1986). Therefore, I suggest the following, consistent prediction:

Hypothesis 2. Beliefs that a new market application of a focal technology represents an opportunity will be more positive when Structural Similarity between a technology and a potential market application is high than when Structural similarity between the two is low.

The final step of analogical problem, which involves implementation of a solution principle acquired from a source, is necessary for successful completion of analogical problem solving, yet often overlooked. Indeed, cognitive psychologists explain that noticing and mapping analogous relations is insufficient. Just because an individual notices and maps relations between a source and target, does not guarantee that the individual will be able to successfully transform the solution principle into a viable solution for a target problem (Chen, 2002). This is consistent with other studies that conclude Procedural transfer is not necessarily an automatic consequence of successful mapping (Novick \& Holyoak, 1991). 
To illustrate the uniqueness of Procedural Similarity, Chen (2002) utilizes a Chinese tale involving a higher-order solution principle of weight equivalence (using the combined weight of smaller objects to weigh something large) to solve the problem of weighing an elephant. Chen (2002) explains that even when keeping the Superficial elements (the objects provided to subjects to utilize when weighing an elephant) and Structural similarity (the solution principle of weight equivalence of smaller objects to weigh something to large to weigh directly) constant, there are two different procedures for implementing the solution principle (sinking compression execution and hanging balance execution); that is the actual problem solver (user of the solution principle) can do two different things). It is easier to apply the solution principle of weight equivalence when the Procedural details of how to implement the principle match in the source and target than when the implementational details are different. When implementational details are different in the proposed target domain (new market), then they are perceived as more ambiguous. This may help explain why some individuals fail to solve certain problems, even when analogous solutions are available to them. Indeed, some studies show that students, for example, fail to solve problems even when they are very familiar with a relevant solution principle in part because students failed to make necessary modifications to the steps used to implement the solution principle (e.g., Catrambone, 1996; Novick \& Holyoak, 1991; Reed \& Bolstad, 1991).

Having tried-and-true Procedural details about how to apply a solution principle to a target problem can increase individuals' certainty that the solution principle will effectively solve the problem. The extant literature provides evidence that the ease with which individuals are able to come up with appropriate, concrete and complete solutions 
for target problems is, to a large extent, determined by the degree of Procedural Similarity between a source analogue and focal target (Chen, 2002). I propose that Procedural Similarity not only influences how effective individuals are at coming up with solutions, but also their degree of confidence or certainty that a particular solution will actually work. In other words, when proposed implementational details for a solution principle into a target problem are not similar to the procedures in the source, one is left to wonder if the proposed procedures will effectively execute the solution principle. On the other hand, when the proposed procedures to apply a solution principle to solve a target problem are very similar to those of the source, individuals will tend to be confident that the efforts will be successful.

For example, consider a documented case of technology transfer used in Grégoire and Shepherd's (2012) experiment on the effects of opportunity differences on Opportunity Beliefs. The authors present subjects with NASA's EAST (extended attention span training) technology (originally developed to serve a market of shuttle pilots through a means of flight simulators) as a potential solution principle to the market need of increasing the concentration ability of ADHD children; in this opportunity idea, the training would be implemented by having children with ADHD play video games in which the training and electroencephalogram neurofeedback is embedded. The video games are conceptualized as low in Superficial Similarity to the flight simulators because video games represent toys children play with whereas flight simulators do not represent toys that children play with; however, Procedural Similarity may also be embedded in this comparison. Although the parts, components and people (Superficial features) associated with video games and flight simulators are, indeed, low in similarity, the way 
the training is implemented via flight simulators and video games is procedurally similar. Specifically, both methods likely involve a trainee sitting in a chair, holding some control device in their hands and watching the 'thing' they are controlling on a screen in front of them while receiving the electroencephalogram neurofeedback that is the solution principle. In this example, the concentration training (solution principle) is implemented in a procedurally similar way to the ADHD children and the pilots (the users are doing nearly the same thing in each market). Therefore, it is plausible - although currently only speculative - that Procedural Similarity could play a role in belief ratings for this case.

Consider an alternative to video games as the method of delivering NASA's training to ADHD children, such as through musical instruments. Like video games, musical instruments are not superficially similar to flight simulators and require a great deal of concentration, yet the sensors could still be attached to the individuals to monitor electric conductivity and send signals. In other words, Superficial similarity is low and Structural similarity is high for both video games and musical instruments; however, the idea of using musical instruments does not seem quite as attractive as a video game; why? The answer is that the use of musical instruments leaves some implementational details as abstract because the way musical instruments are played is considerably different than the way a flight simulator is operated (the original implementation method of the technology); on the other hand, executing training through a video game is similar to executing training through a flight simulator so that the implementational details are inherently provided in the information from the source because the user does effectively the same thing.

This is congruent with findings in cognitive psychology which suggest that the 
main obstacle to using analogical problem solving is difficulty in executing the general idea, not in accessing a source or in mapping the key components between a source and target problem (Chen, 2002). In short, the known-positive effects of Procedural Similarity on actual execution of a solution principle in a target problem's domain are not the only effects of Procedural Similarity. The idea here is that the degree of similarity between procedures that are known to work (from an existing source) and procedures that are proposed to be utilized to implement a solution principle to a target problem also influence the degree of certainty that individuals will have regarding the success of solving the target problem. Therefore, I offer the following prediction:

Hypothesis 3. Beliefs that a new market application of a focal technology represents an opportunity will be more positive when Procedural Similarity between a technology and a potential market application is high than when Procedural Similarity between the two is low.

Hypotheses Related to Research Question 2: Procedural similarity's interaction with Superficial and Structural similarity. The introductory chapter states the second research question of this dissertation as: how does Procedural Similarity moderate the effects that Superficial and Structural Similarities have on Opportunity Beliefs?

To examine the second research question, I will test the interaction effects of Procedural and Superficial Similarities as well as Procedural and Structural Similarities on Opportunity Beliefs. We know that Superficial and Structural similarity positively influence beliefs about the attractiveness of opportunities (Grégoire and Shepherd, 2012); however, the influence of Superficial and Structural similarity may be somewhat contingent on Procedural Similarity. That is, the degree of abstraction in the 
implementation details (Procedural Similarity) between a source and target constrains the selection and application of information from source information (Chen, 2002). In other words, a high degree of abstraction in the third cognitive component, represented by low Procedural Similarity, can negatively influence the success of the first two cognitive components, noticing and mapping; this is the underlying reason for expecting an interaction effect between these opportunity differences.

As discussed, Superficial and Structural Similarities are expected to positively influence Opportunity Beliefs holding everything else equal consistent with Grégoire and Shepherd's (2012) findings; people tend to prefer common features and well-understood configurations when dealing with uncertainty. Here, I consider to what degree, if any, Procedural Similarity interacts with the influence of Superficial and Structural similarity on Opportunity Beliefs. To clarify, it is helpful to distinguish between two methods of solving problems: in the first method, an individual trying to solve a problem is essentially uninformed and is, therefore, engaged in self-generation of potential solutions (Perfetto, Bransford, \& Franks, 1983); in the second method, a problem solver utilizes previously acquired, relevant information from other problem situations as is the case in the contextual choice of this dissertation. In the second type of problem solving, it is not sufficient for relevant information to merely exist, available to utilize; an important aspect of solving problems without relying on completely self-generated answers is that relevant information about solutions must be noticed, accessed, and applied (Perfetto et al., 1983). In this dissertation, I focus on the second type of problem solving. Procedural Similarity deals with the application aspect of solving problems via this method. Noticing and accessing information are primarily related to Superficial and Structural Similarity. I 
do not consider Superficial and Structural Similarity as moderators of Procedural Similarity because if a potential solution is not noticed/accessed, then application is irrelevant.

Even if one possesses the required knowledge to make a useful analogy, analogical transfer is not complete if something impedes the noticing of analogy potential and/or subsequent access of relevant knowledge. Indeed, Superficial similarity between a technology and a market problem is important because of its saliency, or ease of notice, as well as individuals' tendency to prefer to access common features in uncertain situations, as discussed above. Superficial Similarity refers to those aspects of a potential technology-market combination that are solution-irrelevant but very salient details (Chen, 1996). That is, Superficial Similarity plays a role in analogical problem solving partly because its saliency helps individuals notice the potential for analogy to get the analogyball rolling. The higher the Superficial Similarity, the more confident individuals are that a solution principle is available to access through analogy.

Procedural Similarity, on the other hand, primarily influences individuals' confidence in the ability of an accessed solution principle to be applied in a new problem's domain (Chen, 1996). However, this direct effect on Opportunity Beliefs is not the only influence Procedural Similarity is likely to have. Although the primary influence of Procedural Similarity is on confidence in application, the absence of details regarding how to apply an accessed solution principle can also diminish the positive influence of other types of similarity because it constrains the selection of information (Chen, 2002). Empirical evidence shows that subjects are not only better able to execute solutions when Procedural Similarity is high, but they are also better able to generate solutions from 
analogous situations when Procedural Similarity is high (Chen, 2002). Procedural Similarity influences solution generation because, as Chen (2002) suggests, Procedural Similarity constrains information selection. That is, the fewer Procedural details that a technology and a potential market application have in common, the less likely individuals are to access other types of information or notice the potential for analogy.

Although not directly considered or tested, Shane's (2000) article on Prior Knowledge and opportunity recognition provides an example of this potential interaction effect between Superficial elements and Procedural details. Upon learning about and subsequently discussing the market opportunities that other entrepreneurs had identified for MIT's 3-dimensional printing (3DP ${ }^{\mathrm{TM}}$ ) technology, one of the individuals that successfully applied the technology to a new market, Marina Hatsopoulos, acknowledged how difficult it would have been to recognize the other opportunities (Shane, 2000). It is evident from the explanations of the various licenses of $3 \mathrm{DP}^{\mathrm{TM}}$ that they varied in their degree of Superficial and Procedural Similarity; for example, they varied by industry of the market, materials output by the technology, how the printing machine was actually used and the type of market need or problem the technology solved for each entrepreneur versus the technology's original purpose (Shane, 2000). Furthermore, there is an apparent interaction between Superficial elements and Procedural details of how to actually use the technology which seem to influence at least one entrepreneurs' confidence in the prospects of recognizing a particular opportunity. Indeed, upon hearing how someone else exploited the $3 \mathrm{DP}^{\mathrm{TM}}$ technology, Marina discussed why it would be so difficult to recognize that particular opportunity, stating that originally "you could not make metal parts using the $3 \mathrm{DP}^{\mathrm{TM}}$ process $[($ Superficial Similarity $)] \ldots$ you would have to think of a 
different way to use the machine [(Procedural Similarity)]" (Shane, 2000, p. 456). It seems evident that a scholarly examination of potential interaction effects between Superficial Similarity and Procedural Similarity is worthwhile.

As discussed, the model also predicts a positive relationship between Structural Similarity and Opportunity Beliefs, all else equal. When discussing how people make sense of something new or uncertain, I noted that individuals tend to exhibit preference for things or situations that share many one-to-one correspondences with that which they are familiar with (Gentner \& Gunn, 2001). With respect to Structural Similarity, then, individuals tend to have positive judgments when a technology's capabilities more closely match the needs of the market. The second part of research question number 2 asks to what degree, if any, Structural Similarity's influence on Opportunity Beliefs is affected by the degree of Procedural Similarity.

Consider two of the examples provided above of market applications for Breathalyzer technology. The technology's original underlying capability is measuring the amount of alcohol in a human's breath. The need of the first market was to measure the amount of alcohol in husbands (high Structural Similarity), and the need of the second market was to measure the amount of alcohol in a driver (high Structural Similarity). Both markets represent high Structural Similarity with the underlying technology; therefore, this dissertation predicts that, all else equal, individuals would tend to develop high positive beliefs that both of these market-applications represented opportunities. In short, the technology does what the market needs and so, all else equal, people will tend to believe the market application is an opportunity. However, does the high consistency between capability and need continue to influence beliefs as strongly 
when the details about how to implement the capability into a market are abstract (low Procedural Similarity)? I submit that the effect is weakened. Indeed, the need to assess the alcohol level in drivers was known far previous to the exploitation of this opportunity; the deterring factor that prevented this opportunity from being identified earlier was an implementation problem. The opportunity was not identified until after someone figured out a new way to embed the technology (Procedural details) despite the known match between technology capability and market needs.

Inferring that a solution principle that worked in one domain (e.g., measuring alcohol in husbands) will work in another domain (e.g., measuring alcohol in drivers) hinges on both whether or not the solution is an appropriate solution and if that solution principle can be feasibly applied. As mentioned, when it is not clear how to apply a solution principle, beliefs will be less positive (direct effect of Procedural Similarity). Furthermore, when it is not clear how to apply a solution principle, individuals will tend to question whether the solution principle is an appropriate solution principle at all.

Beliefs about something that cannot be directly observed instantaneously, such as whether or not an opportunity idea is profitable, are generally formed through some degree of inference (Fishbein \& Ajzen, 1975). Inference making occurs when individuals must construct meaning beyond the information that is explicitly provided (Harris, 1981). When making inferences, individuals generally rely on relationships between held cognitions or beliefs of an attribute value and logical links to another attribute's value (e.g., Dick, Chakravarti, \& Biehal, 1990; Fishbein \& Ajzen, 1975). For example, Dick et al. (1990) relates some inferential processes with social judgments; when we do not know the values of specific attributes of an individual, we infer values based on the information 
we have about the social categories the individual belongs to. Consumers, for instance, may infer that brands they like (dislike) have favorable (un-favorable) attribute levels; i.e., making the potentially erroneous connection that one attribute score implies another (Dick et al., 1990).

In the context of this dissertation, technology commercialization, the relevant issue is determining whether a technology is capable of solving a problem and, if so, if it is feasible to apply the technology within the problem's domain profitably. When Procedural Similarity is low (details about applying or implementing a solution are absent or abstract because users in the new market will execute the solution principle differently than the technologies' original users did), it does not necessarily indicate that a solution cannot be applied; rather it leaves the evaluator the cognitively difficult task of trying to infer Procedural details from whatever information they have at hand (Chen, 2002). Cognitive energy expended on trying to determine if abstract or novel Procedural details (those that do not match how the technology is originally embedded or implemented), also distracts attention away from other opportunity differences such as Superficial and Structural Similarity, thereby diminishing their influence. Indeed, cognitive psychologists suggest potential interaction effects between similarity types. Chen (1995), for example, explains that either Superficial or Procedural Similarity alone is probably not sufficient for achieving transfer and one's influence is partially contingent upon one the level of the other. On the one hand, surface similarities might increase the likelihood of noticing a potentially useful solution principle, but they do not ensure that problem solvers will be able to benefit from the solution principle because of potential obstacles in transforming how the actual target (in this case users) will make use of the solution principle (how it is 
implemented). On the other hand, even if the source and target shared a similar method for implementing a solution principle, absolving the need to transform implementation details for the new users or problem solvers, the solution principle may not be retrieved if there are not enough Superficial Similarities for an individual to notice the potential for analogue. Consistently, I offer the following hypotheses regarding the decreased positive influence that Superficial and Structural Similarities are likely to have when Procedural Similarity is low:

Hypothesis 4a. Procedural Similarity will positively moderate the effect of Superficial Similarity on Opportunity Beliefs, such that the positive relationship between Superficial Similarity and Opportunity Beliefs is greater when Procedural Similarity is high than when it is low.

Hypothesis $4 \mathrm{~b}$. Procedural Similarity will positively moderate the effect of Structural Similarity on Opportunity Beliefs, such that, the positive relationship between Structural Similarity and Opportunity Beliefs is greater when Procedural Similarity is high than when it is low.

Interaction plots for the expected relationships outlined in hypotheses $4 \mathrm{a}$ and $4 \mathrm{~b}$ are shown in figure 1 below. 


\section{Figure 1: Interaction Plots for Hypotheses H4a, H4b, H6a, and H6b}

\section{H4a: Procedural $\times$ Superficial $(+) \rightarrow$ Opportunity Beliefs}

$$
\begin{array}{r}
\text { Opportunity } \\
\text { Beliefs }
\end{array}
$$

Procedural HIGH

, $\quad$ Procedural LOW

,

Superficial Similarity

H4b: Procedural $\times$ Structural $(+) \rightarrow$ Opportunity Beliefs

$$
\begin{array}{r}
\text { Opportunity } \\
\text { Beliefs }
\end{array}
$$

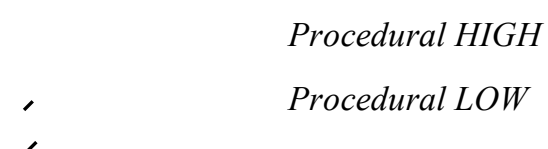

Structural Similarity

H6a: Prior Knowledge of a Technology Negatively Moderates 'Proc $\times$ Struc $(+) \rightarrow$ Opp Beliefs'

LOW Prior Knowledge of Technology

Opportunity '

Beliefs Opportunity '
Beliefs
Procedural HIGH

Procedural LOW

Procedural HIGH

Procedural LOW

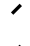

,

Structural Similarity

H6a: Prior Knowledge of a Market Negatively Moderates 'Proc $\times$ Struc $(+) \rightarrow$ Opp Beliefs'

LOW Prior Knowledge of Market

Opportunity

Beliefs
HIGH Prior Knowledge of Market

Opportunity

Beliefs

Structural Similarity
,

HIGH Prior Knowledge of Technology

Structural Similarity
Procedural HIGH

Procedural LOW

,

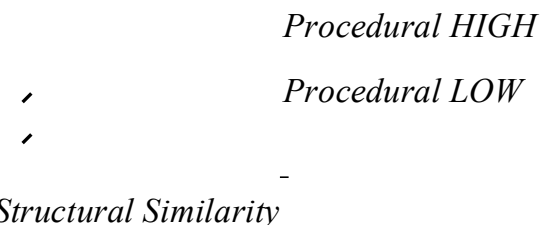




\section{The Opportunity-Individual Nexus}

In the next two subsections, I make predictions regarding the opportunityindividual nexus and Opportunity Beliefs. Specifically, I theorize about individual differences which likely moderate the relationships predicted between opportunity differences and Opportunity Beliefs.

\section{Hypotheses Related to Research Question 3: Moderating roles of Prior Knowledge}

and Global versus Local Precedence. This dissertation's third research question can be separated into two parts. The research question asks how individual differences in Prior Knowledge and Global versus Local Precedence moderate the relationship between opportunity differences and Opportunity Beliefs? First, I will theorize about Prior Knowledge.

Austrian economists emphasize the role of the entrepreneur in economic processes; the Austrian perspective contends that neo-classical economists overlook how decision problems come into existence in the first place (Garrison, 1991). Although I do not intend to dissect the various views of Austrian economics here, a brief discussion of how solving market problems fits into the economy will help illustrate the relevance of Prior Knowledge in analogical problem solving. Hayek (1948) contends that the purpose of competition in the market place is to teach the market who will serve them well: which grocer, travel agency, department store, hotel, doctor or solicitor, the market can expect to provide the most satisfactory solution to problem(s) that individuals in the market face. To Hayek, the market serves the purpose of sorting out which solutions fit with, or successfully solve the economy's problems; Hayek (1948) further contends that market players are better equipped to recognize solutions when they have relevant knowledge, 
such as of demand (markets) or know-how (technologies). Before a potential solution can be formed into a workable business model, entrepreneurs must decide which potential solutions they will utilize or which market needs they will apply a given solution to (Hseih, Nickerson, \& Zenger, 2007).

The suggestion that Prior Knowledge influences the recognition of entrepreneurial opportunities is not new. It is well known that when individuals encounter something new or novel, they make sense of, or deal with, the new thing by applying knowledge and solution strategies they already have; the more relevant knowledge one has, the more one thinks in an assimilative manner (Cropley, 1999). One effect of this is cognitive economy. Prior Knowledge helps individuals recognize opportunities partly because it helps them processes information faster, allowing them to take advantage of narrow windows of opportunities (Busenitz \& Barney, 1997). This is consistent with research on Prior Knowledge in other domains as well which demonstrate that higher Prior Knowledge leads people to make decisions quickly, rather than expending a great deal of time and effort systematic advancing from one step to the next (Logan, 1990). Other scholars note that Prior Knowledge influences the degree to which individuals are able to imagine or think of entrepreneurial opportunities (e.g., Shepherd \& DeTienne, 2004). Prior knowledge also helps entrepreneurs notice and filter signals about potential opportunities (Fiet, 1996; Shane, 2000).

Cognitive psychology research suggests that Prior Knowledge also plays a role in making sense of new or novel situations partly through its influence on analogical transfer (Holland, Holyoak, Nisbett, \& Thagard, 1986). Individuals with rich and deep knowledge are better suited to interpret information and tend to emphasize Structural 
Similarities over Superficial Similarities in processes of opportunity recognition (Holland et al., 1986). Consistently, Grégoire and Shepherd (2012) theorize, and find empirical evidence for, the idea that individuals with greater Prior Knowledge are more likely to heavily rely on Structural Similarity than individuals with less Prior Knowledge as they develop beliefs about opportunity ideas.

This dissertation predicts that Prior Knowledge also moderates the influence of the third type of opportunity difference on Opportunity Beliefs introduced in this dissertation, Procedural Similarity. Although it is clear that Prior Knowledge matters to opportunity recognition, scholars note that we are often not sufficiently precise in regards to what types of knowledge matter and to what processes various types of knowledge matter (Davidsson \& Honig, 2003). This dissertation examines the influence of two types of knowledge, Prior Knowledge of a technology and Prior Knowledge of a market. Further, potential moderation effects that these two types of knowledge have on Procedural Similarity's direct influence on Opportunity Beliefs and Procedural Similarity's interaction effect with Structural Similarity are examined.

First, I will discuss potential moderation effects of Prior Knowledge on the theorized direct relationship between Procedural Similarity and opportunity differences. The selection of technology and market knowledge as the types of knowledge to focus on in this dissertation is a function of one of this dissertation's boundary conditions, technology commercialization and the dissertation's theoretical lens, analogical problem solving, as laid out in chapter 1. Given that using analogies to solve problems refers to the act of transferring previously acquired knowledge or solutions from one domain or context to another, it follows that one's stock of Prior Knowledge in a target and in a 
source will influence how successful individuals are at analogical problem solving (Chen, 2002). It follows that the types of Prior Knowledge that will matter are those related to the relevant domains; here, the relevant domains are a technology (the source of analogue) and a focal market (the target of the analogue). We already know that in the context of technology commercialization, individuals' levels of Prior Knowledge about technologies and markets play a role in analogical problem solving (Grégoire \& Shepherd, 2012). However, the extant literature only explicates Prior Knowledge's influence on two of the three parts of analogical problem solving, Superficial and Structural Similarities between source and target domains. There are reasons to expect, however, that Prior Knowledge will also influence the effect of the third aspect of analogical problem solving, Procedural Similarity, which is of primary focus in this dissertation.

Recall that Procedural Similarity matters to opportunity recognition because even when individuals are very familiar with potential relevant solution principle(s) (Structural Similarity), if they fail to access implementational details for executing a solution principle, then analogical problem solving will not be successful (Catrambone, 1996; Novick \& Holyoak, 1991; Reed \& Bolstad, 1991). That is, Procedural Similarity influences whether or not individuals believe that known Procedural details for executing a solution principle are feasible, or at least modifiable, or if they are so unique that modifying them is too complex. However, Prior Knowledge can help when assessing complexity and making adjustments to existing processes.

Prior knowledge about a relevant context—here, a market or technology—can help facilitate the difficult process of assessing a particular problem's complexity (Chi, 
2006). Furthermore, Prior Knowledge enables individuals to more accurately determine, and make necessary adjustments to deal with, problematic information because individuals who posses more Prior Knowledge are better equipped to know about and void the negative consequences of various contingencies that might arise when implementing a solution principle (e.g., Alba \& Hutchinson, 1987). For these reasons, I expect a positive moderating effect of Prior Knowledge in technologies and markets on the influence that Procedural Similarity has on Opportunity Beliefs. Formally:

Hypothesis 5a. Individuals' Prior Knowledge of a technology will positively moderate the influence of Procedural Similarity on Opportunity Beliefs, such that Procedural Similarity will have a stronger positive impact on Opportunity Beliefs for individuals with higher levels of Prior Knowledge of a technology than it will for individuals with lower levels of Prior Knowledge of a technology.

Hypothesis 5b. Individuals' Prior Knowledge of a market will positively moderate the influence of Procedural Similarity on the Opportunity Beliefs, such that Procedural Similarity will have a stronger positive impact on Opportunity Beliefs for individuals with higher levels of Prior Knowledge of a market than it will for individuals with lower levels of Prior Knowledge of a market..

The hypotheses development above theorized that Procedural Similarity interacts with Superficial and Structural Similarities because Procedural Similarity constrains information selection and application (Chen, 2002). That is, Procedural Similarity not only directly effects beliefs about execution of solution principles, but also the ability of individuals to generate solutions from analogous contexts or situations (Chen, 2002; Perfetto et al., 1983). Previous hypotheses development discussed how low Procedural 
Similarity is likely to leave an evaluator with the cognitively difficult task of inferring Procedural details and suggested an interaction effect with the other opportunity differences considered herein (Chen, 2002). If there is some construct that influences inference, then, it likely moderates this relationship; there is evidence that knowledge, indeed, influences inference with respect to Structural Similarity. Specifically, individuals that have lower levels of Prior Knowledge rely on forward-looking inference (Dew, Read, Sarasvathy, \& Wiltbank, 2009). That is, when individuals with low Prior Knowledge are presented with a positive example from the past of how market needs were met, they are more likely to infer future positive signals and judgments because they do not have sufficient knowledge to provide counter-evidence or reality checks (Dew et al., 2009). Conversely, individuals with higher levels of Prior Knowledge can substitute direct evaluation of known information for the indirect, and more likely over-optimistic, inferences that coincide with unfamiliarity. It follows that when individuals are left to infer Procedural details (Procedural Similarity) for solution principles (Structural Similarity) as discussed in the interaction hypotheses above, those with lower Prior Knowledge of a technology or market will tend to make more positive judgmentsperhaps, inferring too much from too little-whereas those with more Prior Knowledge will utilize their knowledge as counterfactual evidence, tempering their optimism. Therefore, I predict the following:

Hypothesis 6a. The positive moderation effect of Procedural Similarity on the relationship between Structural Similarity and Opportunity Beliefs is stronger when Prior Knowledge of a Technology is low than when it is high. 
Hypothesis $6 b$. The positive moderation effect of Procedural Similarity on the relationship between Structural Similarity and Opportunity Beliefs is stronger when Prior Knowledge of a Market is low than when it is high.

Interaction plots for the expected relationships listed in hypotheses $6 \mathrm{a}$ and $6 \mathrm{~b}$ are shown in figure 1.

Another individual level difference that is likely to influence the degree to which opportunity differences influence Opportunity Beliefs is Global versus Local Precedence. As discussed previously in this dissertation, Global Precedence refers to one's Precedence with individuals tending to exhibit either a Global or Local Precedence. Individuals' presidencies are sometimes conceptualized as either Global or Local perceptual biases. Individuals with a Global Precedence focus on how things are configured, or the big picture (Basso \& Lowery, 2004; Navon, 1977); at the other end of the continuum, individuals with a Local Precedence tend to focus on the parts or components rather than the big picture (Navon, 1977). Global versus Local Precedencies are often theorized to influence visual-spatial tasks such as evaluating similarity between images (e.g., Basso \& Lowery, 2004; Förster, 2009; Navon, 1977). However, scholars have recently taken note of this construct's potential to influence beyond the perception of visual-spatial imaging tasks (Förster, 2009). For example, Förster, Liberman and Shapira (2009, p. 384 emphasis added) explain that "people can think about the same action (e.g., watering plants) in abstract, Global terms (e.g., designing the room) or in more concrete, Local terms (e.g., getting the water in the can and pouring it over the plants).” They further suggest a potential link between Global Precedence (Global versus Local) and perceptions about novel situations, which highlights why it is reasonable to 
investigate if there is a link between Precedence and perceptions about uncertain entrepreneurial opportunities.

The construct of Global versus Local Precedence does not indicate that individuals cannot process information both globally and locally; rather the construct indicates which type (Global versus Local), and to what degree, individuals give Precedence to one or the other (Förster, 2009). Indeed, individuals' capacity for processing information is limited (Miller, 1956). Therefore, as we receive an abundance of information, we must select—usually subconsciously—which information to focus on or process first (Förster, 2009). Global versus Local Precedence theory simply states that some individuals consistently tend to process big picture information (Global information) first whereas others consistently tend to process details (Local information) first. Furthermore, cognitive psychology indicates that people seek consonance between the information they process and the beliefs and expectations that they subsequently derive (Festinger, 1957); one of the primary ways of achieving cognitive consonance is by lowering the importance of some factors. Given individuals' cognitive limitations, how will a Global Precedence, then, influence the relationships between opportunity differences in Superficial, Structural and Procedural Similarities and Opportunity Beliefs differently than a Local Precedence will? To answer this question, it is helpful to consider if each type of similarity is more appropriately classified as either a big picture factor (Global) or details factor (Local). Superficial and Procedural Similarities are concerned with details, whereas Structural Similarity is considered with higher order relationships (Chen, 2002). 
First, Superficial Similarity deals with specific details, such as: objects, characters, parts, components, materials, etc. (Genter, 1983; Grégoire \& Shepherd, 2012); individuals who focus on specific details (Local Precedence), then, are more likely to process and be attentive to Superficial Similarities than individuals who focus more on the big picture (Global Precedence). This leads to the following hypothesis regarding likely moderating effects of Global versus Local Precedence on the relationship between Superficial Similarity and Opportunity Beliefs:

\section{Hypothesis 7a. Global versus Local Precedence will moderate the} relationship between Superficial Similarity and the perceived attractiveness of a technology-market combination such that the positive relationship between Superficial alignment and Opportunity Beliefs will be higher for individuals with a Local Precedence.

Second, Structural Similarities are more likely to be heavily weighted by individuals that focus on the big picture. Indeed, cognitive psychologists provide empirical evidence that in visual-spatial tasks, Global Precedence involves identifying Structural relations between stimuli that influence judgments rather than relying on the specific, individual components themselves (Förster, 2009); in other words, Structural Similarity deals with big picture factors suggesting that a Global Precedence would strengthen the positive relationship between Structural Similarity and Opportunity Beliefs. Furthermore, Global Precedence is known to lead to a focus on similarity whereas Local Precedence leads to a focus on dissimilarity (Förster, 2009). If a market's people, objects and other Superficial features are dissimilar to a technology's Superficial features, then individuals must rely on higher order (big picture) relationships (e.g., 
Structural Similarity) to successfully analog the two domains. Individuals who tend to focus more on higher order relationships, such as those with a Global Precedence, should be influenced to a greater-positive degree by Structural Similarity than individuals who do not give Precedence to higher order relationships; formally:

Hypothesis 7b. Global versus Local Precedence will moderate the relationship between Structural Similarity and the perceived attractiveness of a technology-market combination such that the positive relationship between Structural alignment and Opportunity Beliefs will be higher for individuals with a Global Precedence.

Finally, Procedural Similarity is concerned with the details regarding how to implement or execute Structural relationships; that is Procedural Similarity is concerned with how users interact with and execute higher order solution principles (Chen, 2002). As is the case with the other details factor, Superficial Similarity, Procedural Similarity's importance is magnified when individuals tend to process details prior to big picture information. Consistent with cognitive psychologists' explanations of limitations on our capacity to process large amounts of information, if we prefer to process details first, then details will influence our beliefs and expectations more whereas if we prefer to process big picture factors, then higher order relationships will influence our beliefs and expectations more. This leads to the following hypothesis regarding the moderating effect of Global versus Local Precedence's influence on the relationship between Procedural Similarity (a details factor) and Opportunity Beliefs:

Hypothesis 7c. Global versus Local Precedence will moderate the relationship between Procedural Similarity and the perceived attractiveness of a technology- 
market combination such that the positive relationship between Procedural alignment and Opportunity Beliefs will be lower for individuals with a Global Precedence. 
Figure 2: Model of Individual-Opportunity Nexus and Opportunity Beliefs

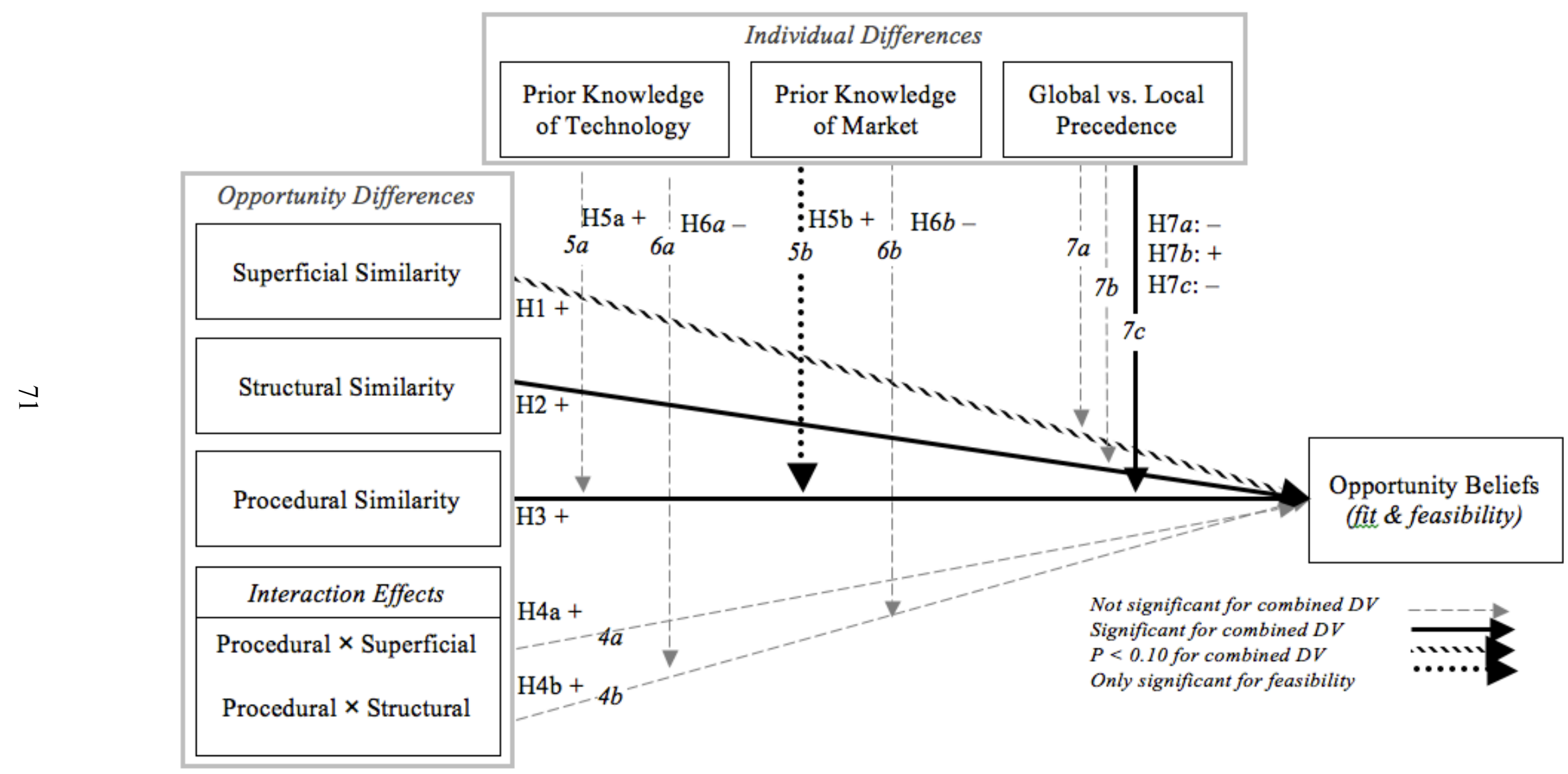




\section{Chapter Summary}

Opportunity Beliefs play a substantial role in the recognition stage of the entrepreneurial process because individuals who encounter the same opportunity ideas may not recognize such ideas as actual opportunities if they do not form positive beliefs about the ideas (e.g., Grégoire \& Shepherd, 2012; Shane \& Venkataraman, 2000). This chapter of this dissertation theorizes about constructs at both the individual and opportunity levels that might influence the formation of such beliefs in the context of opportunity ideas that fall within the context of technology commercialization. Specifically, this chapter focuses on theorizing about instances of technology commercialization in which a technology was developed for a specific purpose to fill some need, and is later being considered for licensing to solve another market need, problem or want. As such, I treat the context as one of solving problems through the use of analogy.

Solving problems through analogy is a process that is influenced by three types of similarity: Superficial, Structural and Procedural (Chen, 2002). These types of similarity combine to determine how certain individuals are likely to be regarding the potential for successfully noticing, mapping and implementing a solution from a source to a target. As such, I predict direct and interaction relationships between the differences that opportunities exhibit for these types of similarity and individuals' beliefs about opportunity ideas. Further, I theorize that differences across individuals in their Prior Knowledge about markets and technologies, as well as their tendency to process Global or Local information first, will moderate the strength of the relationships between opportunity differences and Opportunity Beliefs. 


\section{CHAPTER 3 - RESEARCH DESIGN AND METHODS}

\section{Chapter Overview}

When examining the roles of cognitive factors in the processes of making decisions or forming beliefs, policy capturing-experimental designs offer an advantage over other designs (Davidsson, 2007). Many dominant research methods, such as traditional surveys and interviews rely on retrospection and one's own understanding of his or her beliefs. Policy capturing, however, allows researchers to model decisions and beliefs without relying on one's own understanding of their perceptions and beliefs (Louviere, 1994; Shepherd \& Zacharakis, 1999). The experimental design of this dissertation allows me to decompose individuals' degrees of certainty regarding the fit and feasibility between a technology and market. I am, therefore, able to make inferences about how each of the types of similarity contributes, if at all, to individuals fit and feasibility beliefs.

Chapter 3 begins by describing of the characteristics of the sample collected in the execution of the experiment. Next, I describe the design of the experiment. After describing the nature of the experimental design, I provide a description of each variable used to capture the constructs of the theoretical model shown in figure 1.2. My description of variables includes samples of the technology and market descriptions, which are available verbatim in appendix 2. Following the description of the variables associated with the theoretical model, I outlay the controls that I will measure and test to 
rule out other likely explanations for beliefs about opportunities. Finally, I explain the data analysis method that I will use to test the hypotheses and summarize the chapter.

\section{Sample}

As management research has developed as a field, more and more researchers have called for replication of previous results (cf., Amir \& Sharon, 1990; Hubbard, Vetter, \& Little, 1998; Scandura \& Williams, 2000). These, and other similar, calls for replication make the case that the accumulation of scientific knowledge is dependent upon replications using various samples (Amir \& Sharon, 1990). Further, scholars suggest that one strategy for accumulating scientific knowledge is to examine whether known results replicate across samples that are moderately high in generalizability (Scandura \& Williams, 2000). Although replication is not of primary interest here, it is a factor to consider when deciding upon an appropriate sample given the replication of the known, positive direct effects of Superficial and Structural Similarities on Opportunity Beliefs. Grégoire \& Shepherd (2012) utilized a narrow sample of 98 entrepreneurs from the domains of life science, medical and biological technologies, as well as a broader sample of 51 entrepreneurs operating in a more diverse set of industries. These scholars demonstrated that high Structural and Superficial Similarities lead to positive beliefs in both a narrow sample and a broad sample of entrepreneurs. As such, my sample of managers and engineers is appropriate to test my hypotheses and will provide sufficient power.

The sampling frame is focused on individuals that are likely to expend some cognitive energy directed at ascertaining and evaluating information related to new sources of supply and changes in demand. As mentioned, previous scholars have already 
moved from more homogenous to more heterogeneous samples, testing the direct effects of two opportunity differences using a homogenous sample from three related industries and, then, a more generalizable sample from many industries (Grégoire \& Shepherd, 2012). Furthermore, considering the fact that the individuals who actually licensed the technologies used in this dissertation into the 'true' new markets were not previously entrepreneurs (e.g., an electrical engineer, a scientist, a chief executive officer); in short, a sample containing only entrepreneurs is not necessary. Indeed, the actual individuals who licensed the focal technologies were employed professionals whose jobs involved thinking about problems that markets face and potential solutions to such problems. Consistently, I focus my sampling efforts on individuals whose professions likely direct some of their cognitive energy in similar ways. Therefore, the main criterion for inclusion in the sampling frame is that an individual be either an upper level manager or an engineer.

I utilized Qualtrics' services for data collection. Qualtrics sent the instrument, with several screener questions, to individuals that they believed were either upper level managers or engineers. Because there is actually no way to know with certainty that a potential candidate is either an upper level manager or an engineer ex ante, one of the screener questions asked respondents to choose a profession that most closely matches their own from a provided list. The list included upper level manager and engineer as well as many other common professions, such as: fire fighter, policeman, teacher and middle manager. The screener also included an 'other' profession to account for the impossibility of anticipating every possible profession. Furthermore, I later asked 
respondents for their exact job title in an open-ended question to ensure that they were, indeed, either upper level managers or engineers.

A power analysis, using the $\mathrm{G}^{*}$ Power 3.1.9 analysis tool, indicated that I needed approximately 396 evaluations (99 individuals with 4 evaluations each). A sample size of 99 individuals is consistent with Grégoire \& Shepherd's (2012) initial sample of 98 entrepreneurs who provided 4 evaluations each. I targeted a final sample size of 150 individuals with 4 evaluations per individual, realizing that I would lose some to screener questions and failed attention checks. Because Qualtrics could not perfectly identify if targeted participants were, indeed, upper level managers/engineers or not, they sent the initial screener questions to 4,475 individuals. Because I compensated participants and was limited to a specific dollar amount, Qualtrics closed the survey once enough participants had successfully passed the screener questions so that I ran out of funds. Within one week, 257 (5.7\%) individuals filled out the initial screener questions. Of those, 82 were not allowed to participate because they did not select either upper level manager or engineer from the list of professions. 10 more were not allowed to participate because the open-ended job title question revealed that they were not actually an upper level manager or engineer. Twenty other respondents failed one of the other screeners, such as: age, response speed was too fast or failed a question aimed at determining if respondents were paying attention (e.g., please select the $3^{\text {rd }}$ circle from the left) and were not allowed to complete the survey, resulting in a preliminary sample size of 145 individuals (580 evaluations). 
Table 2: Sample Description

Sample size (level-1) evaluations: $n=464$

Sample size (level-2) individuals: $n=116$

\begin{tabular}{llc} 
Variable & & Mean / $/$ \\
\hline Age & & 44.5 \\
Gender & Female & 39.7 \\
& Male & 60.3 \\
& No college & 10.3 \\
& Some college & 20.7 \\
& 2-year degree & 13.8 \\
& 4-year degree & 35.3 \\
& Master's degree & 16.4 \\
Race & Doctoral/professional degree & 3.6 \\
& Hispanic & 4.3 \\
& African American & 3.4 \\
& Asian & 5.2 \\
& Native American & 0.9 \\
Job Title & Other Non-Caucasian & 0.9 \\
& Caucasian & 85.3 \\
& Upper-level Manager & 65.5 \\
& Engineer / Technology Developer & 34.5 \\
\hline
\end{tabular}

Although 145 individuals passed the screener questions and completed the survey instrument, the final analysis only includes 116 individuals (464 evaluations) because $29^{1}$ individuals did not pass the attention check placed after the fourth scenario. A post-test analysis shows significant correlations between the attention checks and levels of the independent variables are reported for the 116 individuals that did pass the attention checks in table 5 below. A sample size of 116 individuals (464 evaluations) exceeds the amount needed as indicated by my power analysis.

\footnotetext{
${ }^{1}$ Results are provided for the entire sample (including the 29 individuals who failed the attention check) in appendix 3 . The results for both samples are very similar. All of the path signs are in the same direction for the sample that includes the 29 individuals as they are for the sample that excludes the 29 individuals. The moderation effect of Local Precedence on Procedural Similarity, which was significant for the sample that excludes the 29 individuals, is only marginally significant $(\mathrm{p}=0.07)$ when the 29 are included. Also, including the extra 29 individuals changes the 3 -way interaction of Prior Knowledge of Technology $x$ Procedural $\times$ Structural from non-significant to just significant with a p-value just below 0.05 .
} 
Table 3: Industries Represented

\begin{tabular}{lc}
\hline \multicolumn{1}{c}{ Industry } & Percent of Sample \\
\hline Accounting & 0.9 \\
Advertising & 0.9 \\
Aerospace & 0.9 \\
Biotech & 0.9 \\
Business services & 5.2 \\
Computer (hardware/software) & 14.7 \\
Construction & 4.3 \\
Consulting (non-engineering) & 3.4 \\
Education & 2.6 \\
Engineering consulting & 9.5 \\
Entertainment/recreation & 2.6 \\
Finance/banking/insurance & 3.4 \\
Food service & 5.2 \\
Government/military & 5.2 \\
Healthcare/medical & 1.7 \\
Internet & 1.7 \\
Legal & 0.9 \\
Manufacturing & 7.8 \\
Media/printing/publishing & 0.9 \\
Non-profit & 5.2 \\
Pharmaceutical/chemical & 0.9 \\
Professional services & 3.4 \\
Real estate & 0.9 \\
Research/science & 6.0 \\
Sanitation & 0.9 \\
Telecommunications & 0.9 \\
Transportation/distribution & 0.9 \\
Utilities & 1.7 \\
Wholesale & 6.9 \\
\hline &
\end{tabular}




\section{Experiment Design}

As mentioned, policy-capturing experimental designs utilize various levels of attributes that are theorized as relevant to a particular decision, opinion or belief formation to allow researchers to decompose decisions or belief policies. This allows researchers to better understand which, and to what degree, attributes influence a decision, opinion or belief formation of interest (Louviere, 1994). Following Grégoire \& Shepherd (2012), I conceptualize the various types of relevant similarity at two levels, low and high. I use a 2 (Procedural $) \times 2($ Structural $) \times 2($ Superficial $)$ design with the first between, and that last 2 within, subjects factors. I provide examples in the subsection, "Similarity Types" below as well as full descriptions of the scenarios in appendix 2.

I list the variables in subsections below in the same order that they are collected in during the experiment. Chronologically, participants read through a scenario and respond to the dependent variable items for that scenario, respond to questions regarding their Prior Knowledge of that scenario's technology and market, and do the same for three more scenarios. After providing all of their dependent construct related responses, respondents are shown the final scenario again and they respond to items designed to assess whether or not they are paying attention and giving meaningful cognitive effort. Specifically, respondents look over the final scenario and answers questions similar to those used in the pre-test to demonstrate that they are putting forth meaningful cognitive effort as explained in the Attention Check section below. Next, participants complete the Navon (1977) task thereby indicating their Global versus Local Precedence and respond to the scaled Global versus Local Precedence question provided by Solomon et al. (2004). Finally, participants answer items that pertain to the control variables that are 
listed below. I detail each measure in the paragraphs directly below.

In order to uphold the external validity of this research, I modeled the scenarios after actual, documented cases of technology transfer. Specifically, each subject read four market descriptions that represent actual, recent attempts by individuals to exploit technologies into new markets through license agreements. All subjects read the exact same market descriptions. That is, every person who participated in the experiment, regardless of whether they were randomly assigned to the low or high Procedural Similarity group, read the exact same description of the market idea to evaluate.

Each market description is accompanied by a description of the underlying technology that the entrepreneur is attempting to license and exploit in the market described. Similar to the market descriptions, the technology descriptions are based on actual, documented technologies underlying the technology commercialization licenses. However, unlike the market descriptions, the technology descriptions were altered in order to capture varying levels of Superficial, Structural and Procedural Similarities as described in the subsection below, "Similarity Types". Every person who participated in the experiment read a technology-market combination for each quadrant consistent with a $2 \times 2$ within subjects design for Superficial and Structural Similarity. However, subjects in the low Procedural Similarity group only saw technology-market descriptions that represent low Procedural Similarity, and subjects in the high Procedural Similarity group only saw technology-market descriptions that represent high Procedural Similarity (between subjects, with randomization). The method involves a Latin-square design with 4 different versions for each within-group similarity manipulation, each with 2 different orders of markets to allow for testing of potential order effects. 
The reason that technology descriptions are altered to capture the levels of the types of similarity rather than the market descriptions is to ensure that each participant is evaluating the same market idea. Researchers note that when nascent entrepreneurs, or would-be entrepreneurs, learn about a new technology, they begin to think about whether or not applying a focal technology to a particular market might actually be an entrepreneurial opportunity (Grégoire \& Shepherd, 2012; Shane \& Venkataraman, 2000). The process of individuals thinking about their degree of certainty regarding whether or not an initial idea is actually an opportunity or not is the phenomenon that I am interested in. It follows that research that is interested in examining factors that determine individuals' degrees of certainty that an opportunity idea is actually an opportunity should follow the same manipulation pattern that Grégoire \& Shepherd (2012) demonstrated. Specifically, these scholars held market descriptions constant across subjects and only altered technology descriptions to capture the various levels of the theorized independent variables; I follow this same design.

\section{Beliefs about Opportunities (Level - 1 Dependent Variables)}

Recognizing that which Opportunity Beliefs are relevant depends on which stage of the entrepreneurial process one is focusing on (Grégoire et al., 2010; Shepherd et al., 2007), I use dependent variables that are consistent with the early evaluation question of entrepreneurship: is that an opportunity for me? Specifically, to capture the dependent construct, Opportunity Beliefs, I ask respondents about their degrees of certainty that a supply source (1) fits with and (2) can be feasibly implemented to a market. Researchers have previously demonstrated that these dimensions of Opportunity Beliefs are consistent with early phases of entrepreneurship (Grégoire et al., 2010). I use this dependent 
variable because I am interested in entrepreneurs' general beliefs (or degree of certainty) about whether an initial market idea actually is an opportunity for someone. Grégoire et al. (2010) developed and validated this measure to be consistent with the entrepreneurial process according to the IO perspective. Specifically, relevant early phase Opportunity Beliefs are primarily articulated in two dimensions: the fit between a new means of supply and a potential target market, and the feasibility of introducing that new means of supply in the target market (Grégoire \& Shepherd, 2012).

The measure of early Opportunity Beliefs that I use captures each of the two dimensions, fit and feasibility, with multiple items. First, fit is measured with three items that collectively capture the degree to which individuals feel certain that: (1) The technology can be used to solve the problems of the market described; (2) The technology has the capabilities to answer the needs of the market described; and (3) There is a 'match' between what the technology does, and what the market described demands.

Second, feasibility is captured with two items that collectively capture whether or not individuals believe that: (1) Applying the technology with individuals / firms in the market described does constitute a feasible opportunity, and (2) The technology is sufficiently developed to be applied profitably with individuals / firms in the market described. These items were also used by Grégoire and Shepherd (2012), and are assessed with a 9-point likert type scale after subjects are instructed to "please select the number that most closely corresponds to your evaluation of the following statements" directly after reading a market and corresponding technology description. I vary the order that these dependent variable items are asked within each subject so that I can test for order effects. 


\section{Similarity Types (Level - 1 Independent Variables)}

Each subject views four actual technology-market descriptions and responds to the questions that capture the dependent variables for each technology-market pair. In other words, at the same time that a subject sees a market description they see one technology description. However, each subject does not see the same technology description. Rather, as explained above, technology descriptions are altered to reflect different levels of the three focal types of similarity. In this section, I explain these alterations to demonstrate how each type of similarity is included in the experimental design at both low and high levels.

While developing the scenarios, I consulted with several academics and entrepreneurs regarding which technology-market combinations to include. In all, over 20 possible technology-market combinations were considered; however, discussions with academics and entrepreneurs narrowed the list down to the four chosen. After choosing the four technology-market pairings, I developed multiple descriptions of the technologies to capture both high and low levels of the three similarity types. In order to validate that the scenarios capture high and low levels, three academics within the area of entrepreneurship and three practicing entrepreneurs who are not involved in this project independently read through and commented on all of the technology and market descriptions - both high and low for each type. After incorporating their comments into the scenarios, a computer information system academic and I read through all of the scenarios again to check for clarity and face validity.

Next, a pretest was utilized with three entrepreneurship academics and seven entrepreneurs to test whether the multiple technology descriptions actually captured high 
and low levels of Superficial, Structural and Procedural Similarities. The ten participants each read through four technology-market pairings, resulting in a sample size of 40 evaluations. Pretest participants were randomly assigned in the same manner as participants in the actual experiment to see one possible combination of similarity levels for each technology. Similar to Grégoire and Shepherd's (2012) pretest, the entrepreneurs and academics were asked to read an opportunity scenario (containing both a technology description and a market description) and, then: (1) list the aspect(s) in which the market was different from the technology (indicates a low level of similarity) and (2) list the aspect(s) in which the market was similar to the technology (indicates a high level of similarity).

The results of the pretest are shown in table 4 and confirmed the internal validity of the various technology descriptions. On average, the academic experts and entrepreneurs that participated in the pretest listed: more Superficial dissimilarities when Superficial Similarity was supposed to be low than when it was high (1.55 vs. $0.35, p \leq$ $.001)$; more Superficial Similarities when Superficial Similarity was supposed to be high than when it was low ( 1.35 vs. $0.35, p \leq .001)$; more Structural dissimilarities when Structural Similarity was supposed to be low than when it was high (1.25 vs. $0.00, p \leq$ .001); more Structural Similarities when Structural Similarity was supposed to be high than when it was low (1.25 vs. $0.25, p \leq .001)$; more Procedural dissimilarities when Procedural Similarity was supposed to be low than when it was high $(0.75$ vs. $0.00, p \leq$ .001); and more Procedural Similarities when Procedural Similarity was supposed to be high than when it was low (0.96 vs. $0.13, p \leq .001)$. Although this pretest demonstrates that the various technology descriptions capture higher and lower levels of each similarity 
type, it is important to note that substantive differences between the opportunities are unknown.

Superficial Similarity. Opportunity differences that capture the degree of similarity between things such as (i) a technology's: developer(s); context; parts; inputs; people; materials and physical output, and (ii) a market's: people; users; materials and tools are encompassed in Superficial Similarity (Grégoire and Shepherd, 2012). Each technology-market combination has an inherent level (either high or low) of Superficial Similarity. For example, one of the scenarios used in this experiment was developed at a university in conjunction with retired Air Force pilots to be used by the U.S. military to train new combat pilots. The new 'true' market for this technology is educators using the technology to train students of visual and experimental science domains, such as physics. This represents a low degree of Superficial Similarity because the people and context for the technology development (retired pilots, new combat pilots, etc.) is not similar to the new market's people and context (educators, young students, experimental science, etc.). Because the 'true' technology-market combination represents low Superficial Similarity, I created multiple descriptions of the technology (keeping the market description the exact same) to represent high Superficial Similarity. To do so, I portrayed the technology as developed by Stanford University's Departments of Adolescent Psychiatry and Artificial Intelligence Engineers to be used by young children that are learning a second language. Adolescent psychiatrists, young children and learning a second language together represent a high degree of Superficial Similarity to the new market of educators, young students and experimental science. I provide the entire set of scenarios with 
headings to show which versions represent high or low Superficial Similarity in appendix 2 below.

Structural Similarity. Opportunity differences that capture the degree of similarity between higher order relationships such as (i) a technology's: capabilities; purpose and functional, scientific and logical mechanisms, and (ii) a market's: reasons for dissatisfaction with existing solutions; source of latent demand and causes or mechanisms underlying why the market wants what it wants are encompassed in Structural Similarity (Grégoire and Shepherd, 2012). Each technology-market combination has an inherent level of Structural Similarity (high or low). For example, one of the technologies was actually developed for the purpose of making military air-combat training more realistic (the 'true' purpose and capability of the technology); however, the 'true' new market wants to license the technology because it is unsatisfied with existing methods of identifying students' learning styles. Because the 'true' new market's need (identifying students' learning styles) is not similar in regards to higher order relationships of underlying latent demand to the 'true' technology's original purpose/capability (making military air-combat training more realistic), the true level of Structural Similarity for this technology-market combination is low. Although I show all subjects the true new market application of this technology, I alter the technology so that some see a technology description that represents low Structural Similarity and others see one that represents high. To capture high Structural Similarity for this particular scenario, I portray the technology as originally developed to help understand individuals' learning styles. The survey includes 4 different technology-market pairs to ensure that every subject will see 
both high and low levels of Structural Similarity and both high and low levels of Superficial Similarity in a $2 \times 2$ format.

Procedural Similarity. Opportunity differences that capture the degree of similarity between (i) how a technology was originally executed or implemented to users (i.e., how users interacted with the technology in order to benefit from its capabilities), and (ii) how a new market will interact with a technology (how the technology will be implemented to users in the new market) in order to benefit from its capabilities are encompassed in Procedural Similarity (cf., Chen, 2002). Similar to the Superficial and Structural Similarities, each technology-market combination has an inherent level of Procedural Similarity. Keeping with the technology-market combination described in the Superficial and Structural Similarity descriptions above, the 'true' procedure or implementational details of the technology involve users participating in a simulated contest of some kind against an artificial intelligent agent which uses this type of interaction to learn about users. In the new market, however, the artificial agent does not participate in the contest; rather, the agent merely observes users' actions to learn about them.

In short, this aspect of the design captures differences between a technology and market that are not captured by Superficial or Structural Similarities. Even when Superficial features between a technology and market are highly similar (e.g., adolescent psychiatrists and students or trainees $\approx$ educators and science students), and Structural relationships between a technology and a market are highly similar (e.g., identifying learning styles of pilot trainees $\approx$ identifying learning styles of science students), Procedural details about how a technology is implemented to users can still be different 
(e.g., a technology's agent participates in a contest against a student $\approx$ a technology's agent merely observes a student participate in a contest against someone/something else). This version of the technology description captures this third type of difference. Half of the subjects are randomly assigned to low Procedural Similarity and half will see technologies that are high in Procedural Similarity.

Attention Check. Solving problems via analogy is an attentive process that requires meaningful cognitive effort (Chen, 2002). In addition to pre-testing the scenarios to check for internal validity of high and low levels of each similarity type, I ask subjects an attention question for each type of similarity. I ask these questions directly after they respond to the dependent variable questions for the final scenario that they see (after dependent variable items are locked in). The attention questions are designed to decipher how attentive a participant is being. The attention check questions provide an opportunity for participants to demonstrate how much cognitive effort they are putting forth while completing the survey. These questions are based on a 9-point Likert scale anchored by very different and very similar. The attention check questions are:

1. Please indicate the extent to which you feel the above market description is very different or very similar to the technology description in regards to: people, places, things, objects and materials.

2. Please indicate the extent to which you feel the above market description is very different or very similar to the technology description in regards to: the technology's purpose compared to the market's need. 
3. Please indicate the extent to which you feel the above market description is very different or very similar to the technology description in regards to: how users in the market will use the technology versus how it was originally used.

Table 4: Manipulation Internal Validity Pre-test

\begin{tabular}{lll}
\hline Similarity Type & High vs. Low Mean Similarities & High vs. Low Mean Differences \\
\hline Superficial & 1.35 vs. $0.35^{* * *}$ & 0.35 vs. $1.55^{* * *}$ \\
Structural & 1.25 vs. $0.25 * * *$ & 0.00 vs. $1.25 * * *$ \\
Procedural & 0.96 vs. $0.13 * * *$ & 0.00 vs. $0.75 * * *$ \\
\hline
\end{tabular}
${ }^{*} \mathrm{p}<0.05,{ }^{*} \mathrm{p}<0.01,{ }^{* * *} \mathrm{p}<0.001$

\section{Prior Knowledge and Global versus Local Precedence (Level - 2 Moderator Variables)}

Prior Knowledge. To capture the degree to which individuals possess Prior Knowledge about a focal technology or focal market, I utilize four items; two of the items capture their level of Prior Knowledge of Technology and two capture their level of Prior Knowledge of Market. The questions are the same questions that Grégoire and Shepherd (2012) utilize to capture individuals' levels of Prior Knowledge of Technologies and Markets. Subjects are asked to 'please select the number that most closely corresponds to your level of Prior Knowledge for each of the following: (1) the technology, (2) the scientific and engineering principles underpinning the technology, (3) the market of interest and (4) the problems affecting this market and current solutions. Each of these four items is measured using a 7-point likert type scale, anchored by 'minimal' and 
'considerable'. I utilize the average of the two technology (market) items to represent Prior Knowledge of a Technology (Market).

Global versus Local Precedence. The other individual level moderator, Global versus Local Precedence, is measured using two different methods. First, I measure Global vs. Local Precedence using an adapted Navon (1977) task provided to me be Michael R. Basso, from the Department of Psychology at the University of Tulsa (Basso \& Lowery, 2004). The task consists of a series of images, displayed in sets of 3. Each set of images consists of a top image (the base) and two target images below—one on the left and one on the right. Prior to viewing the initial set of images, each subject is told the following:

"You will be shown 3 images for a brief moment, using the top image as the standard, please select one of the bottom 2 images (LEFT or RIGHT) which you feel most closely matches the top (standard) image."

After reading the instructions, each subject is shown a series of sets of images. Consistent with extant use of Navon (1977) tasks, subjects only see a set of images for a very brief moment before they are asked to provide their response. An example of a set of images is provided in appendix 1 . Note that there is not an objectively correct answer regarding which target image matches the standard image more closely. Rather, one of the images for each set matches the standard locally and one matches the standard globally. As discussed in chapter 2, individuals can process information both globally and locally; however, individuals tend toward one or the other. Rating 16 sets of images will provide a measure of the extent to which an individual exhibits a Global or a Local Precedence. The sets of images vary in their number and size of Local components. 
The second method that I used to measure Global versus Local Precedence is Solomon et al.'s (2004) scaled measure. Navon (1977) tasks are primarily used to measure individuals' tendencies to process visual and/or spatial information either globally or locally. More recently, however, scholars are conducting research interested in whether individuals tend to process action-oriented information either globally or visually — as is the case here. Solomon et al. (2004) provide a scaled measure to capture Global versus Local Precedence in contexts where relevant information is not visual or spatial in nature. Because the present context is not visual or spatial, I utilize Solomon's measure for Global versus Local Precedence for my analysis. I am still measuring Global versus Local Precedence via a Navon (1977) task because Solomon et al.'s (2004) measure is not as well established in the extant literature.

\section{Controls}

All control variables discussed below are level-2, individual-level, variables. I do not use level-1, opportunity-level control variables because each subject rates the same four market ideas and the variance between the technology descriptions that subjects read are part of the theorized model and are described in the similarity differences section above.

Any control variables where zero does not have any meaning are entered into statistical software as grand-mean centered. Exceptions to grand-mean centered controls, then, are: dummy variables, the number of firms started and the number of firms still in existence. I treat these variables as uncentered because for these variables, zero is a meaningful response. 
Individual Differences in education, background and experience. Admittedly, there are many drivers of individuals' beliefs and perceptions about entrepreneurial activities. For example, numerous studies demonstrate that human capital significantly impacts individuals' likelihood of engaging in entrepreneurial activities (e.g., Davidsson \& Honig, 2003; Gimeno, Folta, Cooper, \& Woo, 1997; Ucbasaran, Westhead, \& Wright, 2008). Consequently, I measure and control for individual differences in education, entrepreneurial experience, entrepreneurial success, entrepreneurial intention, employment status, length of employment and industry.

Specifically, subjects are asked to select: one of eight education levels that represents their highest level of education (ranging from less than high school to professional degree); their number of firms started (and subsequently if still in existence) ranging from 1 to more than 10 ; the degree of their intention to start a new firm within the next five years measured on a 9-point Likert scale anchored by I certainly will not and I certainly will; their employment status and length of employment measured in years.

Creative/innovative self-efficacy. Making connections via analogical problem solving is, to some extent, a creative process (Gick \& Holyoak, 1980; Hargadon \& Bechky, 2006). Given the link between creativity and analogical processing, it is natural to control for the degree to which individuals feel they are skilled at thinking in creative or novel ways. Indeed in their study on analogical problem solving in entrepreneurial contexts, Grégoire and Shepherd (2012) reasoned that innovation and creativity are more directly applicable to opportunity recognition than other domains such as marketing, and therefore, validated a creative/innovative self-efficacy construct. This construct utilizes some items from Chen, Greene and Crick's (1998) innovation construct and some items 
from Tierney and Farmer's (2002) creative self-efficacy construct. I control for individual variance in efficacy in creativity and innovation using this same construct. The items used are measured on a 7-point Likert type scale and are anchored by completely disagree and completely agree.

\section{Data Analysis Method}

Each individual that participates in this experiment is included in the data set four times, once for each technology-market combination that they provide Opportunity Beliefs for. In other words, the nature of the data that this experiment produces is nested. Indeed, I am interested in how the nexus of individuals and opportunities influences Opportunity Beliefs. As such, I use a statistical software called Hierarchical Linear Modeling 7 (hereafter, HLM) (Raudenbush, Bryk, Cheong, Congdon, \& du Toit, 2001) to examine the degree to which opportunity-recognition beliefs vary within and between individuals, capturing the extent to which variation is moderated by individual-level constructs. HLM is used in a wide variety of social sciences because it offers the following benefits over single level statistical packages: better accuracy regarding type I error rates; proportioned variance across each of the different levels included in a model instead of assuming, potentially incorrectly, that variance is attributable to one level; assessment of both within and between variance and direct predictors at multiple levels (McCoach, 2010).

Prior to running HLM models, I checked the data for common method bias. The extant literature suggests that common method biases are common problems in behavioral research, especially in psychology research (Podsakoff, MacKenzie, Lee, \& Podsakoff, 2003). In order to identify whether or not a remedy is needed for this 
dissertation's data, I ran Podsakoff et al.'s (2003) common method variance test by forcing an exploratory factor analysis containing all of the variables in the model into one component loading. If there is not any common method bias then the extraction sums of the squared loadings should explain less than $50.00 \%$ of the cumulative variance for the forced component. For the data herein, the cumulative percent of variance explained is only $25.81 \%$; therefore, it appears that common method variance is not a problem for this data.

I run models sequentially according to the guidelines provided by McCoach (2006, 2010). First, I run an unconditional model so that I can assess the inter-correlation coefficient to examine the extent to which HLM is even necessary. That is, the unconditional model allows me to test whether regression's independence of responses assumption is violated. Next, I run a random coefficients model to show the extent to which the known similarity types account for unexplained variance in Opportunity Beliefs. I follow the guidelines provided by McCoach (2010) to start with a null model, followed by a random coefficients model, control model, trimmed control model and final hypothesized model. Consistent with McCoach's (2010) guidelines, I utilize a sequential model building process used by McCoach, O'Connell and Levitt (2006, p. 342), which involves removing "variables that did not contribute to the variation in [the dependent variable] at either level of analysis" as I proceed from the control model to trimmed control model. To maintain a conservative test of controls, I only remove controls that were not significant using either the normal or robust standard errors at or below 0.10; this is more conservative than McCoach, O'Connell and Levitt's (2006) guidelines and example of removing any non-significant $(\mathrm{p}>0.05$ using standard errors 
only) effects from the model. After finalizing the trimmed control model, I add in the theorized individual-level moderators to examine both the extent to which they change the direct relationships between opportunity differences and Opportunity Beliefs to provide the coefficients $\left(\gamma_{\mathrm{s}}\right.$ and $\left.u_{\mathrm{s}}\right)$ listed in chapter 4 .

\section{Chapter Summary}

In this chapter, I outline the experimental design, variables used to capture the constructs relevant to the dissertations theoretical model, control variables and the data analysis method used to test the hypotheses. I provide tables that are relevant to this chapter in the appendix. Specifically, appendix 1 lists the measured dependent, independent, moderating and primary control variables along with their citations. In table appendix 1, I also provide details about each measured variable's level, scaling and anchoring. I provide the actual language used for each version of each technology-market combination in appendix 2 (Grégoire, Shepherd, \& Lambert, Measuring OpportunityRecognition Beliefs: Illustrating and Validating an Experimental Approach, 2010).

In sum, this dissertation replicates Grégoire and Shepherd's (2012) $2 \times 2$ within subject experiment design, but does so while including a between subjects grouping of Procedural Similarity resulting in a $2 \times 2 \times 2$ factorial design. The nature of the data is beliefs about opportunities nested within individuals, therefore, requiring data analysis techniques capable of examining multi-level data and assessing both within and between relationships, which is why I use HLM. 
Table 5: Means, Standard Deviations and Correlations

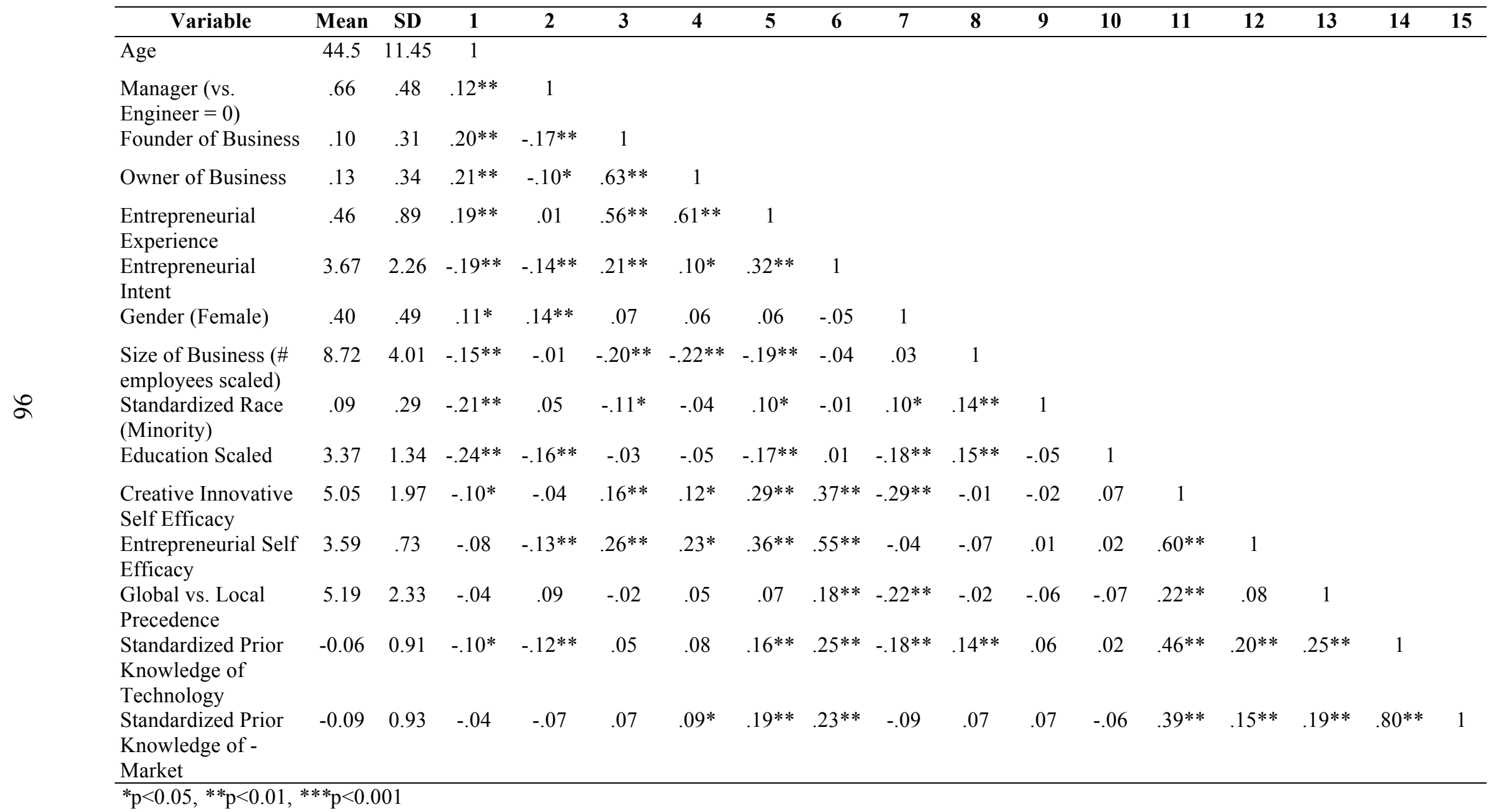




\section{CHAPTER 4 - ANALYSIS AND RESULTS}

\section{Chapter Overview}

In Chapter 4, I outline the results of the empirical models that I ran according McCoach's $(2006,2010)$ steps as listed in chapter 3. I also provide a more succinct report of the results in tables thoughout the chapter. Specifically, I proceed by, first, reporting the degree to which variability in the dependent construct, Opportunity Beliefs, is explained by both opportunity-level and individual-level predictors, along with the random effects and standard deviations for the within person variability $\left(\sigma^{2}\right)$ and opportunity-beliefs intercept $\left(\tau^{00}\right)$. Second, I report the coefficients $\left(\gamma_{\mathrm{s}}\right)$ for the direct effects of the independent variables in the first half of the results sub-section below. Third, I report the slope-coefficients $\left(u_{\mathrm{s}}\right)$ for the hypothesized moderators in the second half of the results subsection below. Finally, I conclude the chapter by briefly summarizing the results.

The results below support the first major point of the dissertation, that Procedural Similarity has unique effects on Opportunity Beliefs. That is, the empirical results support my previously stated arguments that Procedural Similarity is distinct from Superficial Similarity and that Procedural Similarity positively impacts Opportunity Beliefs.

The results below, however, only show partial support for the theorized interaction effects. Specifically, none of the interaction effects between similarity types 
are supported, and only some of the interaction effects between similarity types and individual-level moderators are significant. The most interesting interaction effect that is supported is the moderating effect of Global versus Local Precedence on the relationship between Procedural Similarity and Opportunity Beliefs. The results below provide evidence that individuals who exhibit a Local Precedence tend to rely more on Procedural details when forming Opportunity Beliefs than individuals who exhibit a Global Precedence.

In short, I am able to provide some answers through significant effects related to research questions 1 and 3, but not to research question 2. Research question 2 asked about possible interaction effects between Procedural Similarity and the other two types of similarity; however, none of those interaction paths were significant. I will, however, offer possible reasons for why the hypotheses associated with research question 2 are be non-significant in the Chapter 5 thereby providing some insights to research question 2 . I will discuss the implications of the results for paths related to research questions 1 and 3 in Chapter 5. I will also offer some thoughts regarding why none of the paths related to research question 2 were significant. Generally, the results reported below allow me to make some contributions to the literatures on the IO perspective, Structural Alignment Theory and Global versus Local Precedence. I am able to explain approximately $14.5 \%$ of the variance in Opportunity Beliefs for this sample using the formula: (Null Model 
Intercept Variance Component $u_{0}$ - Final Model Intercept Variance Component $u_{0}$ ) / Null Model Intercept Variance Component $u_{0}$ or $(0.23630-0.20214) / 0.23630$.

\section{HLM and the Inter-class Correlation}

The inter-class correlation provides an empirical test of an often over-looked assumption that other statistical methods, such as Ordinary Least-Squares regression, rely on. Specifically, regression-based statistical methods assume survey responses are completely independent of an individual/context. This assumption is often referred to as independence of responses. It is possible to empirically test if this assumption is violated. A metric that indicates if the assumption is violated, and if so to what extent, is referred to as the inter-class correlation. The inter-class correlation can be assessed with HLM software. I used HLM to calculate an inter-class correlation for this dissertation's data.

HLM separates the percent of variability in the outcome variable to show how much of the outcome's variability is explained by some factor(s) related to an individual or context (McCoach, 2010). Demonstrating that part of the variance in Opportunity Beliefs is a result of level-1 predictors and part is a result from level-2 predictors helps corroborate my theoretical justification for this dissertation; namely, that opportunity differences matter. Specifically, the unconditional model reported in table 6 confirms the need for a multilevel inspection of the dependent construct, Opportunity Beliefs. That is, the unconditional model demonstrates that regression's independence of responses assumption is violated. Indeed, $29.6 \%$ of the variability in Opportunity Beliefs is explained by factors specific to the individual, and the remaining $70.4 \%$ of the variability in Opportunity Beliefs is explained by some other factor. This does not necessarily mean that the variables that I control for and hypothesize as predictors can explain the 
variability in Opportunity Beliefs; rather, it demonstrates the need for multi-level inspection of Opportunity Beliefs by considering both individual and opportunity-level factors as I do in this dissertation.

In short, the inter-class correlation for this data confirms that the independence of responses assumption is violated, thereby confirming the central premise undermining this research; namely, that opportunity differences, not just individual differences, matter to opportunity discovery. Furthermore, the inter-class correlation demonstrates the importance of the first chronological evaluation question, "is that an opportunity for me", demonstrating it deserves scholarly attention.

After verifying that the responses were not independent of the individuals, I proceeded to follow McCoach (2010, p. 252) steps for "dealing with dependence". McCoach (2010) explains that traditional regression-based methods assume that the relationship between two variables is constant across an entire sample. However, it is possible that relationships between variables may vary due to a common factor, such as a common individual or context (McCoach, 2010). McCoach (2010) provides a step-bystep process for running multi-level models in which data is nested or otherwise clustered. She and other scholars have demonstrated (with deviance criterion) that this step-by-step approach is superior to other multi-level modeling techniques (e.g., McCoach, Madura, Rambo-Hernandez, O'Connell, \& Welsh, 2013; McCoach \& Adelson, 2010; Ware \& Kitsantas, 2011). In the paragraphs that follow, I detail how I implemented each of McCoach's $(2006,2010)$ multi-level modeling steps which I also described in Chapter 3.

First, I ran a model with only the three similarity types and all of the controls 
included as predictors of Opportunity Beliefs. Then, I trimmed controls that had p-values greater than 0.10 (controls were only trimmed if the p-value was greater in both the standard model and the model using robust standard errors). That is, I followed the steps outlined by McCoach (2010); however, I used a more conservative p-value of 0.10. I also used a more conservative test by considering p-values calculated using both standard and robust standard errors. Next, I added in the predicted moderators and interaction effects and re-ran the model to test the hypotheses. I detail the results of the control model in table 7. I report the results in the tables for fit and feasibility combined (Opportunity Beliefs), fit individually and feasibility individually separately in tables 8 (Opportunity Beliefs), 9 (fit) and 10 (feasibility). In the results section below, I indicate whether an effect significantly predicted fit only, feasibility only or the combination of fit and feasibility (Opportunity Beliefs).

Table 6: Random Effects, Standard Deviations and Inter-correlation Coefficient

\begin{tabular}{ll}
\hline & \multicolumn{1}{c}{ Unconditional Model } \\
\hline & Variance $(S D)$ \\
Within Person, $\sigma^{2}$ & $0.56(0.75)$ \\
Opportunity Beliefs Intercept, $\tau_{00}$ & $0.24(0.49) * * *$ \\
Inter-correlation Coefficient & 0.296 \\
\hline${ }^{*} \mathrm{p}<0.05, * * \mathrm{p}<0.01, * * * \mathrm{p}<0.001$ &
\end{tabular}


Table 7: Control Model

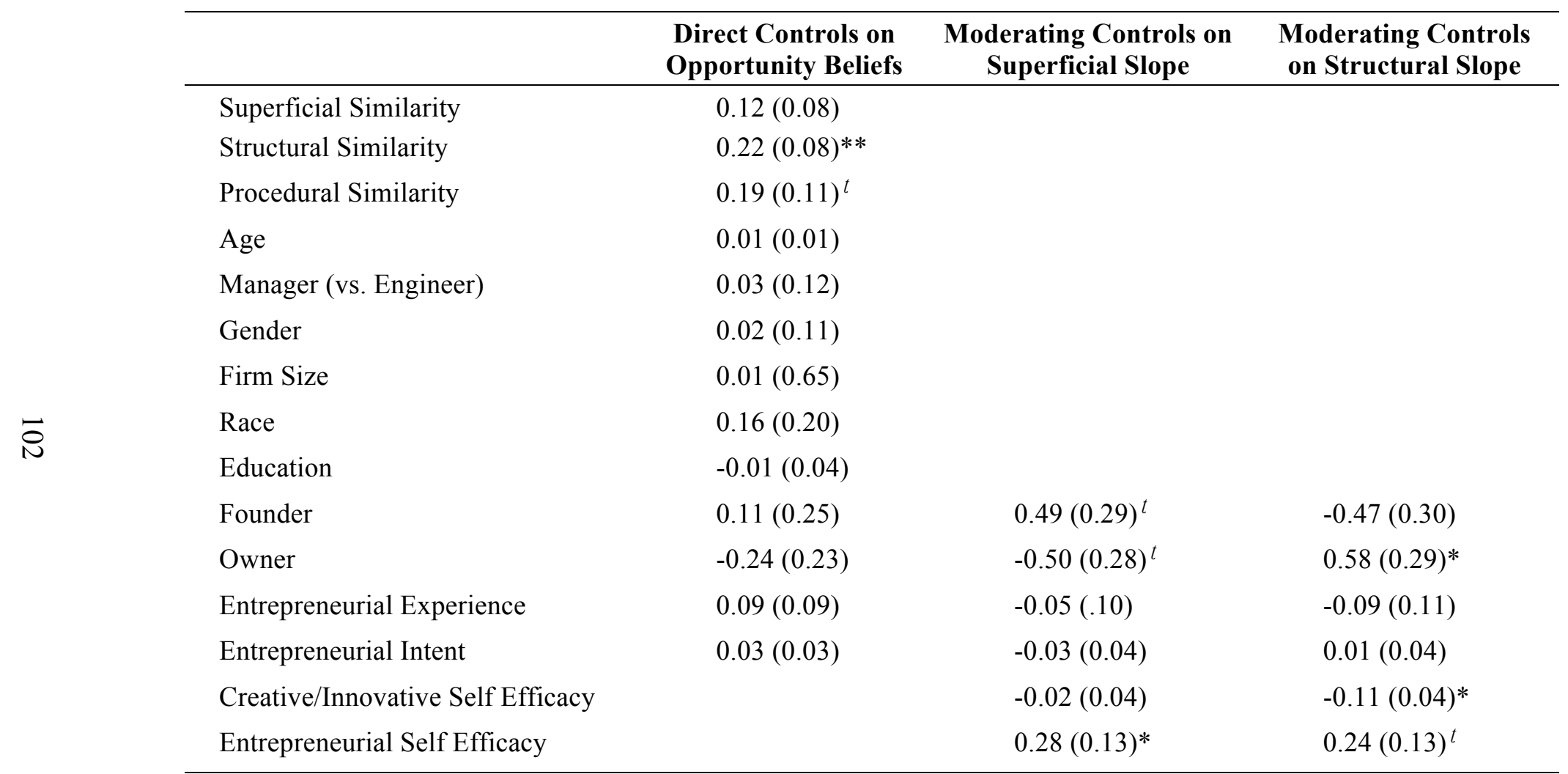

${ }^{t} p<.10,{ }^{*} \mathrm{p}<0.05,{ }^{*}{ }^{*} \mathrm{p}<0.01,{ }^{* * *} \mathrm{p}<0.001$ 


\section{Results}

Opportunity Differences. Generally, the central idea of this dissertation, that Procedural Similarity is distinct from Superficial Similarity and plays a role in determining the extent to which individuals will form positive beliefs about the fit and feasibility of potential supply-demand pairings, is supported. Previous research has already theorized and empirically demonstrated that Superficial Similarity plays a role in the formation of beliefs about potential opportunities (Grégoire \& Shepherd, 2012).

Prior to testing individual hypotheses related to these three similarity types, it was important to assess whether these three types of similarity were distinct in the context of technology commercialization. As discussed in Chapter 3, a pre-test of the internal validity of the scenarios used demonstrated that each similarity type was distinct and both low and high levels were represented. Specifically, a sample of entrepreneurs and academics listed significantly more superficial similarities when a scenario was supposed to represent high superficial similarity than when a scenario was supposed to represent low superficial similarity. Likewise, the sample listed more dissimilarity when a scenario was intended to represent low levels of Superficial Similarity. The results were consistent across Structural and Procedural Similarities as well. Examining differences in both the number of similarities and dissimilarities listed provided two tests for each type of similarity as shown in appendix 2 .

This pre-test also demonstrates the uniqueness of each type of similarity. Specifically, the similarity types were shown to the pre-test sample at the same time. That is, a participant read through a scenario that had all three types of similarity embedded in it at either a high or low level. Participants in the pre-test sample saw multiple scenarios 
to capture the various levels of each similarity type using and identical ordering as the data collection effort. Participants listing of similarities and dissimilarities mirrored the intended levels for each similarity type, indicating that the similarity types were distinct from one another.

Because I conducted the pre-test of the technology-market scenario versions using a different sample than I use for the hypotheses tests, my results rest on an important assumption. Specifically, I assume that the distinctness and various levels for each similarity type will come across to the experiment sample as it did for the pre-test sample.

I contended in Chapter 2 that Procedural Similarity may have been embedded in the previously used measures for Superficial Similarity or perhaps was left out of studies altogether. Here, I consider Procedural Similarity as a distinct type of similarity with its own direct effects on Opportunity Beliefs. Specifically, hypotheses 1, 2 and 3 predict that Superficial, Structural and Procedural Similarities, respectfully, will each have a positive direct effect on Opportunity Beliefs. The results reported below show that hypotheses 2 and 3 are supported whereas the coefficient for the path that I predicted in hypothesis 1 is marginally ( $p$-value $=0.06)$ significant.

The coefficients for each similarity type's effect on Opportunity Beliefs are all positive as predicted. However, only the coefficients for Structural Similarity and Procedural Similarity, the two similarity types that I predict will matter the most, are significant. It is worth noting that the p-value for Superficial Similarity of 0.06 is marginally significant and may become significant with higher power. Indeed, it is reasonable to suspect that perhaps with a larger sample size, or different sampling frame, this path might also be significant. Nevertheless, only the paths for Structural and 
Procedural Similarities are supported using my sample. The coefficient for Structural Similarity is 0.22 and is significant below the 0.01 level, indicating that the more Structurally Similar a supply source is to a demand source, the more positive beliefs people will generally form about the pairing actually being an opportunity. Procedural Similarity's coefficient is 0.97 and is significant below the 0.001 level. These results support the central premise of this dissertation, that Procedural Similarity is distinct from Superficial Similarity and has a unique effect on the formation of beliefs about opportunities.

Hypotheses $4 \mathrm{a}$ and $4 \mathrm{~b}$ predict interaction effects between the new similarity type, Procedural Similarity, and each of the other similarity types, Superficial and Structural. However, neither of these hypotheses is supported. None of the paths predicted in hypotheses $4 \mathrm{a}$ or $4 \mathrm{~b}$ are significant for fit, feasibility or the combination. The only path that is marginally significant is the interaction effect between Procedural Similarity and Superficial Similarity on feasibility with a p-value of 0.06 . However, even if this path were significant—perhaps with a larger sample size — the direction of the path is negative whereas the hypothesis $4 \mathrm{a}$ predicts a positive effect. Therefore, hypotheses $4 \mathrm{a}$ and $4 \mathrm{~b}$ are not supported for any of the dependent variables.

Individual Differences. The remaining hypotheses all predict individual-level moderating effects on the relationships between opportunity differences and Opportunity Beliefs. There are three individual level moderators in this dissertation's model, Prior Knowledge of Technology, Prior Knowledge of Market and Global versus Local Precedence. Although I will discuss each of these separately below, generally: Prior Knowledge of Technology does not moderate the relationship between Procedural 
Similarity and Opportunity Beliefs; Prior Knowledge of Market only moderates the effect of (Procedural Similarity) when feasibility is the dependent variable and not in the direction predicted; and Global versus Local Precedence does moderate the effect of the new opportunity difference, Procedural Similarity, in the direction predicted, but not the effects of Superficial or Structural Similarities.

For this sample, Prior Knowledge of Technology does not positively moderate the effect that Procedural Similarity, has on fit, feasibility or Opportunity Beliefs as is predicted in hypothesis H5a. Although the sign of the path is positive, as predicted, for fit, feasibility and Opportunity Beliefs, none of these moderation paths are significant. Therefore, hypothesis 5a is not supported.

Prior Knowledge of Technology does not negatively moderate the effect that opportunity difference interaction, Procedural $\times$ Structural, has on fit, feasibility or Opportunity Beliefs as is predicted in hypothesis 6a. None of these paths are significant. Therefore, hypothesis $6 \mathrm{a}$ is not supported.

The other type of Prior Knowledge considered is also not supported as a moderator. Specifically, for this sample, Prior Knowledge of Market does not positively moderate the effect that Procedural Similarity has on fit, feasibility or Opportunity Beliefs as predicted in hypothesis $5 \mathrm{~b}$. Although the moderation path is significant for the effect of Procedural Similarity on feasibility, the coefficient is negative whereas hypothesis $5 \mathrm{~b}$ predicts a positive moderation effect. The moderation path for the effect of Procedural Similarity on Opportunity Beliefs is marginally significant with a p-value below 0.08 ; however, the sign is negative whereas hypothesis $5 \mathrm{~b}$ predicts a positive moderation effect. The sign is also in the opposite direction of that predicted when fit is 
the dependent variable and the path is not significant. Therefore, hypothesis $5 \mathrm{~b}$ is not supported.

Prior Knowledge of Market does not negatively moderate the effect that opportunity difference interaction, Procedural $\times$ Structural, has on fit, feasibility or Opportunity Beliefs as is predicted in hypothesis $6 \mathrm{~b}$. The coefficients were in the direction predicted for fit and Opportunity Beliefs, but not for feasibility. Furthermore, none of the paths were significant. Therefore, hypothesis $6 \mathrm{~b}$ is not supported.

Previous research demonstrates that Prior Knowledge of Markets and Technologies moderates the influence that Superficial and Structural Similarities have on both beliefs about fit and feasibility; however, the present study only finds a moderating effect of Prior Knowledge for the effects of Procedural Similarity on feasibility. Furthermore, the moderation effect demonstrated in the present study is in the opposite direction of the moderation effects shown in previous studies on the other types of similarity. Here, the more Prior Knowledge one has about a market, the less influence Procedural Similarity has on their beliefs.

The final individual difference considered herein, Global versus Local Precedence, received support for one of the similarity types, Procedural Similarity. Therefore, Global versus Local Precedence does not negatively moderate the main effect of Superficial Similarity on fit, feasibility or Opportunity Beliefs as predicted in hypothesis 7a. Although the path is negative as predicted, the p-values are not significant for any of the models. Therefore, hypothesis $7 \mathrm{a}$ is not supported.

Global versus Local Precedence does not positively moderate the main effect of Structural Similarity on fit, feasibility or Opportunity Beliefs as predicted in hypothesis 
7b. Although the path is positive as predicted, the p-values are not significant for any of the models. Therefore, hypothesis $7 \mathrm{~b}$ is not supported.

Global versus Local Precedence does negatively moderate the main effect of the new opportunity difference, Procedural Similarity, on Opportunity Beliefs as predicted in hypothesis 7c. However, it is largely the relationship between Procedural Similarity and fit that is driving these results; the p-value when feasibility is the dependent variable is marginally significant at $\mathrm{p}=0.05$. Generally though, hypothesis $7 \mathrm{c}$ which predicts that individuals who tend to have a Local Precedence - that is, individuals that focus more on details than the big picture-will place greater emphasis on Procedural Similarity than those with a Global Precedence when forming beliefs about the fit and feasibility of potential supply-demand pairings is supported. Indeed, the moderation slope coefficient is significant and in the direction predicted for the combined dependent variable, Opportunity Beliefs. 
Table 8: Results - Opportunity Beliefs (fit \& feasibility Combined)

\begin{tabular}{|c|c|c|c|c|c|c|c|}
\hline & & & $\begin{array}{c}\text { Opportunity } \\
\text { Beliefs }\end{array}$ & $\begin{array}{c}\text { Superficial } \\
\text { Slope }\end{array}$ & $\begin{array}{l}\text { Structural } \\
\text { Slope }\end{array}$ & $\begin{array}{l}\text { Procedural } \\
\text { Slope }\end{array}$ & $\begin{array}{c}\text { Procedural } \times \\
\text { Structural }\end{array}$ \\
\hline $\begin{array}{l}\text { Hypothesized } \\
\text { IVs: }\end{array}$ & Structural Similarity & Coefficient & $0.22(0.07)^{* *}$ & & & & \\
\hline \multirow{3}{*}{$\begin{array}{l}\text { Trimmed } \\
\text { Controls: }\end{array}$} & Founder & Coefficient & & $0.51(0.28)^{t}$ & & & \\
\hline & Owner & Coefficient & & $-0.58(0.25)^{*}$ & $0.20(0.21)$ & & \\
\hline & $\begin{array}{l}\text { Entrepreneurial Self } \\
\text { Efficacy }\end{array}$ & Coefficient & & $0.21(0.09) *$ & $0.24(0.13)^{t}$ & & \\
\hline \multirow[t]{2}{*}{$\begin{array}{l}\text { Hypothesized } \\
\text { Moderators: }\end{array}$} & $\begin{array}{l}\text { Prior Knowledge of } \\
\text { Market }\end{array}$ & Coefficient & $0.06(0.09)$ & $-0.09(0.10)$ & $-0.02(0.12)$ & $-0.32(0.17)^{t}$ & $0.25(0.23)$ \\
\hline & $\begin{array}{l}\text { Prior Knowledge of } \\
\text { Technology }\end{array}$ & Coefficient & $0.09(0.10)$ & $0.05(0.11)$ & $-0.14(0.14)$ & $0.22(0.19)$ & $-0.05(0.25)$ \\
\hline
\end{tabular}


Table 9: Results - Opportunity Beliefs (fit Only)

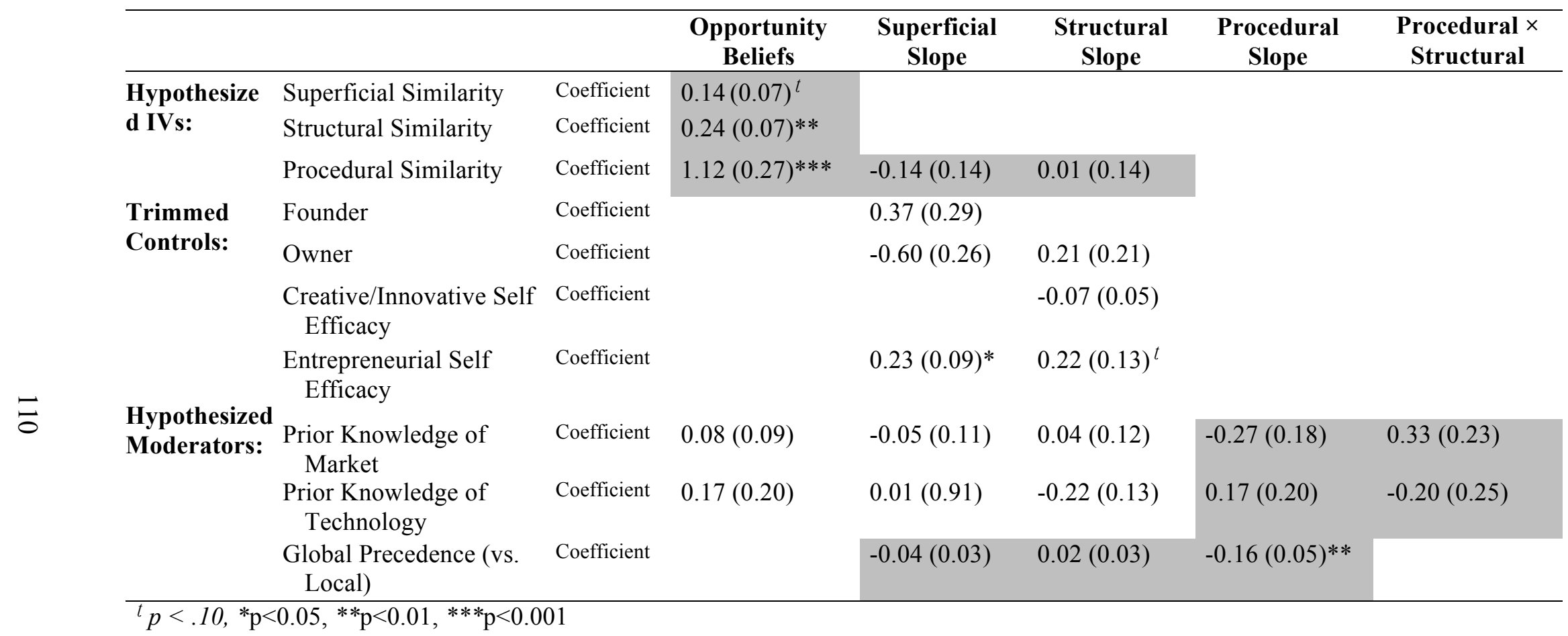


Table 10: Results - Opportunity Beliefs (feasibility Only)

\begin{tabular}{|c|c|c|c|c|c|c|c|}
\hline & & & $\begin{array}{l}\text { Opportunity } \\
\text { Beliefs }\end{array}$ & $\begin{array}{l}\text { Superficial } \\
\text { Slope }\end{array}$ & $\begin{array}{l}\text { Structural } \\
\text { Slope }\end{array}$ & $\begin{array}{l}\text { Procedural } \\
\text { Slope }\end{array}$ & $\begin{array}{c}\text { Procedural } \times \\
\text { Structural }\end{array}$ \\
\hline \multirow{3}{*}{$\begin{array}{l}\text { Hypothesize } \\
\text { d IVs: }\end{array}$} & Superficial Similarity & Coefficient & $.12(0.07)^{t}$ & & & & \\
\hline & Structural Similarity & Coefficient & $0.19(0.02)^{* *}$ & & & & \\
\hline & Procedural Similarity & Coefficient & $0.77(0.27)^{* * *}$ & $-0.26(0.14)^{t}$ & $0.07(0.16)$ & & \\
\hline \multirow{4}{*}{$\begin{array}{l}\text { Trimmed } \\
\text { Controls: }\end{array}$} & Founder & Coefficient & & $0.72(0.29)^{*}$ & & & \\
\hline & Owner & Coefficient & & $-0.55(0.26)^{*}$ & $0.19(0.23)$ & & \\
\hline & $\begin{array}{l}\text { Creative/Innovative Self } \\
\text { Efficacy }\end{array}$ & Coefficient & & & $-0.14(0.05)^{*}$ & & \\
\hline & $\begin{array}{l}\text { Entrepreneurial Self } \\
\text { Efficacy }\end{array}$ & Coefficient & & $0.19(0.10)^{t}$ & $0.25(0.14)^{t}$ & & \\
\hline \multirow[t]{3}{*}{$\begin{array}{l}\text { Hypothesized } \\
\text { Moderators: }\end{array}$} & $\begin{array}{l}\text { Prior Knowledge of } \\
\text { Market }\end{array}$ & Coefficient & $0.02(0.09)$ & $-0.14(0.11)$ & $-0.09(0.13)$ & $-0.39(0.18)^{*}$ & $0.16(0.27)$ \\
\hline & $\begin{array}{l}\text { Prior Knowledge of } \\
\text { Technology }\end{array}$ & Coefficient & $0.14(0.10)$ & $0.11(0.11)$ & $-0.03(0.15)$ & $0.30(0.20)$ & $0.13(0.25)$ \\
\hline & $\begin{array}{l}\text { Global Precedence (vs. } \\
\text { Local) }\end{array}$ & Coefficient & & $-0.04(0.03)$ & $0.05(0.13)$ & $-0.09(0.05)^{t}$ & \\
\hline
\end{tabular}




\section{Opportunity}

Beliefs

\begin{tabular}{|c|c|c|c|}
\hline Hypotheses & $\begin{array}{l}\text { Beliefs } \\
\text { Combined }\end{array}$ & Only Fit & $\begin{array}{c}\text { Only } \\
\text { Feasibility }\end{array}$ \\
\hline $\begin{array}{l}\text { H1: Superficial Similarity (positive effect } \\
\text { on ...) }\end{array}$ & $\begin{array}{l}\text { Marginally } \\
\text { supported }\end{array}$ & $\begin{array}{l}\text { Marginally } \\
\text { supported }\end{array}$ & $\begin{array}{c}\text { Marginally } \\
\text { supported }\end{array}$ \\
\hline $\begin{array}{l}\mathrm{H} 2 \text { : Structural Similarity (positive effect } \\
\text { on ...) }\end{array}$ & Supported & Supported & Supported \\
\hline $\begin{array}{l}\text { H3: Procedural Similarity (positive effect } \\
\text { on ...) }\end{array}$ & Supported & Supported & Supported \\
\hline $\begin{array}{l}\text { H4a: Procedural } \times \text { Superficial (positive } \\
\text { effect on ...) }\end{array}$ & $\begin{array}{c}\text { Not } \\
\text { supported }\end{array}$ & $\begin{array}{c}\text { Not } \\
\text { supported }\end{array}$ & $\begin{array}{c}\text { Not } \\
\text { supported }\end{array}$ \\
\hline $\begin{array}{l}\text { H4b: Procedural } \times \text { Structural (positive } \\
\quad \text { effect on ...) }\end{array}$ & $\begin{array}{c}\text { Not } \\
\text { supported }\end{array}$ & $\begin{array}{c}\text { Not } \\
\text { supported }\end{array}$ & $\begin{array}{c}\text { Not } \\
\text { supported }\end{array}$ \\
\hline $\begin{array}{l}\text { H5a: Prior Knowledge of Technology } \times \\
\text { Procedural (positive effect on ...) }\end{array}$ & $\begin{array}{c}\text { Not } \\
\text { supported }\end{array}$ & $\begin{array}{c}\text { Not } \\
\text { supported }\end{array}$ & $\begin{array}{c}\text { Not } \\
\text { supported }\end{array}$ \\
\hline $\begin{array}{l}\text { H5b: Prior Knowledge of Market } \times \\
\text { Procedural (positive effect on ...) }\end{array}$ & $\begin{array}{c}\text { Not } \\
\text { supported }\end{array}$ & $\begin{array}{c}\text { Not } \\
\text { supported }\end{array}$ & Supported \\
\hline $\begin{array}{l}\text { H6a: Prior Knowledge of Technology } \times \\
\text { Procedural } \times \text { Structural (negative } \\
\text { effect on } \ldots \text {...) }\end{array}$ & $\begin{array}{c}\text { Not } \\
\text { supported }\end{array}$ & $\begin{array}{c}\text { Not } \\
\text { supported }\end{array}$ & $\begin{array}{c}\text { Not } \\
\text { supported }\end{array}$ \\
\hline $\begin{array}{l}\text { H6b: Prior Knowledge of Market } \times \\
\text { Procedural } \times \text { Structural (negative } \\
\text { effect on ...) }\end{array}$ & $\begin{array}{c}\text { Not } \\
\text { supported }\end{array}$ & $\begin{array}{c}\text { Not } \\
\text { supported }\end{array}$ & $\begin{array}{c}\text { Not } \\
\text { supported }\end{array}$ \\
\hline $\begin{array}{l}\text { H7a: Global vs. Local Precedence } \times \\
\text { Superficial (negative effect on ...) }\end{array}$ & $\begin{array}{c}\text { Not } \\
\text { supported }\end{array}$ & $\begin{array}{c}\text { Not } \\
\text { supported }\end{array}$ & $\begin{array}{c}\text { Not } \\
\text { supported }\end{array}$ \\
\hline $\begin{array}{l}\text { H7b: Global vs. Local Precedence } \times \\
\text { Structural (positive effect on ...) }\end{array}$ & $\begin{array}{c}\text { Not } \\
\text { supported }\end{array}$ & $\begin{array}{l}\text { Not } \\
\text { supported }\end{array}$ & $\begin{array}{l}\text { Not } \\
\text { supported }\end{array}$ \\
\hline $\begin{array}{l}\text { H7c: Global vs. Local Precedence } \times \\
\text { Procedural (negative effect on ...) }\end{array}$ & Supported & Supported & $\begin{array}{c}\text { Marginally } \\
\text { supported }\end{array}$ \\
\hline
\end{tabular}




\section{Chapter Summary}

In Chapter 4, I report the results of the HLM models that I ran according to McCoach's (2010) step-by-step guide. I also report these results succinctly in tables though out. I report the empirical results parallel to the hypotheses that are in the theoretical model shown in figure 1.2. Specifically, the chapter explains the notion that the opportunity difference, Procedural Similarity, that is introduced in this dissertation does indeed have a main effect on beliefs about the fit and feasibility of potential supplydemand pairings and should, therefore, be included in future studies of Structural Alignment Theory. Structural Similarity also has a significant and meaningful, positive effect on Opportunity Beliefs; however Superficial Similarity's effect is not significant, but may nevertheless be important to Structural Alignment Theory as I will explain in Chapter 5 below. Furthermore, this chapter explains that the new main effect established by this dissertation of Procedural Similarity positively influencing Opportunity Beliefs is partially moderated by individuals' Prior Knowledge of Markets and Global versus Local Precedence with Local Precedence constraining cognitive perceptions. Chapter 4 outlays the results of the empirical model that are also summarized in table 11; deeper discussion regarding the theoretical and practical implications of these results is provided below in Chapter 5. 


\section{CHAPTER 5 - DISCUSSION AND CONCLUSION}

\section{Chapter Overview}

In this chapter, I further discuss the findings as well as their implications related to theory and practice that I reported in Chapter 4. In this dissertation, I set out to examine the question: how do opportunity differences and individual differences influence Opportunity Beliefs? Specifically, I examined this question in three parts, focusing on answering: (1) How do opportunity differences in Superficial, Structural and Procedural Similarities influence Opportunity Beliefs? (2) How does Procedural Similarity moderate the effects that Superficial and Structural Similarities have on Opportunity Beliefs? and (3) How do individuals Prior Knowledge and Global versus Local Precedence moderate the relationship between opportunity differences and Opportunity Beliefs? In the discussion section of this chapter below, I explain how the results of this study inform each of these three questions. Specifically, I discuss Research Questions 1 and 2 in the subsection, “Opportunity Differences and Opportunity Beliefs", and Research Question 3 in the subsection, "Individual Differences and Opportunity Beliefs". Following the discussion of this dissertation's results vis-à-vis the research questions, I offer implications to the IO perspective, Structural Alignment Theory and literature on Global versus Local Precedence. Next, I offer practical implications of this dissertation's findings. Lastly, I provide concluding thoughts and summarize the chapter. 


\section{Discussion}

Opportunity Differences and Opportunity Beliefs. The central premise of this dissertation is that the IO perspective of entrepreneurship will benefit from a simultaneous empirical examination of the effects of opportunity differences on entrepreneurial discovery as well as the extent to which they are contingent upon individual characteristics. By studying the effects of individual-level characteristics and opportunity-level attributes simultaneously, we can gain a better understanding of the variability that is driven by characteristics of the individual vis-a-vis the opportunity. Furthermore, studying the effects of opportunity differences allows us to study questions such as whether, and why, some opportunities might be more difficult to recognize irrespective of an individual. Extant literature that only considers differences across individuals is unable to examine questions about why some opportunities might be more difficult to recognize for individuals in general. In this study, however, I am able to control for individual differences and examine the main effects of opportunity differences on opportunity recognition.

This dissertation advances scholarly understanding of the IO perspective by explaining how characteristics of opportunities play a role in opportunity recognition through influencing individuals' perceptions. In doing so, this work helps explain why certain individuals recognize a given entrepreneurial opportunity whereas others do not. The entrepreneurial process proceeds in stages from recognition, to evaluation, to exploitation (Shane \& Venkataraman, 2000). Opportunity Beliefs play a substantial role in the recognition stage of the entrepreneurial process because individuals who encounter the same opportunity ideas may not recognize such ideas as actual opportunities if they 
do not form positive beliefs about the ideas (e.g., Grégoire \& Shepherd, 2012; Shane \& Venkataraman, 2000). Eckhardt and Shane (2013), explain that opportunity recognition, even within the objective IO view of opportunities, is not independent of subjective human cognition. They elaborate by contending that scholarly research on opportunity recognition could benefit from studying the subjective perceptions of individuals. Specifically, even though opportunities are characterized as objective within the IO perspective, constructs capturing the notion of conjectures are important to opportunity recognition, yet have largely been "overlooked" in opportunity recognition research (Eckhardt \& Shane, 2013, p. 162). Specifically, Eckhardt and Shane (2013, p. 163) explain that the field needs more research that examines how individuals form conjectures based on "the interaction between individual perceptions and technical and market constraints (opportunity)". In short, entrepreneurs recognize opportunities, in part, by forming conjectures about the information they have related to potential opportunities (Eckhardt \& Shane, 2013). Directly below, I will discuss what we learn from this dissertation with respect to my first research question which asks about the effects of opportunity characteristics on such conjectures: how do opportunity differences in Superficial, Structural and Procedural Similarities influence Opportunity Beliefs?

I theorized that some opportunities are more obvious than others because opportunities differ with respect to the degree of Superficial, Structural and Procedural Similarities that they exhibit between their respective sources of supply (e.g., a technology) and demand (e.g., a market). Consistent with the extant literature, I conceptualize opportunities as pairings of supply sources and demand sources (Shane \& Venkataraman, 2000). I further argue that supply and demand pairings can vary in how 
similar (across three types of similarity) a focal supply source is to a focal demand source. For example, consider the degree of similarity between a military technology (supply source) and an academic market of physics students (demand source) proposed as a potential market to apply the technology to. First, this potential supply-demand pairing exhibits a low degree of Superficial Similarity because military pilots, flight simulators and combat are not similar to high school physics students, educators and a computer hockey game. Second, this potential supply-demand pairing exhibits a high degree of Structural Similarity because how individual superficial features work together to do something (achieve some purpose) is the same for the technology's original application and the new application. Specifically, the technology was designed to tailor combat pilots training to their individual learning styles and the proposed new application is for tailoring education to fit physics students individual learning styles. Finally, the potential pairing exhibits low Procedural Similarity because in the technology's original design, users combatted against a computer opponent; however, in the proposed application, users perform an activity alone without any opponent. I hypothesize that the more similar a supply source is to a demand source with respect to each of these similarity types, the more likely individuals are to recognize a pairing as an opportunity. That is, I theorize that the degree of similarity between a supply source and demand source is directly linked to the obviousness of opportunities. The focus here is not on the notion that an idea may be obvious for future entrepreneurs to find; rather, here obvious refers to the notion that an individual feels certain that what they have found is an opportunity. Hypothetically, if the proposed application from the example above included users competing against an opponent (consistent with the original procedures for using this 
technology), then I would predict that individuals would form more positive beliefs that the pairing represents an opportunity.

The results of this study (outlined in Chapter 4) are largely consistent with the prediction above that the more similar a supply source is to a demand source, the more likely individuals are to form positive Opportunity Beliefs with respect to fit and feasibility. The extant literature identifies Superficial and Structural Similarity as the two types of similarity that are relevant to conjectures formed in the opportunity recognition stage (cf., Grégoire \& Shepherd, 2012). However, this research demonstrates that a third type of similarity, Procedural, is relevant whereas Superficial is not. Indeed, this dissertation demonstrates, that although all three types of similarity may have some impact on Opportunity Beliefs, it is largely Structural and Procedural Similarities (the new type introduced herein) that are driving beliefs, with Superficial Similarity not mattering nearly as much. Indeed, for the present sample, individuals exhibited more certainty that a supply-demand pairing is actually an opportunity when Structural and Procedural Similarity were high; however Superficial Similarity did not have a similar, significant, effect on Opportunity Beliefs. Thus, the present study demonstrates that within the perspective provided by Structural Alignment Theory, Structural and Procedural Similarities are the primary drivers of Opportunity Beliefs.

The non-significant effect of Superficial Similarity on Opportunity Beliefs here, however, does not conclusively invalidate the important contribution made by Grégoire and Shepherd (2012) regarding the influence that Superficial Similarity has on the formation of beliefs about potential opportunities. Indeed, there are several plausible explanations for why Superficial Similarity was only marginally significant here and had 
a weak effect in Grégoire and Shepherd's (2012) experiment. First, it could be that the design of my experiment over-emphasized Procedural Similarity be treating it as between subjects whereas Superficial and Structural Similarity were treated as within subjects. Second, cognitive psychologists that study analogical problem solving from a Structural Alignment Theory perspective contend that Superficial Similarity is mostly relevant to noticing analogies. However, Grégoire and Shepherd (2012) and I both provided the analogous situations to the respondents; it is very likely that to understand the true effects of Superficial Similarity would require an experiment designed to capture the extent to which individuals were able to notice analogous solutions on their own. This result could also be an artifact of the sample. My sample consists of employees, upper-level managers and engineers. Because these individuals are employees rather than entrepreneurs, it is plausible that their perceptions are anchored and bounded by the organizations they work for. Of the three types of similarity, Superficial Similarity is the one that deals with noticing new analogous situations; perhaps, being anchored to one organization limits the cognitive energy focused on Superficial Similarities. Indeed, research on Structural Alignment Theory identifies anchoring information such as industry, competition and experience as constraints to the use of analogical reasoning (Magro \& Nutter, 2012; William, 2010). The idea that individuals' cognitive efforts related to opportunity recognition are constrained by their organization is consistent with prior findings that individuals are more likely to recognize opportunities within the industries they currently work within (Fiet, Norton Jr., \& Van Clouse, 2007). Prior research relatedly finds that opportunity recognition is constrained by social sources of information such as: industry networks, professional forums and work-related mentors (Ozgen \& Baron, 2007). 
My first major contribution is to Structural Alignment Theory literature. I do so by explaining that analogical problem solving is a three-step process, and that its third step is often ignored. I, specifically, explain the distinctiveness of Procedural Similarity and how it is likely to influence Opportunity Beliefs (individuals' certainty that a new source of supply fits with and can be feasibility implemented to a demand source). This research demonstrates that our previous understanding of analogical problem solving in entrepreneurship is incomplete and, possibly confounded. Structural Alignment Theory has advanced within psychology literature from Genter's (1983) original two-step model (including Superficial and Structural Similarities only) to a present understanding of a three-step model, which added Procedural Similarity (Chen, 2002). I further extend this theory be showing that management literature on Structural Alignment Theory was missing the third, critical, component of Procedural Similarity. In addition to ignoring Procedural Similarity, the extant literature sometimes conceptualizes Procedural Similarities as Superficial Similarities, and therefore, has not considered the possibility that Procedural Similarities have a distinct influence on Opportunity Beliefs. Instances in which Procedural Similarities were conceptualized as Superficial Similarities in the extant literature, might need to be re-examined.

The results also contribute to the literature on analogical problem solving by showing which steps in the process are most critical. Analogical problem solving involves the following three steps, each of which relates to a similarity type as follows: (1) Superficial Similarity relates to noticing the potential for analogy, (2) Structural Similarity relates to mapping correspondences into a solution principle and (3) Procedural Similarity relates to implementing the acquired solution principle. 
Considering the results of this dissertation vis-à-vis the process of analogical problem solving, brings to light that the critical steps of analogical problem solving are step 2 (mapping correspondences into a solution principle) and step 3 (implementing a solution principle), not step 1 (noticing the potential for analogy) and step 2 as previously thought. A second major contribution of this dissertation is to consider all of these steps together and demonstrate that steps 2 and 3 drive the formation of Opportunity Beliefs whereas step 1 does not. When we consider the relationship between the new similarity type (Procedural) and the similarity type with the strongest effect from the extant literature (Structural), it makes sense that Structural and Procedural Similarity have a greater impact on Opportunity Beliefs than Superficial Similarity does. Specifically, Procedural Similarity is concerned with the details regarding how to implement or execute Structural relationships; that is Procedural Similarity is concerned with how users interact with and execute higher order solution principles (Chen, 2002). This suggests that future researchers examining questions related to analogical problem solving need to carefully consider how each step in the process may, or may not, relate to specific research questions. When examining issues related to noticing the potential to solve problems via analogy, research should emphasize step 1 (Superficial Similarity). However, when examining issues related whether an analogy offers a solution that fits with and can be feasibly applied to a focal problem, research should focus on steps 2 (Structural Similarity) and 3 (Procedural Similarity).

The results of this dissertation fail to support the interaction hypotheses related to research question 2, which asks: how does Procedural Similarity moderate the effects that Superficial and Structural Similarities have on Opportunity Beliefs? That is, this 
dissertation does not show that the effects of Superficial Similarity and Structural Similarity on Opportunity Beliefs are contingent upon the level of Procedural Similarity between a supply source and demand source as predicted. I consider why the results failed to support these interaction hypotheses below.

After considering these results, it appears that the interaction hypotheses are inconsistent with Structural Alignment Theory and not that there is an empirical explanation or experimental design flaw which can explain the lack of support for these hypotheses. Based on these findings, I suggest that a more careful consideration of Structural Alignment Theory's explanation of the role of each of these similarity types in the process of solving problems via analogies makes it clear that these hypotheses should probably never have been predicted in the first place. Specifically, there seems to be a chronological order to the process of solving problems via analogy and each similarity type has a set place within that chronology. In the process of solving problems via analogy, Chen (2002) explains that Superficial Similarity comes first by influencing the degree to which an individual might notice the possibility of solving a problem by using a solution principle available in an analogous situation. Second, Structural Similarity involves mapping one-to-one correspondences to form beliefs about the degree to which the solution principle makes sense for a focal problem. Finally (the fact that this comes last is key), Procedural Similarity involves an individual making sense of, or adapting, the implementational details related to executing a solution principle. That is, steps 2 and 3 are each contingent upon successful completion of the prior step. If an individual never notices an analogy (step 1), then that individual cannot map one-to-one correspondences (step 2) between the analogy and focal problem. Similarly, if an individual does not map 
one-to-one correspondences to identify a solution principle, then they cannot adapt implementational details (step 3) for executing the analogy's solution principle in the problem's domain. Therefore, by the time Procedural Similarity is relevant (chronologically), whatever influence Superficial and Structural Similarity might have on a situation has probably already occurred. Therefore, Superficial and Structural Similarities' influence on beliefs is almost certainly not contingent upon Procedural Similarity because it would undermine the chronology of process as described in Structural Alignment Theory literature.

In sum, the results for this sample support two of the opportunity differences (Structural and Procedural) as having a direct effect on Opportunity Beliefs. This demonstrates that Procedural Similarity should be included in future research on the process of analogical problem solving within Structural Alignment Theory. Despite the lack of significance for Superficial Similarity in the results herein, it is my view that Superficial Similarity should also be included in future research on the process of analogical problem solving within Structural Alignment Theory until these findings are confirmed by further research. Specifically, it seems likely that the reason Superficial Similarity was not significant has more to do with how this experiment was designed than it does with a general lack of importance of Superficial Similarity. That is, I completed step 1 of the process for participants by providing them with the analogies, effectively 'noticing' the analogies for them.

Individual Differences and Opportunity Beliefs. My third major contribution is related to a common question asked by entrepreneurship researchers: why are some individuals more likely than others to recognize a particular opportunity. Specifically, I 
examine the more detailed research question: how do individuals Prior Knowledge and Global versus Local Precedence moderate the relationship between opportunity differences and Opportunity Beliefs? I advance understanding of the nexus of individuals and opportunities (IO) (Shane \& Venkataraman, 2001), by offering individual level characteristics that the relationship between opportunity characteristics and perceptions of fit and feasibility are contingent upon. Given that analogical transfer is a cognitive process, individual-level differences that influence cognitive processing of information, such as Prior Knowledge and Global versus Local Precedence should impact the influence that analogies have on individuals' beliefs about potential supply-demand pairings (Basso \& Lowery, 2004; Grégoire \& Shepherd, 2012). Specifically, I theorize moderating effects of Prior Knowledge related to a focal technology, Prior Knowledge related to a focal market and individual differences in Global versus Local Precedence on the relationship between opportunity differences and Opportunity Beliefs.

We already know from the extant literature (Grégoire \& Shepherd, 2012), that some opportunity differences have effects on beliefs about opportunities contingent upon Prior Knowledge. Extending this reasoning, I theorized that the effect of Procedural Similarity on Opportunity Beliefs is contingent on Prior Knowledge of Markets and Technologies as well. However, results indicate that the effect of Procedural Similarity is only contingent upon Prior Knowledge of Markets and for its effect on beliefs about feasibility, not fit. Beliefs about feasibility refer to an individual's degree of certainty that a technology is sufficiently developed to be profitably applied to a focal market (Grégoire et al, 2010). Beliefs about fit, on the other hand, refer to an individual's degree of certainty that a technology can solve the problems of a market (Grégoire et a, 2010). 
Interestingly, the moderation effect of Prior Knowledge of Markets on the effect of Procedural Similarity on feasibility was also in the opposite direction predicted. That is, the more knowledge that an individual has about a focal market, the less Procedural Similarity matters to that person's beliefs about how feasible it is to profitably implement a technology to a focal market. It seems then, that when individuals have higher levels of knowledge related to a focal market, they are already confident in their knowledge of what could, or could not, be feasibly implemented to that market. That is, individuals with high familiarity with a market, may feel that they already have sufficient knowledge regarding how adaptable a market is to new methods of interacting with technologies so as to make Procedural Similarity less important to them when forming beliefs about feasibility.

As indicated above, the study did not find support for Prior Knowledge as a moderator for beliefs about fit. Prior Knowledge is particularly interesting and important as a moderator because as Grégoire and Shepherd (2012) point out that high levels of Prior Knowledge can facilitate positive belief formation about non-obvious opportunities. Given the importance of non-obvious opportunities (Barney, 1991), it is important to consider the non-significant results herein vis-à-vis the significant effects of Prior Knowledge reported in the extant literature (Grégoire \& Shepherd, 2012).

The discrepancy between results here and the extant literature could simply be a result of insufficient power. Indeed, Grégoire and Shepherd (2012) received 'mixed support' with their similarly sized sample. Furthermore, I included an extra similarity type with only a slightly larger sample (116 vs. 99 individuals). It is also worth noting that although Prior Knowledge was not significant at the 0.05 threshold for fit beliefs, the 
moderation effect was marginally significant when fit and feasibility were aggregated into the dependent construct, Opportunity Beliefs $(\mathrm{p}$-value $=0.076)$. Therefore, it seems reasonable that Grégoire and Shepherd's (2012) finding that Prior Knowledge facilitates the formation of positive beliefs about non-obvious opportunities is likely valid despite the non-significant results for fit.

The other moderator that I examine, and find some support for, as a potentially relevant individual difference is Global versus Local Precedence. Cognitive psychologists indicate that people seek consonance between information they process and the beliefs and expectations that they subsequently derive (Festinger, 1957). One of the primary ways of achieving cognitive consonance is by lowering the importance of dissonant cognitions (Festinger, 1957). Individuals convince themselves that the more dissonant a factor is to their incumbent or preferred state (such as how they process information), the less importance is assigned to that factor. Similarly, individuals tend to give heightened importance to factors that are less dissonant to one's incumbent or preferred state. I theorized that Global versus Local Precedence influences the relationships between opportunity differences in Superficial, Structural and Procedural Similarity and Opportunity Beliefs in a similar manner. Indeed, the data partially support this moderation effect, showing that individuals who exhibit a Local Precedence actually do rely more on a factor that is consistent with how they process information, Procedural Similarity. Individuals with a Local Precedence, then, convince themselves that factors that are less consistent with how they process information (such as global factors) are not as important as factors that are more consistent with how they prefer to process information. 
Global versus Local Precedence did not significantly moderate the relationships between Superficial and Structural Similarity and Opportunity Beliefs, however. The lack of significance for Global versus Local Precedence on Superficial Similarity's influence could actually be due to the fact that I effectively 'noticed the potential for analogy' for participants, thereby undermining the role of Superficial Similarity in the process of analogical problem solving. As discussed above, I performed step 1 for participants by providing them with analogies containing solutions for focal problems, potentially undermining the role of Superficial Similarity in belief formations. In my view, therefore, these results do not definitively indicate that Global versus Local Precedence does not moderate the effects of Superficial Similarity. Indeed, the p-value, although not significant, was somewhat low at 0.14 . Future research on the potential moderating effects of Global versus Local Precedence on Superficial Similarity's effects would need to allow participants to notice analogies directly.

The lack of significance for Global versus Local Precedence as a moderator of Structural Similarity's influence is much more difficult to reconcile. Specifically, there is nothing in the design of the experiment that appears to account for lack of significance. Furthermore, the supported moderation effect discussed in detail below for Global versus Local Precedence on Procedural Similarity's influence suggests that this construct does play a role in analogical problem solving. Therefore, it seems plausible, even likely, that individuals who tend to exhibit a Global Precedence should give more weight to informational factors that are Global (configural) in nature such as information related to Structural Similarity. The lack of results for a moderation effect on Structural Similarity coupled with the support for moderation on Procedural Similarity seem to indicate that 
exhibiting a Local Precedence is more constricting to cognitive processing than exhibiting a Global Precedence. In other words, individuals who exhibited a Local Precedence were, indeed, constricted in their cognitive processing of information to focus more on details than the big picture. However, individuals who exhibited a Global Precedence were not constricted in their cognitive processing; they processed both Global and Local information without relying on the big picture at the expense of information related to the details.

If this is true, then individuals with a Global Precedence may have an advantage when it comes to processing information about potential opportunities. This would suggest that individuals responsible for monitoring external environments, such as upperlevel managers, should be individuals who exhibit a Global Precedence. Indeed, a simple linear regression revealed that the upper-level managers were significantly (positive coefficient with a p-value of 0.026) more likely to exhibit a Global Precedence than the engineers in this sample. This is consistent with Mueller's (2011) dissertation finding that expert entrepreneurs tend to focus on big-picture information such as Structural relationships when mentoring novice entrepreneurs on the topic of opportunity recognition.

The significant moderation of Global versus Local Precedence on the direct relationship between Procedural Similarity and Opportunity Beliefs indicates that individuals who tend to focus on details are particularly concerned with how end-users interact with technologies when evaluating potential opportunities. This is a critical contribution when considering the original rationale for studying this topic. Specifically, I contended that management has ignored the third step of analogical problem solving (the 
first two steps being noticing analogies which might contain relevant solutions and mapping correspondences to identify solutions), implementing a solution principle, when examining what Structural Alignment Theory has to say about the formation of Opportunity Beliefs. The third step is important because recent psychology literature on Structural Alignment Theory suggests that individuals will find it difficult to execute a solution if there is not enough details available regarding how a solution principle can be executed with users (Chen, 2002). We now have evidence that not only does the third step of the process directly impact Opportunity Beliefs, but that for the class of people that tend to focus on details before processing big picture or configural information, the third step which involves Procedural Similarity matters even more. I believe this is an important finding because it directly answers a recent call for "research to investigate additional differences among entrepreneurial opportunities" as well as the extent to which they are contingent upon individual differences (Grégoire \& Shepherd, 2012, p. 775). My findings document both an additional opportunity difference that can influence Opportunity Beliefs as well as an individual difference that strengthens the effect of the new opportunity difference. In short, this dissertation shows evidence of an additional cognitive factor that influences whether some individuals are able to make insightful yet cognitively demanding connections that might lead to the recognition of opportunities.

\section{Implications}

Theoretical Implications. The findings herein have theoretical implications to: (1) the IO perspective within entrepreneurship, (2) Structural Alignment Theory and (3) research streams on Global versus Local Precedence. I will discuss implications to each of these separately. 
In a recent debate within the Academy of Management Review, Eckhardt and Shane (2013) argued that the IO perspective is critical to entrepreneurship's distinctiveness. These scholars specifically contended that the field needs research that focuses on theories that might further our understanding of individual perceptions as well as technological (supply) and socioeconomic (demand) constraints. This dissertation advances understanding of the interaction of information about such informational constraints (namely, information about technologies and markets) with individual characteristics and their influence on individuals' perceptions. Furthermore, this dissertation utilizes Structural Alignment Theory and Global versus Local Precedence to explain these interactions.

The conceptualization of entrepreneurship as the recognition, evaluation and exploitation of opportunities naturally leads researchers to ask three high-level research questions: (1) how to individuals recognize opportunities (e.g., Fiet, 2007, Gruber, et al., 2012, Shane, 2000); (2) once an opportunity has been recognized, how do individuals determine whether or not they should pursue the opportunity (e.g., Foo, 2011); and (3) once an individual is committed to pursuing an opportunity, how do they go about exploiting it (e.g., Welpe, Spörrle, Grichnick, Michl, \& Audretsch, 2012). Within the IO perspective of entrepreneurship, scholars primarily answer the first question with theories related to whether individuals will find opportunity ideas in the first place. This makes sense given that there are two major assumptions about the nature of opportunities within the IO perspective: (i) that opportunities exist waiting to be identified (Shane \& Venkaraman, 2000) and (ii) that opportunities are uncertain ex ante (Casson, 1982; Shane \& Venkataraman, 2000). However, only the first of these assumptions has received 
significant attention in extant literature. Therefore, the majority of studies on opportunity recognition investigate how to find opportunity ideas. The results of this dissertation, however, indicate that the second major assumption about opportunities also deserves attention and needs different theories for explanation than are presently offered in the majority of extant research. Specifically, we need theories that are adept at explaining why and how individuals form perceptions' about, and deal with, uncertainty just as Eckhardt and Shane (2013) recently suggest. This research is a step in that direction.

One major theoretical implication of this dissertation is that information external to an individual can influence their perceptions about opportunities. Eckhardt and Shane (2013, p. 161), explain that antagonists of the IO perspective mainly oppose it due to a disagreement about whether the IO perspective "takes into account the subjective perceptions of individuals in the entrepreneurial process." This dissertation utilizes a theory, Structural Alignment Theory, that adheres to the assumptions of the IO perspective about opportunities as existing objectively, while at the same time taking into account the subjective perceptions of individuals. The implication here is that Structural Alignment Theory should be included in entrepreneurship research on opportunity recognition because it helps us understand how individuals form conjectures about opportunities. Specifically, even though the IO perspective conceptualizes opportunities as objective, the "IO nexus has a separate construct to represent the subjective perceptions that individuals have about the existence of an opportunity for profit ... [which has been] ... overlooked" (Eckhardt \& Shane, 2013, p. 162). This dissertation provides additional theoretical arguments and empirical evidence for the notion that Structural Alignment Theory is adept at furthering our scholarly understanding of this 
second construct (conjectures) which has previously been overlooked until recent research began to examine the dependent construct, Opportunity Beliefs (cf. Grégoire \& Shepherd, 2012). Future research on the IO perspective should also investigate independent variables, constructs and theories that further our understanding of when, and to what degree, conjectures are positively formed about opportunity ideas.

The second major theoretical implication of this dissertation is that the third step, executing a solution principle, of analogical problem solving within Structural Alignment Theory is indeed distinct and is critical to understanding how conjectures are formed. Structural Alignment Theory is used in a wide variety of fields such as education, consumer psychology and management (e.g. Chen, 2002; Grégoire \& Shepherd, 2012; Markman \& Gentner, 1993). Yet, within the 3,886 citations (at the time this dissertation was written) of Genter's (1983) seminal paper on Structural Alignment Theory, only 20 refer to the term Procedural Similarity. Furthermore, most of those papers are conference proceedings and none of them consider the influence that Procedural Similarity can have on third persons that are not actually users of a focal solution principal. This indicates that Procedural Similarity has been overlooked. This dissertation empirically demonstrates that: (a) Procedural Similarity is distinct, (b) Procedural Similarity has a unique effect (separate from the other types of similarity) and (c) the said effect can actually influence a third party (upper-level manager or engineer) that is not even the actual end user. This dissertation, thus, implies that future researchers should include Procedural Similarity in their theorizing of Structural Alignment Theory. Future research on Structural Alignment Theory should consider the influence of Procedural Similarity 
not only on end users but also on others whose conjectures about problem-solving analogies are relevant.

Finally, this dissertation offers implications to literature on Global versus Local Precedence by considering its influence as a moderator between action-oriented, nonvisual spatial, information and subjective belief formations. Previously, Global versus Local Precedence was only considered as a moderator for tasks that were visual and spatial in nature. Furthermore, this dissertation provides evidence that exhibiting a Local Precedence constrains an individual's cognitive processing. Important implications to future research on both Global versus Local Precedence and Structural Alignment Theory in management areas follow. Specifically, research on Global versus Local Precedence could benefit from understanding the extent to which experts in specific domains tend to process information globally. If they do, a plausible explanation is the idea that a Global Precedence does not constrain individuals as much as a Local Precedence does. To use the terms used in the seminal paper on Global versus Local Precedence (Navon, 1977): it is easy enough to look at the 'trees' after one sees the 'forest'; but, once an individual is fixated on the 'trees' it is more difficult to, then, see the big picture of the 'forest'.

Another area that this dissertation offers implications to within literature on Global versus Local Precedence is the recent work that focuses on understanding how Global processing is sparked by situations involving novelty. Förster, Liberman and Shapira, (2009, p. 383) suggest "that expecting novelty induces Global processing". This would help explain why the present research, and extant management literature studying Structural Alignment Theory, consistently find that Structural Similarity is the most impactful to belief formations in the context of entreprenuership. Specifically, because 
technology licensing often involves novelty, thereby inducing experimental participants to expect novelty, respondents in this context are more likely to process information globally. Global processing favors perception of broad categories and impedes processing information about details and narrow categories (Förster et al., 2009). Two implications to future research follow. First, future research that aims to uncover the true effects of Superficial, Structural and Procedural Similarities in entrepreneurship contexts may need to involve scenarios that are less novel than technology licensing to avoid inducing Global information processing. This is important because Global information processing focuses attention on Structural Similarity which is the most broad gestault of the three type of similarity. Alternatively, reseearchers could maniuplate expectations of novelty to examine its effects on the degree to which individuals focus on Structural Similarity when forming Opportunity Beliefs. Second, Global processing may offer insights into why some individuals are better adept at generating novel solutions than others.

Practical Implications. One of the more interesting implications of this dissertation relates to how individuals might think about recognizing new markets in which they can commercialize technologies. Specifically, consider the term 'market innovation' popularized in modern entrepreneurship pedagogy by Furr and Ahlstrom's book (2011), "Nail It Then Scale It". Market innovation, as opposed to the previously more dominant technology innovation, is interested in identifying new markets to commercialize technologies in rather than developing new technologies. Their book, and subsequent pedagogical practices, argues that focus should be placed on identifying problems, or pains, in markets and then finding suitable solutions rather than just on developing solutions (technologies) and then searching for problems to apply them to. 
This dissertation suggests that in addition to focusing on previously unmet or under-met market problems, aspiring entrepreneurs might be able to pursue market innovation through focusing on how end-users interact with technologies. The incumbent method of focusing on problems, is consistent with current trends in entrepreneurship education which are emphasizing that students should focus on identifying un-met market problems or under-served market pains (i.e. problems that are only partially solved or not solved at all), and then generate minimum viable solutions as the seed of their new venture. To my knowledge, however, focusing on how end-users interact with technologies is not as commonly emphasized in entrepreneurship education. It seems that one area that future research and entrepreneurship education ought to focus on is identifying new business opportunities by focusing on how end-users might interact with new products or new versions of products vis-à-vis how they have interacted with previous solutions to their problems/needs, even for problems that are already sufficiently solved.

Another practical implication of this dissertation relates to convincing others that information in an organization's environment, such as a new source of supply, can actually represent an opportunity. The dependent variable of this dissertation is Opportunity Beliefs; these beliefs could theoretically be for anyone, not just oneself. Consider the point made by Dutton and Jackson $(1987 ; 1988)$ that managers' cognitions systematically affect how external information is processed and responded to, and, therefore organizational outcomes. Dutton and Jackson (1987) explain that two managers observing the same environmental changes might label an issue differently; one labeling the environmental issue as an opportunity and one not labeling it as an opportunity. The present research offers insights regarding why this discrepancy in labels might exist, 
thereby providing insights to managers as to how they might be able to convince their counterparts that an environmental issue either is, or is not, and opportunity. Explaining why certain individuals, but not others, discover specific opportunities helps managers understand why others view the same external environment differently. If a manager understands why a counterpart (perhaps another manager in the same firm) disagrees about whether information in their external environment represents and opportunity or not, the manager might be able to help their counterpart focus on certain aspects the environmental information, thereby influencing future perceptions about the environmental information.

\section{Conclusion}

Opportunity Beliefs play a substantial role in the recognition stage of the entrepreneurial process because individuals who encounter the same opportunity ideas may not recognize such ideas as actual opportunities if they do not form positive beliefs about the ideas (e.g., Grégoire \& Shepherd, 2012; Shane \& Venkataraman, 2000). I theorize about constructs at both the individual and opportunity-levels that might influence the formation of Opportunity Beliefs, thereby contributing to the IO entrepreneurship literature.

I provide evidence that opportunities differ with respect to how similar their supply side is with their demand side along 3 similarity dimensions: Superficial, Structural and Procedural. For the first time within management literature, I consider the distinctiveness of Procedural Similarity (from Superficial Similarity), thereby capturing all three steps of analogical problem solving. My results are consistent with Structural 
Alignment Theory's prediction that individuals tend to prefer matches high in similarity over matches low in similarity.

I provide evidence supporting Structural Alignment Theory's prediction that individuals prefer implementation details for solution principles that are tested and proven (new applications of solution principles are high in Procedural Similarity to old applications of the same solution principle). I demonstrate, for the first time, that this effect holds even when the individual is not the actual beneficiary or user of the solution principle thereby contributing back to the original cognitive psychology literature from which Structural Alignment Theory was developed. All other known tests that consider Procedural Similarity have done so from the perspective of the end user (in this context the customer in the market). However, I demonstrate that Procedural Similarity can also influence the formation of beliefs for third party individuals who are considering the degree to which a new supply source fits with and can be feasibly implemented to solve another individuals', or group of individuals', problem(s) (as opposed to the reference individual's direct problem).

Besides providing the first evidence of a direct relationship between Procedural Similarity and Opportunity Recognition for people on average, my study provides evidence that for a certain class of people, Procedural Similarity is particularly meaningful. Specifically, those individuals who tend to process details of information before the configuration of information more heavily rely on the degree of Procedural Similarity in the belief formation process. 


\section{Limitations}

There are some important limitations to keep in mind when considering the implications of this dissertation's results. First, this dissertation only examines one very specific type of opportunity (technology commercialization) and this dissertation operates under the assumption that opportunities exist, waiting to be identified. Scholars have demonstrated that some opportunities are actually created endogenously through the actions of creative individuals or firms (Alvarez \& Barney, 2007). Certainly, this constrains any implications that arise from this dissertation to opportunities that adhere to the assumptions of the IO perspective. That is, some opportunities do not fall within the assumptions set forth by the IO perspective (Alvarez \& Barney, 2007). Opportunities that fall within the creation perspective, for example, "are endogenously generated through process such as creative imagination and effectuation" (Garud \& Giuliani, 2013, p. 158). From the creation perspective, meaning making is not constructed subjectively through conjectures and beliefs but, rather, is part of a relational process that is ongoing (Garud \& Giuliani, 2013). The results herein, then, are unable to say anything about the creation of endogenous opportunities.

A second limitation of this dissertation relates to the degree of match between the participants in the sample and the cases of technology transfer utilized. Specifically, although I tried to include individuals that tend to think about markets, technologies and end-user interactions with products, it is unlikely that the actual individuals in my sample have ever heard of, let alone deeply considered, the cases of technology transfer utilized. This may be a contributing factor as to why Prior Knowledge was not a significant moderator for the newly introduced opportunity difference, Procedural Similarity, 
whereas Prior Knowledge was a significant moderator in Grégoire and Shepherd's (2012) study of Superficial and Structural Similarity. Relatedly, even if the individuals in the sample were familiar with a focal market or technology, they did not spend the amount of time considering a potential opportunity that an individual likely would in real life. The individuals in the sample only took a few minutes to read about and consider each scenario on average. It seems plausible, however, that an individual actually trying to decide if a technology could be profitably applied to a market (feasibility) to solve its problems (fit) would spend considerably more time and resources researching the potential opportunity.

Similar to the above, the third limitation of this dissertation relates to the external validity of the experimental design. The design of the experiment required individuals to evaluate 4 completely unrelated potential opportunities sequentially in a very short period of time. It is very unlikely that an individual would ever evaluate unrelated potential opportunities back-to-back. Although I utilized a Latin-square design to rule out ordering effects associated with evaluating scenarios back-to-back, the generalizability of this experimental design is still limited because individuals are not likely to actually evaluate opportunities in a similar sequential manner.

Finally, although this dissertation studies a dependent construct related to evaluation, namely, Opportunity Beliefs about fit and feasibility, the scope of evaluation studied is quite narrow. Indeed, this dissertation only approaches the question, "Is that an opportunity?" The results herein do not say anything to address another important and related question, "Is that an opportunity for me?" That said, scholars note the importance of both questions and this limitation merely limits the scope of this dissertation's 
contributions to the very early beliefs that individuals might form about a potential opportunity (Shepherd, McMullen, \& Jennings, 2007).

In short, this dissertation contributes to the literature by examining the often ignored, but important, second assumption about opportunities, that they are uncertain. The first assumption in the IO perspective, that opportunities exist waiting to be identified, suggests an inherent level of objectiveness; however, the second assumption, that opportunities are uncertain, brings to light the importance of individuals' subjective perceptions about the objective realities they encounter and the dependent construct of interest here, Opportunity Beliefs. The uncertainty of opportunities demands that theories account for more than just the 'finding' of objective opportunities. As mentioned, opportunities represent the possibility to act, the possibility to do something better to satisfy a market failure in hope of bettering and individual a firm, or society (Grégoire, et al., 2010). This dissertation contributes to this literature stream by providing an additional opportunity level construct, Procedural Similarity, and an additional individual level construct, Global versus Local Precedence, that play a role in the formation of individuals subjective perceptions (what one thinks a market demands, one's perception of what a source can accomplish, etc.) of some objective reality (what a market actually demands, what a source is actually capable of, etc.). Understanding more about the formation of these subjective perceptions, Opportunity Beliefs, is important because it plays a role in determining which opportunities will be recognized and by whom.

\section{Chapter Summary}

In the final chapter of this dissertation, I focus on expounding possible implications associated with the empirical results explained in Chapter 4. I discuss 
individual implications of the results in accordance with the three research questions that this dissertation sought out to answer. The results provide significant contributions that help answer two of the three research questions posed in this study. Specifically, the study provides empirical evidence that Procedural Similarity, a new opportunity difference, influences the formation of the subject Opportunity Beliefs that individuals form about potential markets to commercialize technologies in (research question 1). The results also shed light on the extent to which the new opportunity difference's influence is contingent upon an individual difference (research question 3). However, the results do not say anything with respect to how the new opportunity difference influences known relationships between previously known opportunity differences and Opportunity Beliefs (research question 2). However, there is some evidence that when Procedural Similarity is explicitly considered herein (it was left out of previous studies), Superficial Similarity no longer has a significant influence on Opportunity Beliefs. While this does not indicate that Superficial Similarity does not play a role in how Opportunity Beliefs are formed, it raises questions about research on Superficial Similarity that provides analogies to participants. Specifically, how can a researcher study the effects of Superficial Similarity, which deals with noticing analogies when participants are never asked to notice of think of analogies? These findings imply that it is more likely that the experimental design is the reason Superficial Similarity did not have a significant positive effect on Opportunity Beliefs. This is an important insight, which suggests that it is important to examine these links further. 


\section{REFERENCES}

Ajzen, I. (1985). From intentions to actions: A theory of planned behavior. Springer.

Ajzen, I. (1991). The theory of planned behavior. Organizational behavior and human decision processes , $50(2), 179-211$.

Alba, J. W., \& Hutchinson, J. W. (1987). Dimensions of conumer expertise. Journal of Consumer Research , 17 (4), 411-454.

Alvarez, S. A., \& Barney, J. B. (2007). Discovery and creation: alternative theories of entrepreneurial action. Strategic Entrepreneurship Journal , 1 (1-2), 11-26.

Amir, Y., \& Sharon, L. (1990). Replication research: A "must" for the scientific advancement of psychology. Journal of Social Behavior \& Personality , 5 (4), 5169.

Ardichvili, A., Cardozo, R., \& Ray, S. (2003). A theory of entrepreneurial opportunity identification and development. Journal of Business Venturing , 18 (1), 105-123.

Barney, J. (1991). FIrm resources and sustained competetive advantage. Journal of Management, 17, 99-120.

Baron, R. A. (2004). The cognitive perspective: a valuable tool for answering entrepreneurship's basic "why" questions. Journal of Business Venturing , 19 (2), 221-239. 
Baron, R. A., \& Ensley, M. D. (2006). Opportunity recognition as the detection of meaningful patterns: Evidence from comparisons of novice and experienced entrepreneurs. Management Science, 52 (9), 1331-1344.

Basso, M. R., \& Lowery, N. (2004). Global-local visual biases correspond with visualspatial orientation. Journal of Clinical and Experimental Neuropsychology , 26 (1), 24-30.

Bassok, M. (1990). Transfer of domain-specific problem-solving procedures. Journal of Experimental Psychology: Learning, Memory, and Cognition , 16 (3), 522-533.

Broniarczyk, S. M., \& Alba, J. W. (1994). The role of consumers' intuitions in inference making. Journal of Consumer Research , 21 (3), 393-407.

Busenitz, L. W., \& Barney, J. B. (1997). Differences between entrepreneurs and managers in large organizations: Biases and heuristis in strategic decisionmaking. Journal of Business Venturing , 12 (1), 9-30.

Cardon, M. S., Wincent, J., Singh, J., \& Drnovsek, M. (2005). Entrepreneurial passion: The nature and influence of emotions in entrepreneurship. Academy of Management Papers Proceedings.

Casson, M. (1982). The entrepreneur: An economic theory. Totowa, NJ: Barnes \& Noble Books.

Catrambone, R. (1996). Generalizing solution procedures learned from examples. Journal of Experimental Psychology: Learning, Memory, and Cognition , 22 (4), 1020-1031. 
Catrambone, R., \& Holyoak, K. J. (1989). Overcoming contextual limitations on problem-solving transfer. Journal of Experimental Psychology: Learning, Memory, and Cognition, 15 (6), 1147-1156.

Chen, C. C., Green, P. G., \& Crick, A. (1998). Does entrepreneurial self-efficacy distinguish entrepreneurs from managers? Journal of Business Venturing , 13 (4), 295-316.

Chen, Z. (2002). Analogical problem solving: A heirarchical analysis of procedural similarity. Journal of Experimental Psychology , 28 (1), 81-98.

Chen, Z. (2002). Analogical problem solving: A heirarchical analysis of procedural similarity. Journal of Experimental Psychology , 28 (1), 81-98.

Chen, Z. (1995). Analogical transfer: From schematic pictures to problem solving. Memory and Cognition , 23 (2), 255-269.

Chen, Z. (1996). Children's analogical problem solving: The effects of superficial, structural, and procedural similarity. Jounral of Experimental Child Psychology, $62(3), 410-431$.

Chi, M. (2006). Two approaches to the study of experts' characteristics. In N. Charness, P. Felsovich, \& R. Hoffman, The Cambridge Handbook of Expertise and Expert Performance. Cambridge University Press.

Cropley, A. J. (1999). Creativity and cognition: Producing effective novelty. Roeper Review , 21 (4), 253-260.

Dahlqvist, J., \& Wiklund, J. (2011). Measuring the market newness of new ventures. Journal of Business Venturing , 27 (2), 185-196. 
Davidsson, P. (2007). Strrategies for dealing with heterogeneity in entrepreneurship research. Academy of Management Meeting. Philadelphia.

Davidsson, P. (2003). The domain of entrepreneurship research: some suggestions. In J. A. Katz, \& D. A. Shepherd, Advances in entrepreneurship, firm emergence and growth (Vol. 6, pp. 315-372). Oxford, UK: Elsevier / JAI Press.

Davidsson, P., \& Honig, B. (2003). The role of social and human capital among nascent entrepreneurs. Journal of Business Venturing , 18 (3), 301-331.

Denrell, J., Fang, C., \& Winter, S. G. (2003). The economics of strategic opportunity. Strategic Management Journal , 24 (10), 977-990.

Dew, N., Read, S., Sarasvathy, S. D., \& Wiltbank, R. (2009). Effectual versus predictive logics in entrepreneurial decision-making: Differences between experts and novices. Journal of Business Venturing , 24 (4), 287-309.

Dick, A., Chakravarti, D., \& Biehal, G. (1990). Memory-based inferences during consumer choice. Journal of Consumer Research , 17 (1), 82-93.

Dutton, J. E., \& Jackson, S. E. (1987). Categorizing strategic issues: Links to organizational action. Academy of Management Review , 12, 76-90.

Dutton, J., \& Jackson, S. (1988). Discerning threats and opportunities. Administrative Science Quarterly, 33, 370-387.

Eckhardt, J. T., \& Shane, S. A. (2013). Response to the Commentaries: The individualOpportunity (IO) Nexus Integrates Objective and Subjective Aspects of Entrepreneurship. Academy of Management Review , 38 (1), 160-163. 
Förster, J. (2009). Relations between perceptual and conceptual scope: how global versus local processing fits a focus on similarity versus dissimilarity. Journal of Experimental Psychology: General , 138 (1), 88-111.

Förster, J., Liberman, N., \& Shapira, O. (2009). Preparing for novel versus familiar events: shifts in global and local processing. Journal of Experimental Psychology , $138(3), 383-399$.

Fairlie. (2006). Entrepreneurship among disadvantaged groups: An analysis of the dynamics of self-employment by gender, race and education. In S. Parker, Z. Acs, \& D. Audretsch, Handbook of Entrepreneurship (Vol. 2). Kluwer Academic Publishers.

Festinger, L. (1957). A theory of cognitive dissonance (Vol. 2). Stanford University Press.

Fiet, J. O. (2007). A Prescriptive Analysis of Search and Discovery. Journal of Management Studies , 44 (4), 592-611.

Fiet, J. O. (1996). The informational basis of entrepreneurial discovery. Small Business Economics , 8 (6), 419-430.

Fiet, J. O., Norton Jr., W. I., \& Van Clouse, G. H. (2007). Systematic search as a source of technical innovation: An empirical test. Journal of Engineering and Technology Management, 24 (4), 329-346.

Fishbein, M., \& Ajzen, I. (1975). Belief, attitude, intention and behavior: An introduction to theory and research. Addison-Wesley Publishing Co.

Foo, M. D. (2011). Emotions and entrepreneurial opportunity evaluation. Entrepreneurship Theory and Practice, 35, 375-393.

Foss, N. (2007). Strategic belief management. Strategic Organization , 5 (3), 249-258. 
Furr, N., \& Ahlstrom, P. (2011). Nail It Then Scale It: The Entrepreneur's Guide to Creating and Managing Breakthrough Innovation. Lehi, Utah: NISI Publishing.

Garrison, R. W. (1991). New Classical and Old Austrian Economics: Equilibrium Business Cycle Theory in Perspective. The Review of Austrian Economics , 5 (1), 91-103.

Garud, R., \& Giuliani, A. P. (2013). A Narrative Perspective on Entreprenuerial Opportunities. Academy of Management Review , 38 (1), 157-160.

Geake, J. G. (2009). Neuropsychological characteristics of academic and creative giftedness. In L. Shavinina, International handbook on giftedness. Springer Science.

Gentner, D. (1983). Structure-mapping: A theoretical framework for analogy. Cognitive Science, 7 (2), 155-170.

Gentner, D. (1989). The mechanisms of analogical learning. In S. Vosniadou, \& A. Ortony, Similarity and analogical reasoning (pp. 199-241). Cambridge, U.K.: Cambridge University Press.

Gentner, D., \& Gunn, V. (2001). Structural alignment facilitates the noticing of differences. Memory \& Cognition, 29 (4), 565-577.

Gentner, D., \& Markman, A. B. (2005). Defining structural similarity. Journal of Cognitive Science, 6 (1), 1-20.

Gentner, D., \& Markman, A. B. (1997). Structure mapping in analogy and similarity. 52 (1), 45-56. 
Gentner, D., Rattermann, M. J., \& Forbus, K. D. (1993). The Roles of Similarity in Transfer: Seperating Retreivability from Inferential Soundness. Cognitive Psychology, 25 (4), 524-575.

Gick, M. L., \& Holyoak, K. J. (1980). Analogical problem solving. Cognitive Psychology , $12(3), 306-355$.

Gimeno, J., Folta, T. B., Cooper, A. C., \& Woo, C. Y. (1997). Survival of the fittest? Entrepreneurial human captial and the persistence of underperforming firms. Administrative Science Quarterly, 42 (4), 750-783.

Goldstone, R. L. (1994). The role of similarity in categorization: Providing a groundwork. Cognition, 52 (2), 125-157.

Gompers, P., Kovner, A., Lerner, J., \& Scharfstein, D. (2010). Performance persistence in entreperneurship. Journal of Financial Economics , 96 (1), 18-32.

Goswami, U., \& Brown, A. L. (1990). Higher-order structura and relational reasoning: Contrasting analogical and thematic relations. Cognition , 36 (3), 207-226.

Grégoire, D. A., \& Shepeherd, D. A. (2012). Technology-Market Combinations and the Identification of Entrepreneurial Opportunities: An Investigation of the Opportunity-Individual Nexus. Academy of Management Journal , 55 (4), 753 786.

Grégoire, D. A., Barr, P. S., \& Shepherd, D. A. (2010). Cognitive processes of opportunity recognition: The role of structural alignment. Organization Science, $21(2), 413-431$. 
Grégoire, D. A., Shepherd, D. A., \& Lambert, L. S. (2010). Measuring OpportunityRecognition Beliefs: Illustrating and Validating an Experimental Approach. Organizational Research Methods , 13 (1), 114-145.

Gruber, M., MacMillan, I. C., \& Thompson, J. D. (2012). Escaping the Prior Knowledge Corridor: What Shapes the Number and Variety of Market Opportunities Identified before Market Entry of Technology Start-ups? Organization Science, doi: 10.1287/orsc.1110.0721 .

Hambrick, D. C., \& Mason, P. A. (1984). Upper echelons: The organization as a reflection of its top managers. Academy of Management Review , 9 (2), 193-206.

Hargadon, A. B., \& Bechky, B. A. (2006). When collections of creatives become creative collectives: A field study of problem solving at work. Organization Science , 17 (4), 484-500.

Harris, R. J. (1981). Inferences in information processing. The Psychology of Learning and Motivation , 15, 81-128.

Hastie, R. (2001). Problems for judgement and decision making. Annual Review of Psychology, 52 (1), 653-683.

Hayek, F. A. (1948). Individualism and economic order. London: Routledge and Kegan Paul.

Haynie, J. M., Shepherd, D. A., \& McMulling, J. S. (2009). An opportunity for me? The role of resources in opportunity evaluation decisions. Journal of Management Studies , 46 (3), 337-361. 
Haynie, M., \& Shepherd, D. A. (2009). A measure of adaptive cognition for entrepreneurship research. Entrepreneurship Theory and Practice , 33 (3), 695714.

Holland, J. H., Holyoak, K. J., Nisbett, R. E., \& Thagard, P. (1986). Induction: Processes of inference, learning, and discovery. Cambridge: MA: Bradford/MIT Press.

Holland, J. H., Holyoak, K. J., Nisbett, R. E., \& Thagard, P. (1986). Induction: Processes of Inference, Learning, and Discovery. Cambridge, MA: MIT Press.

Holyoak, K. H., \& Koh, K. (1987). Surface and structural similarity in analogical transfer. Memory \& Cognition , 15 (4), 332-340.

Hseih, C., Nickerson, J. A., \& Zenger, T. R. (2007). Opportunity discovery, problem solving and a theory of the entrepreneurial firm. Journal of Management Studies , $44(7), 1255-1277$.

Hubbard, R., Vetter, D. E., \& Little, E. L. (1998). Replication in strategic management: Scientific testing for validity, generalizability, and usefulness. Strategic Management Journal , 19 (3), 243-254.

Kahneman, D., \& Tversky, A. (1979). Prospet theory: An analysis of decision under risk. Econometrica: Journal of Econometric Society , 47 (2), 263-291.

Kaish, S., \& Gilad, B. (1991). Characteristics of opportunities search of entrepreneurs versus executives: Sources, interests, general alterness. Journal of Business Venturing , $6(1), 45-61$.

Keane, M. T., Ledgeway, S., \& Duff, S. (1994). Constraints on analogical mapping: A comparison of three models. Cognitive Science, 18, 387-438. 
Kihlstrom, R. E., \& Laffont, J. J. (1979). A general equilibrium entrepreneurial theory of firm formatoni based on risk aversion. The Journal of Political Economy , 87 (4), 719-748.

Knight, F. H. (1921). Risk, uncertainty, and profit. New York, NY: Houghton Mifflin Co. Krueger, N. F., Reilly, M. D., \& Carsrud, A. L. (2000). Competing models of entrepreneurial intentions. Journal of Business Venturing , 15 (5-6), 411-432.

Logan, G. D. (1990). Repetition priming and automaticity: Common underlying mechanisms? Cognitive Psychology , 22 (1), 1-35.

Louviere, J. J. (1994). Analyzing decision making: Metric conjoing analysis. Beverly Hills, CA: Sage Publications, Inc.

Magro, A. M., \& Nutter, S. E. (2012). Evaluating the Strength of Evidence: How Experience Affects the Use of Analogical Reasoning and Configural Information Processing in Tax. The Accounting Review , 87 (1), 291-312.

Markman, A. B., \& Gentner, D. (1993). Structural alignment during similarity comparisons. Cognitive Psychology , 25, 431-467.

Markman, A. B., \& Loewenstein, J. (2010). Structural comparison and consumer choice. Journal of Consumer Psychology, 10 (2), 126-137.

Markman, G. D., Siegel, D. S., \& Wright, M. (2008). Research and technology commercialization. Journal of Management Studies , 45 (8), 1401-1423.

McCoach, D. B. (2010). Heirarchical linear modeling. In G. Hancock, \& R. Mueller, The reviewer's guide to quantitative methods in the social sciences. Routledge. 
McCoach, D. B., \& Adelson, J. L. (2010). Dealing With Dependence (Part I): Understanding the Effects of Clusterd Data. Gifted Child Quarterly, 54 (2), 152155.

McCoach, D. B., Madura, J. P., Rambo-Hernandez, K. E., O'Connell, A. A., \& Welsh, M. E. (2013). Longitudinal Data Analysis. In D. B. McCoach, J. P. Madura, K. E. Rambo-Hernandez, A. A. O'Connell, \& M. E. Welsh, Handbook of Quantitative Methods for Educational Research (pp. 199-230). SensePublishers.

McCoach, D., O'Connell, A., \& Levitt, H. (2006). Ability grouping across kindergarten using an Early Childhood Longitudinal Study. Journal of Educational Research, $99(3), 339-346$.

McMullen, J. S., \& Shepherd, D. A. (2006). Entrepreneurial action and the role of uncertainty in the theory of the entrepreneur. Academy of Management Review , $31(1), 132-152$.

Miller, G. A. (1956). The magical number sevel, plus or minus two: some limits on our capacity for processing information. Psychological Review , 63 (2), 81-97.

Mueller, B. A. (2011). Teaching an individual to fish: The influence of expert opportunity identification process modeling on aspiring entrepreneurs. $A A T$ 3488102, 165. ProQuest Dissertations \& Theses.

Namy, L. L., \& Gentner, D. (2002). Making a Silk Purse Out of Two Sow's Ears: Young Children's Use of Comparison in Category Learning. Journal of Experimental Psychology, 131 (1), 5-15.

Navon, D. (1977). Forest before trees: The precedence of global features in visual perception. Cognitive Psychology, 9 (3), 353-383. 
North, D. C. (2006). Understanding the process of economic change. Academic Foundation.

Novick, L. R., \& Holyoak, K. J. (1991). Mathematical problem solving by analogy. Journal of Experimental Psychology: Learning, Memory, and Cognition , 17 (3), 398-415.

Oliver, R. L., \& Winer, R. S. (1987). A framework for the formation and structure of consumer expectations: Review and propositions. Journal of Economic Psychology, 8 (4), 469-499.

Ozgen, E., \& Baron, R. A. (2007). Social sources of information in opportunity recognition: Effects of mentors, industry networks, and professional forums. Journal of Business Venturing , 22 (2), 174-192.

Perfetto, G. A., Bransford, J. D., \& Franks, J. J. (1983). Constraints on access in a problem solving context. Memory \& Cognition , 11 (1), 24-31.

Podsakoff, P. M., MacKenzie, S. B., Lee, J. Y., \& Podsakoff, N. P. (2003). Common method biases in behavioral research: a critical review of the literature and recommended remedies. Journal of Applied Psychology , 88 (5), 879-903.

Raudenbush, S. W., Bryk, A. S., Cheong, Y. F., Congdon, R. T., \& duToit, M. HLM 7: Heirarchical Linearand Nonlinear Modeling. Illinois: Scientific Software International, Inc.

Reed, S. K., \& Bolstad, C. A. (1991). Use of examples and procedures in problem solving. Journal of Experimental Psychology: Learning, Memory, and Cognition, $17(4), 753-766$. 
Roehm, M. L., \& Stenthal, B. (2001). The moderating effect of knowledge and resources on the persuasive impact of analogies. Journal of Consumer Research , 28 (2), 257-272.

Santos, F. M., \& Eisenhardt, K. M. (2000). Constructing markets and shaping boundaries: Entrepreneurial power in nascent fields. Academy of Management Journal , 43 (6), 1248-1264.

Sarasvathy. (2008). Effectuation: Elements of entrepreneurial expertise. Northampton, MA: Edward Elgar Publishing.

Scandura, T. A., \& Williams, E. A. (2000). Research Methodology in Management: current practices, trends, and implications for future research. Academy of Management Journal , 43 (6), 1248-1264.

Shane, S. (2000). Prior knowledge and the discovery of entrepreneurial opportunities. Organization Science, 11 (4), 448-469.

Shane, S., \& Venkataraman, S. (2000). The promise of entrepreneurship as a field of research. Academy of Management Review , 25 (1), 217-226.

Shepherd, D. A. (2011). Multilevel entrepreneurship research: Opportunities for studying entrepreneurial decision making. Journal of Management, 37 (2), 412-420.

Shepherd, D. A., \& DeTienne, D. R. (2004). Prior knowledge, potential financial reward, and opportunity identification. Entrepreneurship Theory and Practice , 29 (1), 91112.

Shepherd, D. A., \& Zacharakis, A. (1999). Conjoint Analysis: A new methodological approach for researching the decision policies of venture capitalists. Venture Capital: An International Journal of Entrepreneurial Finance , 1 (3), 197-217. 
Shepherd, D. A., McMullen, J. S., \& Jennings, P. D. (2007). The formation of opportunity beliefs: Overcoming ignorance and reducing doubt. Strategic Entrepreneurship Journal , 1 (1-2), 75-95.

Tierney, P., \& Farmer, S. M. (2002). Creative self-efficacy: Its potential antecedants and relationship to creative performance. Academy of Management Journal , 45 (6), 1137-1148.

Ucbasaran, D., Westhead, P., \& Wright, M. (2008). Opportunity identification and pursuit: does and entrepreneur's human capital matter? Small Business Economics , $30(2), 153-173$.

Walsh, J. P., \& Fahey, L. (1986). The role of negotiated belief structures in strategy making. Journal of Management , 12 (3), 325-338.

Ware, H. W., \& Kitsantas, A. (2011). Predicting Teacher Commitment Using Principal and Teacher Efficacy Variables: An HLM Approach. The Journal of Educational Research, 104 (3), 183-193.

Welpe, I. M., Spörrle, M., Grichnick, D., Michl, T., \& Audretsch, D. B. (2012). Emotions and opportunities: The interplay of opportunity evaluation, fear, joy, and anger as antecedent of entrepreneurial exploitation. Entrepreneurship Theory and Practice , 36, 69-96.

William, D. W. (2010). Why do different new ventures internatinalize differently? A cognitive model of entrepreneur internationalization decision. Unpublished Dissertation, Georgia State University . 
Zhang, S., \& Fitzsimons, G. J. Choice-process satisfaction: The influence of attributed alignability and option limiation. Organizational Behavior and Human Decision Processes , 77 (3), 192-214. 


\section{APPENDIX 1: DEPENDENT, INDEPENDENT, MODERATING AND PRIMARY CONTROL VARIABLES}

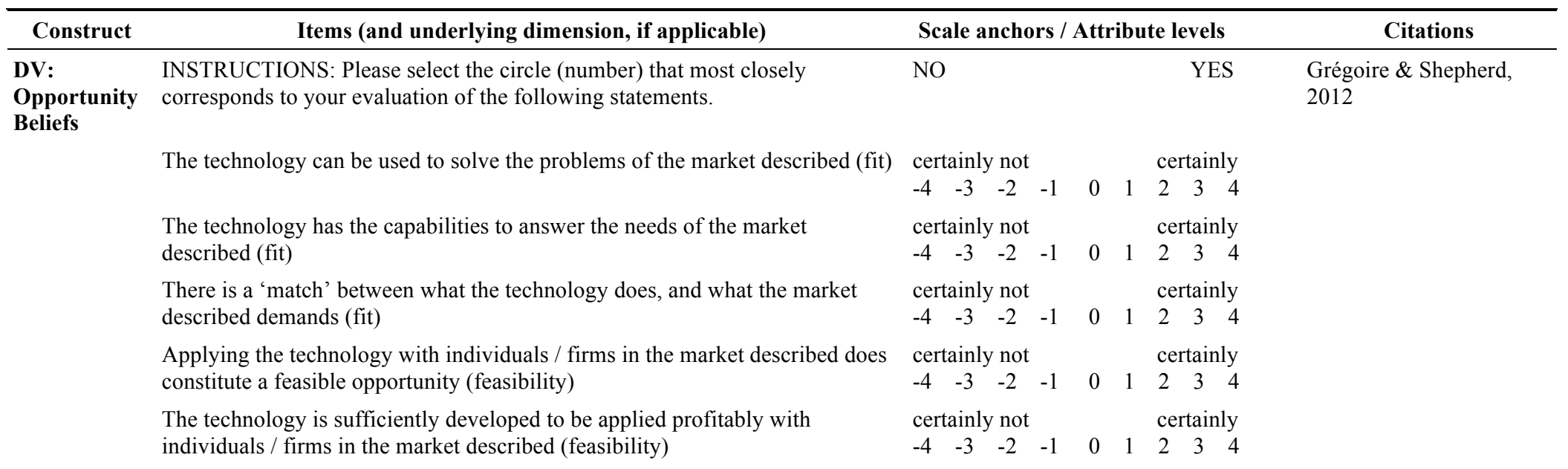

IVs: $\quad$ Full factorial experimental design captures all 8 possible scenarios $\left(2^{3}=8\right)$

Opportunity

Differences

Superficial similarity

Structural similarity

Procedural similarity

Moderator: INSTRUCTIONS: Please select the circle (number) that most closely Individual
INSTRUCTIONS: Please select the circle (number) that most closely
corresponds to your level of Prior Knowledge for each of the following:
2 levels (high / low)

2 levels (high / low)

2 levels (high / low)

MINIMAL

CONSIDERABLE
Grégoire \& Shepherd, 2012

Grégoire \& Shepherd, 2012

Chen, 2002

Grégoire \& Shepherd, 2012 


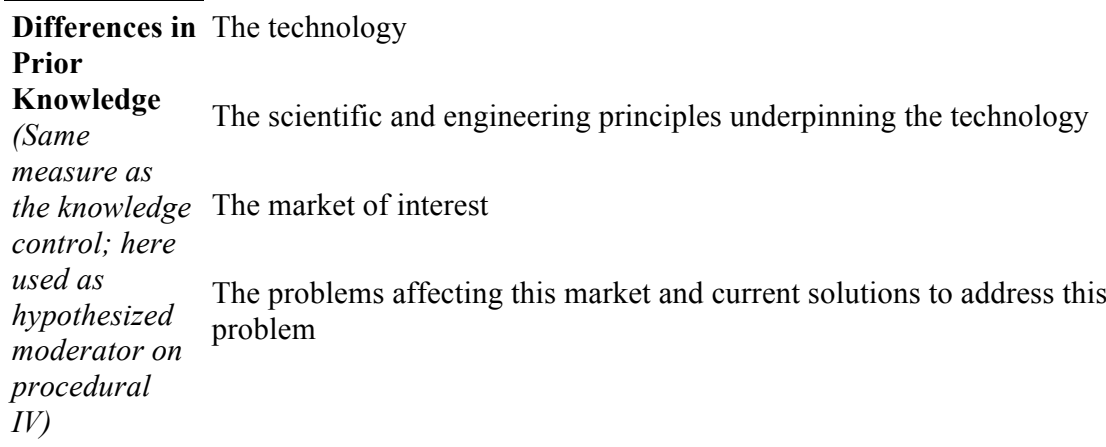

Knowledge

(Same

The scientific and engineering principles underpinning the technology

measure as

the knowledge The market of interest

control; here

used as

hypothesized

moderator on

The problems affecting this market and current solutions to address this problem

procedural

IV)

Moderator: INSTRUCTIONS: You will be shown 3 images for a brief moment; using the Individual top image as the standard, please select one of the bottom 2 images (left or

Differences in right) which you feel mostly closely matches the top image.

Global versus

Local

Precedence

NOTE: participants are presented with 16 screens containing 'Navon Tasks'. If LOCAL

\begin{tabular}{|c|c|c|c|}
\hline \multicolumn{2}{|l|}{ minimal } & & considerable \\
\hline 12 & 3 & 4 & 67 \\
\hline \multicolumn{3}{|l|}{ minimal } & considerable \\
\hline 2 & 3 & 4 & 5 \\
\hline \multicolumn{3}{|l|}{ minimal } & considerable \\
\hline 2 & 3 & 4 & 5 \\
\hline i. & & & considera \\
\hline 2 & 3 & 4 & 5 \\
\hline
\end{tabular}

a score of 16 ; however, if a participant selects none of the images based on

Global configuration (instead selecting on the basis of Local components), they

are given a score of 1 .

\begin{tabular}{|c|c|}
\hline $\begin{array}{l}\text { Control: } \\
\text { Individual }\end{array}$ & $\begin{array}{l}\text { INSTRUCTIONS: Please select the circle (number) that most closely } \\
\text { corresponds to your level of Prior Knowledge for each of the following: }\end{array}$ \\
\hline $\begin{array}{l}\text { ifferences in } \\
\text { rior } \\
\text { nowledge }\end{array}$ & The technology \\
\hline $\begin{array}{l}\text { (Same } \\
\text { measure as }\end{array}$ & The scientific and engineering principles underpinning the technology \\
\hline $\begin{array}{l}\text { the knowledge } \\
\text { moderator; }\end{array}$ & The market of interest \\
\hline $\begin{array}{l}\text { here used as } \\
\text { control on } \\
\text { Superficial } \\
\text { and Structural } \\
\text { IVs) }\end{array}$ & $\begin{array}{l}\text { The problems affecting this market and current solutions to address this } \\
\text { problem }\end{array}$ \\
\hline
\end{tabular}

\begin{tabular}{|c|c|c|c|}
\hline MINIMA & & & SIDERABLE \\
\hline minimal & & & considerable \\
\hline 12 & 3 & 4 & $\begin{array}{lll}5 & 6 & 7\end{array}$ \\
\hline minimal & & & considerable \\
\hline 12 & 3 & 4 & 5 \\
\hline minimal & & & considerable \\
\hline 2 & 3 & 4 & 5 \\
\hline nimal & & & considerable \\
\hline 2 & 3 & 4 & 56 \\
\hline
\end{tabular}

Control:

INSTRUCTIONS: Please indicate the extent to which you agree with each of

Completely

Completely

Navon, 1977; Basso \&

Lowery, 2004

Grégoire \& Shepherd, 2012 
Individual the following statements.

Differences in

Creative /

Innovative I have a knack for developing new venture ideas.

Self-Efficacy I am good at developing new products and services.

I have a knack for developing new markets and territories.

I am good at generating novel ideas.

I have a knack for further developing ideas of others.

Control: $\quad$ Please indicate your intention to start another new firm within the next five

Individual years.

Differences in

Intentions
Disagree

Agree 2002; Grégoire \&

Shepherd, 2012

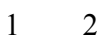

2

4

234

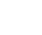

I certainly will not
I certainly will Krueger, Reilly, \&

$\begin{array}{lllll}6 & 7 & 8 & 9 & \text { Carsrud, 2000; Grégoire }\end{array}$ \& Shepherd, 2012

${ }^{1}$ For a complete set of the Navon Tasks used for this construct, please contact the author. 


\section{APPENDIX 2: SCENARIOS}

\section{SOAR Technology Scenario Descriptions}

\section{Market Stimulus 1: everyone sees this market stimulus \\ Heading to show participants: Is there a way to tailor education for each student?}

There are many approaches to teaching visual and experimental science domains, such as physics. Educators now believe that children have unique learning styles (individuals' natural patterns of acquiring and processing information in learning situations). Furthermore, educators believe that learning tasks that are highly visual or experimental in nature, such as physics, should be tailored to fit each student's particular learning style.

At present, most educators do not have a systematic method for identifying what students' learning styles are. A growing number of educators are looking for viable tools to help them identify students' learning styles and, subsequently, tailor learning tasks to match.

"If I license SOAR technology," says Dr. Mike van Lent, "I plan to embed it as a tutor in a computer game in which students play electric field hockey to tailor physics education. Instead of playing against an opponent, students will strategically place electric charges on a screen to cause a unit-charge particle, or puck, to move around obstacles. SOAR simply watches and observes differences between what the student does and what the SOAR tutor would have done if it had participated. By observing a student, SOAR begins to learn a student's learning style and can then customize the next task."

Technology Stimulus 1.1: 25\% see this technology stimulus (High Superficial / High Structural)

Heading to show participants: Stanford to customize foreign language education.

Stanford University is proud to announce that it has developed a new technology called SOAR that could revolutionize the way that young children learn a second language. The technology was developed as a joint project between Stanford's Departments of Adolescent Psychiatry and Artificial Intelligence Engineering to help educators understand the learning styles of children so that their second language education can be tailored to each individual.

SOAR is a software application that uses a sophisticated set of algorithms to understand the learning styles of individuals through the interaction between humans and computers. SOAR catalogs each user's unique set of characteristics and customizes user experiences accordingly.

Low Procedural Similarity (50\% of group see this)

The software has been integrated into computer-based games for young children. Children play against a simulated SOAR agent who talks with the child throughout the game in the foreign language. The SOAR player actually talks with a child as it participates in the game against the child; it can react to changes in a child's behavior or voice pattern to tailor
High Procedural Similarity (50\% of group see this)

The software has been integrated into computer-based games for young children. There is no opponent in the games; rather, children use voice commands spoken in the foreign language to navigate a car around obstacles while a SOAR agent observes. The SOAR agent watches the child and can react to changes in the trainee's behavior or voice pattern to 
Technology Stimulus 1.2: 25\% see this technology stimulus (Low Superficial / High Structural) Heading to show participants: University of Michigan teams up with retired pilots to help train combat pilots.

The University of Michigan is proud to announce that it has developed new training technology called SOAR that could revolutionize the way military combat pilots are trained. The artificial intelligence technology was developed as a joint project with the Special Operations Aviation Regiment of the U.S. military to help understand individual trainees learning styles, preferences, and tendencies.

SOAR is a software application that uses a sophisticated set of algorithms to understand the learning styles of individuals through the interaction between humans and computers. SOAR catalogs each user's unique set of characteristics and customizes user experiences accordingly.

Low Procedural Similarity (50\% of group see this)

The software has been integrated into the U.S. Military's fixed-wing aircraft training simulators. Trainees practice combat against simulated SOAR agents; the SOAR agents actually participate in the combat against the trainee and can react to changes in the environment and changes in the trainees behavior by re-prioritizing their objectives as a human enemy would.
High Procedural Similarity (50\% of group see this)

The software has been integrated into the U.S. Military's fixed-wing aircraft training simulators. There is no opponent in the simulations; rather, trainees navigate around obstacles while a SOAR agent observes. The SOAR tutor watches the trainee and can react to changes in the trainee's behavior or voice pattern to detect preferences, learning styles, etc.

Technology Stimulus 1.3: 25\% see this technology stimulus (High Superficial / Low Structural)

Heading to show participants: Stanford to customize foreign language education.

Stanford University is proud to announce that it has developed a new technology called SOAR that could revolutionize the way that young children learn a second language. The technology was developed as a joint project between Stanford's Departments of Adolescent Psychiatry and Artificial Intelligence Engineering to help make second language training more realistic.

SOAR is a software application that acts like a human because it is capable of adapting to changes in the environment, such as nationality, or others behavior to make foreign language training more realistic.

Low Procedural Similarity (50\% of group see this)

The software has been integrated into computer-based games for young children. Children play against a simulated SOAR agent who talks with the child throughout the game in the foreign language. The SOAR player actually talks with a child and behaves like a native of the country's language the child is learning, making the training more realistic.
High Procedural Similarity (50\% of group see this)

The software has been integrated into computer-based games for young children. There is no opponent in the games; rather, children use voice commands in the foreign language to navigate a car around obstacles while a SOAR agent observes. The SOAR agent watches the child and can react to changes in the trainee's behavior or voice pattern to adjust the environment and obstacles to be more realistic.

Technology Stimulus 1.4: 25\% see this technology stimulus (Low Superficial / Low Structural)

Heading to show participants: University of Michigan teams up with retired pilots to help train combat pilots.

The University of Michigan is proud to announce that it has developed new training technology called SOAR that could revolutionize the way military combat pilots are trained. The artificial intelligence technology was developed as a joint project with the Special Operations Aviation Regiment of the U.S. military to make combat training more realistic. 
SOAR is a software application that acts like a human because it is capable of adapting to changes in the environment or others behavior--by altering the priority of its objectives, for example--to make military training more realistic.

Low Procedural Similarity (50\% of group see this)

The software has been integrated into the U.S. Military's fixed-wing aircraft training simulators. Trainees practice combat against simulated SOAR agents; the SOAR agents actually participate in the combat against the trainee and can react to changes in the environment and changes in the trainees behavior by re-prioritizing their objectives as a human enemy High Procedural Similarity (50\% of group see this) would.

The software has been integrated into the U.S. Military's fixed-wing aircraft training simulators. There is no opponent in the simulations; rather, trainees navigate around obstacles while a SOAR agent observes. The SOAR tutor watches the trainee and can react to changes in the trainee's behavior or voice pattern to adjust the environment and obstacles to be more realistic.

\section{Texel Camera Technology Scenario Descriptions}

Market Stimulus 2: everyone sees this market stimulus

Heading to show participants: Will future video games include realistic versions of famous scenes and buildings?

Video game producers are always looking for ways to make games more realistic. However, transferring reality into a digital format is still a complex issue with imperfect results.

At present there is not a way to exactly replicate a real scene into a digital space. Instead, developers rely on the ability of engineers to add depth to $2 \mathrm{D}$ high definition photos. A growing number of developers are looking for a way to make video games more realistic, more efficiently.

"If I license Texel camera technology," says Chris Brooks, "I plan to mount the Texel camera on a tripod and scan famous scenes and buildings from multiple viewing angles. This will allow our developers to know exact specifications and dimensions so they can generate a digital copy, giving players the experience of actually being in a famous building with accurate dimensions."

Technology Stimulus 2.1: 25\% see this technology stimulus (High Superficial / High Structural)

Heading to show participants: Pixar to bring animation closer to reality.

Pixar, the developer of the popular animated films such as Toy Story, is proud to announce a new Texel camera that fuses digital imagery with depth information via Lidar lasers for use in developing animated scenes.

The camera emits laser pulses and clocks the amount of time it takes the pulses to be reflected off objects and return to the camera. "This is what lidar technology has going for it," said Pixar executive Ed Catmul, "the ability to know every detail of an area's dimensions so you can accurately and realistically re-generate it in a digital space."

Low Procedural Similarity (50\% of group see this)

Digital images, taken beforehand using a regular digital camera, are uploaded to the Texel camera; the camera is then taken to the scene and lined up to try and match the digital image so it can assess depth and size
High Procedural Similarity (50\% of group see this)

The camera scans a building or scene from multiple viewing locations; each time, light is sent in to the scene and the camera simultaneously takes digital photographs and captures depth and size measurements via lasers. 
measurements. This allows developers to obtain actual depth and size of a space and objects in it to use in digital frames.
This allows developers to obtain actual depth and size of a space and objects in it to use in digital frames

Technology Stimulus 2.2: 25\% see this technology stimulus (Low Superficial / High Structural)

Heading to show participants: Utah State University is changing the way we build cities.

Utah State University is proud to announce that one of its civil engineers, Dr. Bob Pack, has developed a new Texel camera that fuses digital imagery with depth information via Lidar lasers for use in city and construction planning.

The camera emits laser pulses and clocks the amount of time it takes the pulses to be reflected off objects and return to the camera. "This is what Lidar technology has going for it," said Dr. Pack, "the ability to know every detail of an area before you start building saves both time and money, as there are fewer surprises."

Low Procedural Similarity (50\% of group see this)

Digital images, taken beforehand using a regular digital camera, are uploaded to the Texel camera; the camera is then taken to the scene and lined up to try and match the digital image so it can assess depths via lasers. This allows civil engineers to obtain a digital image with exact building specifications so they can pre-fabricate a replacement (e.g., a new highway bridge) offsite.
High Procedural Similarity (50\% of group see this)

The camera helps building planners by scanning a building area (scene) from multiple locations and angles before construction, simultaneously taking digital photographs and assessing depths via lasers. This allows civil engineers to obtain a digital image with exact building specifications so they can pre-fabricate a replacement (e.g., a new highway bridge) offsite.

Technology Stimulus 2.3: 25\% see this technology stimulus (High Superficial / Low Structural)

Heading to show participants: Pixar to bring animation closer to reality.

Pixar, the developer of the popular animated films such as Toy Story, is proud to announce a new Texel camera that fuses digital imagery with depth information via Lidar lasers for use in developing animated scenes.

The camera emits laser pulses and clocks the amount of time it takes the pulses to be reflected off objects and return to the camera. "This is what Lidar technology has going for it," said Pixar executive Ed Catmul, "the ability to measure light movements and diffractions so that we can make animations have realistic lighting and shadowing."

Low Procedural Similarity (50\% of group see this)

Digital images, taken before-hand using a regular digital camera, are uploaded to the Texel camera; the camera is then taken to the scene and lined up to try and match the digital image so it can assess lighting reflection and diffraction. This allows developers to obtain actual measurements of light reflection and diffraction to use in animation
High Procedural Similarity (50\% of group see this)

The camera scans a building or scene from multiple viewing locations; each time, light is sent in to the scene and the camera simultaneously takes digital photographs and measures reflection and diffraction of light in the digital photograph. This allows developers to obtain actual measurements of light reflection and diffraction to use in animation.

Technology Stimulus 2.4: 25\% see this technology stimulus (Low Superficial / Low Structural)

Heading to show participants: Utah State University is changing the way we build cities.

Utah State University is proud to announce that one of its civil engineers, Dr. Bob Pack, has developed a new Texel camera that fuses digital imagery with depth information via Lidar lasers for use in city and construction planning.

The camera emits laser pulses and clocks the amount of time it takes the pulses to be reflected off objects and return to the camera. "This is what Lidar 
technology has going for it," said Dr. Pack, "the ability to measure light movements and diffractions so that we can plan for optimal lighting and shadowing in new builds."

Low Procedural Similarity (50\% of group see this)

Digital images, taken before-hand using a regular digital camera, are uploaded to the Texel camera; the camera is then taken to the scene and lined up to try and match the digital image so it can assess lighting reflection and diffraction. This allows developers to obtain actual measurements of light reflection and diffractions to use in planning lighting when designing a building or park, for example.
High Procedural Similarity (50\% of group see this)

The camera scans a building or scene from multiple viewing locations; each time, light is sent in to the scene and the camera simultaneously takes digital photographs and measures reflection and diffraction of light in the digital photograph. This allows developers to obtain actual measurements of light reflection and diffractions when designing a building or park, for example.

\section{Measurement Acquisition Technology Scenario Descriptions}

Market Stimulus 3: everyone sees this market stimulus

Heading to show participants: Can boaters check for water in their fuel before leaving the dock?

Recreational boat owners can be left stranded in open water if their fuel tank has water in it.

Boat owners are looking for alternatives to existing fuel-level monitoring systems because most only measure levels of fluid (not whether or not there is water in the fuel), and the few that can measure water levels only do so as fuel comes into the engine so boaters will not know there is a problem until they are stranded in open water.

"We believe that this technology answers the critical question about water in the tank for boaters before they leave the dock," says Tidewaters Sensors co-founder, Doug Taylor; "we embedded the technology into a linear fuel probe that has two parallel conductors which are simply submerged into an existing fuel tank. The inductors transmit a signal wirelessly to a sensor attached to boats' existing fuel gauges."

Technology Stimulus 3.1: 25\% see this technology stimulus (High Superficial / High Structural)

Heading to show participants: Yamaha Motor Company revolutionizes fluid measurement in recreational vehicles.

Yamaha Motor Company is proud to announce its new measurement acquisition technology that measures type of fluid, not just amount fluid which was a major shortcoming of traditional measurement systems; Yamaha will incorporate the technology into recreational vehicles.

The new measurement technology relies on passive inductors to measure more than just fluid levels; the inductors can automatically re-calibrate for any type of fluid, allowing ATV riders, for example, to check their fuel to make sure it doesn't contain water or other contaminants before venturing out.

Low Procedural Similarity (50\% of group see this)

The technology is embedded into the sides of fluid containers. The inductors placed in the sides of a fluid container need to be parallel. Because the inductors are on the sides of the container, they reach all levels of the fuel to detect water or other contaminants before they reach
High Procedural Similarity (50\% of group see this)

The technology is embedded into a linear probe that has two parallel inductors which are submerged into existing fluid vessels on old aircraft. The probe can extend all the way to the bottom of a fuel tank to detect water or other contaminants before they reach the engine and wirelessly 
the engine and then transmit signals to antennae that are attached to fuel gauges.

Technology Stimulus 3.2: 25\% see this technology stimulus (Low Superficial / High Structural)

Heading to show participants: NASA to make old aircraft safer.

NASA's Langley Research Center is proud to announce its new measurement acquisition technology that measures type of fluid, not just amount fluid which was a major shortcoming of traditional measurement systems; the technology will be used to retrofit aging aircraft.

The new measurement technology relies on passive inductors to measure more than just fluid levels; the inductors can automatically re-calibrate for any type of fluid, allowing pilots to check their fuel to make sure it doesn't contain water or other contaminants before take off.

Low Procedural Similarity (50\% of group see this)

The technology is embedded into the sides of fluid vessels. The inductors placed in the sides of a fluid container need to be parallel. Because the inductors are on the sides of the container, the wires can be attached to the outside of the container (rather than in the fluid) to transmit signals to an airplane's gauges.

Technology Stimulus 3.3: 25\% see this technology stimulus (High Superficial / Low Structural)
High Procedural Similarity (50\% of group see this)

The technology is embedded into a linear probe that has two parallel inductors which are submerged into existing fluid vessels on old aircraft. The probe can wirelessly transmit signals to antennae that are attached to an airplane's gauges. Heading to show participants: Yamaha Motor Company revolutionizes fluid measurement in recreational vehicles.

Yamaha Motor Company is proud to announce its new measurement acquisition technology that alleviates many dangerous shortcomings of traditional measurement systems; the technology will be used in recreational vehicles.

The new measurement technology relies on passive inductors to measure fluid levels thereby avoiding the dangerous shortcomings of traditional systems; namely, electrical arcing and wire degradations due to wear or chemical decay, which can lead to fires or other dangerous problems for recreational riders.

Low Procedural Similarity (50\% of group see this)

The technology is embedded into the sides of fluid vessels. The inductors placed in the sides of a fluid container need to be parallel. Because the inductors are on the sides of the container, the wires can be attached to the outside of the container (rather than in the fluid) to transmit signals to fuel gauges.

Technology Stimulus 3.4: 25\% see this technology stimulus (Low Superficial / Low Structural)

Heading to show participants: NASA to make old aircraft safer.

NASA's Langley Research Center is proud to announce its new measurement acquisition technology that alleviates many dangerous shortcomings of traditional measurement systems' the technology will be used to retrofit aging aircraft.

The new measurement technology relies on passive inductors to measure fluid levels thereby avoiding the dangerous shortcomings of traditional systems; namely, electrical arcing and wire degradations due to wear or chemical decay, which has led to the downing of TWA Flight 800 and Swissair Flight 111 and several space shuttle delays. The inductors can also automatically re-calibrate for various fluid types allowing use for all fluids that
High Procedural Similarity (50\% of group see this)

The technology is embedded into a linear probe that has two paralle inductors which are submerged into existing fluid vessels on old aircraft. The probe can wirelessly transmit signals to antennae that are attached to fuel gauges. 
aircraft use.

Low Procedural Similarity (50\% of group see this)

The technology is embedded into the sides of fluid vessels. The inductors placed in the sides of a fluid container need to be parallel. Because the inductors are on the sides of the container, the wires can be attached to the outside of the container (rather than in the fluid) to transmit signals to an airplane's gauges.
High Procedural Similarity (50\% of group see this)

The technology is embedded into a linear probe that has two parallel inductors which are submerged into existing fluid vessels on old aircraft. The probe can wirelessly transmit signals to antennae that are attached to an airplane's gauges.

\section{Infrared Scanning Technology Scenario Descriptions}

\section{Market Stimulus 4: everyone sees this market stimulus \\ Heading to show participants: Can infrared scanning make Lasik evaluations quicker and more accurate?}

Abbots is proud to announce its new iLASIK laser surgery diagnostics machine that quickly and accurately identifies distortions on the surface of eyes and develops a digital map of how to correct those distortions.

亏ㄱ The diagnostics machine relies on infrared to scan for surface abnormalities instead of a traditional corneal topographer which relied on refracted light from a series of concentric rings. Corneal topographers are widely used in the Lasik industry; however health professionals are always looking for ways to be more accurate and efficient.

"Licensing the infrared scanning technology" says Abbot's CEO Miles D. White, "makes scanning new patient's eyes much easier and more accurate. We simply use the infrared technology to scan a patient's entire eye to look for abnormalities and generate an accurate digital 3D map of the surface of a patient's eyes, revealing needed adjustments to get a LASIK patient's eye to a desire shape and level of smoothness."

Technology Stimulus 4.1: 25\% see this technology stimulus (High Superficial / High Structural)

Heading to show participants: Wilmer Eye Institute takes optometry to the future.

The Wilmer Eye Institute at Johns Hopkins is proud to announce its new eye topography diagnostics technology that quickly and accurately examines the overall shape and surface smoothness of an eye cavity help ocularists create very accurate, custom fitted prosthetic eyes

Ocularists note the importance of finding more accurate ways to create 3D maps of eye cavity's for prosthetic eyes so that eyelids rest properly when an eye is open, and close properly when one blinks, for example.

Low Procedural Similarity (50\% of group see this)

The technology is quick because it only needs to scan a small portion of the eye cavity for the infrared to refract and generate a 3D map of the entire eye cavity.
High Procedural Similarity (50\% of group see this)

The technology relies on infrared which scans a patient's entire eye cavity and cumulates the data to create a $3 \mathrm{D}$ digital map of a patient's eye cavity.

Technology Stimulus 4.2: 25\% see this technology stimulus (Low Superficial / High Structural) 
Heading to show participants: Northrop Grumman Aerospace Systems revolutionizes the production of high powered telescopes.

Northrop Grumman Aerospace Systems and their team of developers is proud to announce a new technology that quickly and accurately tests the overall smoothness and shape of mirrors during the telescope production process to speed up the production process of NASA telescopes.

In the past, NASA relies on extensive grinding, examining, and re-grinding to ensure mirrors are smoothed to exact specifications which can take years. The new technology relies on infrared to generate a 3D map of the surface and shape of telescope mirrors; the test is fast and shortens the amount of retesting required

Low Procedural Similarity (50\% of group see this)

After a mirror receives an initial grinding pass, the scanning station uses infrared to measure just a small part of the mirror which it uses to extrapolate to create a $3 \mathrm{D}$ digital image of the entire surface.
High Procedural Similarity (50\% of group see this)

After a mirror receives an initial grinding pass, the scanning station quickly scans the entire surface of the grinded mirror to generate a 3D digital image of the surface.

Technology Stimulus 4.3: 25\% see this technology stimulus (High Superficial / Low Structural)

Heading to show participants: Wilmer Eye Institute takes optometry to the future.

The Wilmer Eye Institute at Johns Hopkins is proud to announce its new eye topography diagnostics technology that quickly and accurately examines the backside of eyes to check for dis-coloration in the Macular to help with early detection of diabetes (diabetic macular edema).

The early detection of diabetes is critical because pathologic changes leading to complications occur early in diabetes. The health industry is always looking for ways to improve how early diabetes can be detected.

Low Procedural Similarity (50\% of group see this)

The technology only needs to scan a small portion of the backside of an eye; the scanner uses infrared look through an eye and scan a small portion of the Macular to check for dis-coloration (an early sign of diabetes).
High Procedural Similarity (50\% of group see this)

The technology relies on infrared which scans the entire backside of a patient's eye; this way any discoloration (an early sign of diabetes) can be detected as early as possible.

Technology Stimulus 4.4: 25\% see this technology stimulus (Low Superficial / Low Structural)

Heading to show participants: Northrop Grumman Aerospace Systems revolutionizes the production of high powered telescopes.

Northrop Grumman Aerospace Systems and their team of developers is proud to announce a new technology that quickly and accurately scans the backside of telescope mirrors after they receive a thin coat of aluminum reflective coating for early detection of small dis-coloration spots which can expand and lead to larger problems if left alone.

To date, NASA has been unable to detect such dis-colorations until they begin to impact images that are returned from the telescopes.

Low Procedural Similarity (50\% of group see this)

After a mirror receives an aluminum reflective coating, the scanning station uses infrared to scan a small portion of the backside of each mirror to check for any discoloration.
High Procedural Similarity (50\% of group see this)

After a mirror receives an aluminum reflective coating, the scanning station uses infrared to scan the entire of the backside of each mirror to check for any discoloration. 
APPENDIX 3 RESULTS FOR CASES LISTED IN FOOTNOTE 1

\begin{tabular}{|c|c|c|c|c|c|c|c|}
\hline & & & $\begin{array}{c}\begin{array}{c}\text { Opportunity } \\
\text { Beliefs }\end{array} \\
\end{array}$ & $\begin{array}{l}\text { Superficial } \\
\text { Slope }\end{array}$ & $\begin{array}{l}\text { Structural } \\
\text { Slope }\end{array}$ & $\begin{array}{l}\text { Procedural } \\
\text { Slope }\end{array}$ & $\begin{array}{c}\text { Procedural } \times \\
\text { Structural } \\
\end{array}$ \\
\hline $\begin{array}{l}\text { Hypothesized } \\
\text { IVs: }\end{array}$ & Structural Similarity & Coefficient & $0.19(0.07)^{* *}$ & & & & \\
\hline \multirow{3}{*}{$\begin{array}{l}\text { Trimmed } \\
\text { Controls: }\end{array}$} & Founder & Coefficient & & $0.52(0.26) *$ & & & \\
\hline & Owner & Coefficient & & $-0.44(0.22)^{*}$ & $0.21(0.19)$ & & \\
\hline & $\begin{array}{l}\text { Entrepreneurial Self } \\
\text { Efficacy }\end{array}$ & Coefficient & & $0.05(0.08)$ & $0.24(0.11) *$ & & \\
\hline \multirow[t]{2}{*}{$\begin{array}{l}\text { Hypothesized } \\
\text { Moderators: }\end{array}$} & $\begin{array}{l}\text { Prior Knowledge of } \\
\text { Market }\end{array}$ & Coefficient & $0.01(0.09)$ & $-0.13(0.09)$ & $0.11(0.11)$ & $-0.33(0.17)^{t}$ & $0.43(0.22)^{*}$ \\
\hline & $\begin{array}{l}\text { Prior Knowledge of } \\
\text { Technology }\end{array}$ & Coefficient & $0.11(0.19)^{t}$ & $0.10(0.28)$ & $-0.30(0.12)$ & $0.11(0.19)$ & $-0.27(0.23)$ \\
\hline
\end{tabular}




\section{CURRICULUM VITAE}

\section{EDUCATION}

Ph.D. in Entrepreneurship (August 2010 - August 2014), GPA: 3.98

College of Business

University of Louisville, Louisville, Kentucky

Defense Date: June 20, 2014

Degree Date: August 12, 2014

B.S. in Finance (August 2004 - December 2007), GPA: 3.41 / Business GPA: 3.67

Marriott School of Management

Brigham Young University, Provo, Utah

Graduation: December 2007

\section{DISSERTATION}

\section{Is that an Opportunity?}

\section{A Multilevel Investigation of the Opportunity-Individual Nexus and Opportunity Beliefs}

How do opportunity characteristics and individuals' cognitive processing styles influence opportunity beliefs as actors pursue entrepreneurial opportunities? I theorize that both aspects of the opportunity-individual nexus influence opportunity identification through their influence on the formation of opportunity beliefs about fit and feasibility. Using analogical problem solving as a theoretical lens, I develop and test hypotheses related to: independent-direct effects of opportunity differences in superficial, structural, and procedural similarities between technologies and markets on opportunity beliefs; interaction effects of opportunity differences on opportunity beliefs; and moderating effects of individual differences, such as global versus local processing styles, on the relationship between opportunity differences and opportunity beliefs.

Chair: Manju K. Ahuja, Ph.D.

University of Louisville

Michael J. Barone, Ph.D.

Dean A. Shepherd, Ph.D.

Indiana University

University of Louisville

Andrew S. Manikas, Ph.D. University of Louisville

Proposal Defense Date: June 26, 2013

Final Defense Date: June 20, 2014

\section{WORKING PAPERS}

Mattingly, E. S., Kushev, T. N., Ahuja, M., \& Ma, D. (Drafted) Moderating Effects of Entrepreneurial Experience, Metacognitive Experience, and Metacognitive Knowledge on Persistence Decision Frameworks 
Ma, D., Mattingly, E. S., Kushev, T. N., \& Ahuja, M. K. (Under Review) Entrepreneurial Persistence: Family Business Focus on Nonfinancial Benefits, Entrepreneurship Theory and Practice.

Mattingly, E. S. \& Westover, J. (Under Review) Enacting Change Through Borrowed Legitimacy: an Institutional Perspective, Submitted to: Journal of Management and Organization

Lucas, K., Manikas, A., \& Mattingly, E.S (Working Paper) Dignity In and At Work: Moderating Effects of Organizational Communication and Solicitation of Worker Involvement, Targeted Journal: Management Communication Quarterly

Mattingly, E. S. \& Ahuja, M. K. (Drafted) Is that an Opportunity? An Investigation of the Opportunity-Individual Nexus and Opportunity Beliefs, Targeted Journal: Academy of Management Review

Mattingly, E. S., Bae, T. J., Fiet, J.O., \& Kerrick, S. (Drafted and Presented at Conference) Structural Similarity and Specific Knowledge in Entrepreneurial Applications of Technologies, Targeted Journal: Entrepreneurship Theory and Practice.

Garrett, R. P., Hornsby, J. S., \& Mattingly, E. S. (Working Paper) Choosing among Multiple Opportunities: Cognition Differences between Corporate Entrepreneurs and Independent Entrepreneurs, Targeted Journal: Journal of Business Venturing

Bae, T. J., Mattingly, E. S., Fiet, J. O., \& Kerrick, S. (Drafted and Presented at Conference) Entrepreneurial Discoveries or Business Models as the Basis for Venture Development, Targeted Journal: Entrepreneurship Theory \& Practice.

Mattingly, E. S., \& Kushev, T. N (Drafted) Firm Founding and the Gap between Opportunity Value and Opportunity Costs, Targeted Journal: Journal of Small Business Management.

Kushev, T. N., Mattingly, E.S., Ma, D., \& Ahuja, M. K. (Drafted) Deciding to Persist: Passion, Feedback, and Attractive Alternatives, Targeted Journal: Journal of Business Venturing.

\section{CONFERENCE PRESENTATIONS}

Mattingly, E.S., Kushev, T. N., Ahuja, M. K., \& Ma, D. (Author and Presenter) Moderating Effects of Entrepreneurial Experience, Metacognitive Experience, and Metacognitive Knowledge on Persistence Decision Frameworks, Academy of Management Meeting: Entrepreneurship Division. Lake Buena Vista, Florida.

Ma, D., Mattingly, E. S., Kushev, T. N., \& Ahuja, M. K. (Author Only) Entrepreneurial Persistence: Family Business Focus on Nonfinancial Benefits, Academy of Management Meeting: Entrepreneurship Division. Lake Buena Vista, Florida.

Mattingly, E. S., Bae, T. J., Fiet, J.O., \& Kerrick, S. (2012) (Author and Presenter) Structural Similarity and Specific Knowledge in Entrepreneurial Applications of 
Technologies, Academy of Management Meeting: Entrepreneurship Division. Boston, Massachusetts.

D’Mello, J., Mattingly, E. S., \& Kushev, T. N. (2012) (Author Only) Explaining Conflicts among Stakeholders in Social Enterprises: A Multi-Theoretic Approach Babson College Entrepreneurship Research Conference. Fort Worth, Texas.

Bae, T. J., Mattingly, E. S., Fiet, J. O., \& Kerrick, S. (2011) (Author and Presenter) Entrepreneurial Discoveries or Business Models as the Basis for Venture Development, Babson College Entrepreneurship Research Conference. Syracuse, New York.

\section{TEACHING EXPERIENCE}

Co-Designed Course, Entrepreneurial Finance - FIN 345, College of Business, University of Louisville, Louisville, Kentucky

Faculty, Management \& Organizational Behavior - MGMT 301, College of Business, University of Louisville, Louisville, Kentucky

- Spring 2013, Average instructor effectiveness: 4.46/5.00

Faculty, Entrepreneurial Finance - FIN 345, College of Business, University of Louisville, Louisville, Kentucky

- Fall 2012, Average instructor effectiveness: 4.32/5.00

- Fall 2013, Average instructor effectiveness: 4.56/5.00

- Spring 2014, Average instructor effectiveness: 4.92/5.00

Assistant, Business Policy \& Strategy - MGMT 441, College of Business, University of Louisville, Louisville, Kentucky

- $\quad$ Spring 2012

Assistant, Entrepreneurship - Various, College of Business, University of Louisville, Louisville, Kentucky

- $2010-2014$

\section{ACADEMIC SERVICE}

Co-designed New Course, Entrepreneurial Finance at University of Louisville

Graduate Teaching Academy Mentor, Delphi Center, University of Louisville (20132014)

Ad Hoc Reviewer, Journal of Business Venturing

Ad Hoc Reviewer, Academy of Management (AOM) annual conference

Ad Hoc Reviewer, United States Association for Small Business and Entrepreneurship (USASBE) annual conference 


\section{HONORS, AWARDS, AND GRANTS}

Doctoral Student Teaching Effectiveness Award, University of Louisville (2013)

Competitive Research Grant, College of Business Research Incentive Grant (CBRIG), University of Louisville (2013)

Selected Participant \& Stipend, Charles Koch Foundation Free Enterprise Workshop on Current Trends in Entrepreneurship Education (2013)

Selected Participant \& Travel Stipend, Entrepreneurship Doctoral Consortium. Academy of Management Annual Meeting, Boston, Massachusetts (2012)

Competitive Research Grant, College of Business Research Incentive Grant (CBRIG), University of Louisville (2012)

Selected Participant \& Research/Travel Stipend, Delphi Center Graduate Teaching Academy Stipend, University of Louisville (2012)

International Honor Society, Beta Gamma Sigma, Brigham Young University Chapter

\section{THEORETICAL, METHODOLOGICAL, AND PEDAGOGICAL TRAINING University of Louisville (2010 - present) Cumulative GPA: 3.98/4.00}

Pedagogical Development

Trends in Entrepreneurship Education Workshop (2013), Charles Koch Foundation, Washington D.C.

Graduate Teaching Academy (2011-2012),

Rodems/Various

University of Louisville Delphi Center

Assisting in University of Louisville's Entrepreneurship Courses (2010 - Present)

Theoretical Doctoral Seminars

- Organizational Behavior Theories

- Human Resources Seminar

- Strategy \& Business Policy Theories

- Strategy \& Organizational Theories

- Sociology \& Evolutionary Theories

- Contemporary Entrepreneurship

- Entrepreneurship from an Economics Perspective

- Finance Theories
Facilitator/Professor

Various Professors

Michelle

Sharon Kerrick \& James Fiet

Professors

Sherry Thatcher

Bruce Kemelgor

Jay Barney

Melissa Baucus

Howard Aldrich

Scott Shane

Simon Parker

David Dubofsky 
- Microeconomics

- New product Strategies/Marketing

- Psychology \& Cognition in Entrepreneurship Research

- Quantitative Entrepreneurship

- Venture Capital Theories

Methodological Development Doctoral Seminars

- Advanced Multivariate Statistics

- Conjoint Analysis and Discrete Choice

- Experimental Data Collection and Analysis

- Experimental Design

- Hierarchical Linear Modeling

- Multivariate Statistics

- Research Design

- Structural Equation Modeling
Yong Chao

Robert Carter

Dean Shepherd

Per Davidsson

James Fiet

Professors

Joseph Petrosko

Robert Carter

Manju Ahuja

Manju Ahuja \&

Michael Barone

Jill Adelson \&

Jesse Owen

Wayne Usui

Manju Ahuja

Jill Adelson

\section{PROFESSIONAL WORK EXPERIENCE}

Professional Bio: My professional experience is broad, including: human resource management entrepreneurship, and administering alternative investment funds. I have been involved in several startups and family businesses in co-founder and finance officer roles. I managed the human resource for my family's business, including establishing health care plans and safe harbor 401k plans. My work outside of entrepreneurship and family business primarily involved working with hedge funds, fund of funds, private equity firms, and real estate investment trusts. My experience with alternative investment funds varies widely from administering onshore and offshore funds as a third party CEO to presenting business to sell. Although I decided to pursue a Ph.D. and career in academia, I am still very passionate about the practice of entrepreneurship, managing organizations and human resources, and alternative investing and stay involved to a small degree with firms my family owns.

Hedge Fund Administrator/Accountant, JD Clark \& Company UMB Fund Services, Ogden, Utah (January 2008 - July 2010), Permission to contact: Chad Allen (801-7374000). I left this position to pursue a career in Academia. 
- CEO function for over 30 hedge funds, fund of funds, private equity companies and REITs

- Asset pricing and NAV calculations

- SEC compliance \& filings

- Portfolio Accounting

- Investor relations

- Audit pro forma preparation
- Competitor benchmarking

- Completed and presented an environmental scan to the CEO and officers as part of an effort to change the competitive strategy

- Prepared financial and partner capital statements

Legal/Finance Analyst, Wencor Group, Springville, Utah (March 2007 - November 2007), Permission to contact: Eric Vernon (801-489-2000). I left this position to pursue a career in the alternative investment industry, which I became interested in while presenting the Wencor Group for sale to private equity investors.

- Participated in offsite strategy meetings

- Helped develop corporate strategy and disseminate the strategy to business-unit presidents

- Research legal and corporate issues

- Company valuation and presentation of group of companies to private equity firms for purchase
- Review and revise contracts, leases and other legal documents

- Financial analysis and support to accounting, HR, and legal departments

- Empirical competitor analysis

- Participated in discovery process during a federal trial for one of the group's startups

Financial Analyst / Human Resource Manager, Frankco Transportation, Inc. (Family Business), Sandy, Utah (April 2005 - March 2007), Permission to contact: Frank Montoya (801-831-0059). I left this family business because I wanted to work in the finance industry.

- Human Resource Functions

- Started a factoring business

- Restructured incentive programs, increasing gross margins from $14 \%$ to $20 \%$

- Established a safe harbor $401 \mathrm{k}$
- Tax filings preparation

- Developed a database for data tracking and reporting

- Developed electronic data interchange (EDI) processes to decrease float time 
Accountant/Consultant, FRM Investments (Family Business), South Jordan, Utah (April 2005 - Present), I did accounting for this business for a couple of years; however, I only consult to a small degree

Volunteer, The Hope Foundation, Machupichu, Peru (2 weeks during August 2005), Permission to contact: Frank Montoya (801-831-0059)

Custodian, Brigham Young University Bookstore, Provo, Utah (January 2005 - April 2005)

Payroll/Front Desk Clerk, National-9 Colony Inn Suites, Provo, Utah (August 2004 December 2004)

Volunteer Missionary, The Church of Jesus Christ of Latter-day Saints, Seoul, Korea (June 2002 - June 2004), Permission to contact: Jay R. Bangerter (801-444-6650)

Accountant, Associated Food Stores, Inc., Salt Lake City, Utah (August 1999 - June 2002), Permission to contact: Doug Carlile (801-973-4400). I left this position to serve a mission for my church.

- Coordinated electronic data interchange (EDI) transactions
- Accounting

- Managed document retention compliance

Co-founder/Accountant, Foursquare, Inc., Kearns, Utah (April 1998 - August 1999), Co-founded with Ronald Elden Mattingly (Deceased). We terminated this company because our Vapor Tran Transformer Engineer retired and there were not any suitable replacements.

- Co-founded a Vapor Tran transformer consulting firm
- Accounting

- Project management and coordinating 